\title{
AN ANALYSIS OF HUMAN
}

\section{DISTURBANCE TO ROCKY INTERTIDAL}

\section{COMMUNITIES OF SAN LUIS OBISPO}

\section{COUNTY}

\author{
A Thesis \\ presented to \\ the faculty of California Polytechnic State University, \\ San Luis Obispo \\ In partial fulfillment of the requirements for the Degree \\ Master of Science in Biological Sciences \\ by \\ Grant Tyler Waltz
}

December 2012 
(C) 2012

Grant Tyler Waltz

ALL RIGHTS RESERVED 


\section{COMMITTEE MEMBERSHIP}

TITLE:

An Analysis Of Human Disturbance To Rocky Intertidal

Communities Of San Luis Obispo County
AUTHOR:
Grant Tyler Waltz

DATE SUBMITTED: December 2012

COMMITTEE CHAIR: Dean Wendt, Associate Dean and Associate Professor COMMITTEE MEMBER: John Steinbeck, Tenera Environmental Inc. COMMITTEE MEMBER: John Perrine, Assistant Professor 


\author{
ABSTRACT \\ An Analysis Of Human Disturbance To Rocky Intertidal \\ Communities Of San Luis Obispo County \\ Grant Tyler Waltz
}

The number of coastal areas open to public access in California and San Luis Obispo County is increasing due to the acquisition by California State Parks of land previously owned by private entities. For example, California State Parks acquired property from the Hearst Corporation in 2005, which included 18 miles of coastline. California State Parks is responsible for providing public access in these newly acquired areas and also for maintaining the health of the natural systems found on these properties. Part of the California State Parks' strategic vision maintains that they seek to consider the impacts of every decision they make on the next seven generations of Californians. To balance the competing demand of providing access with long-term sustainability, State Parks managers require sound scientific data to evaluate the impacts of human access to the ecosystems they manage.

One ecosystem susceptible to human access in these new State Park areas and in other areas throughout the state is the rocky intertidal (e.g. Beauchamp and Gowing 1982, Ghazanshahi et al. 1983, Hockey and Bosman 1986, Povey and Keough 1991, Addessi 1994, Fletcher and Frid 1996, Brown and Taylor 1999, Murray et al. 1999, Van De Werfhorst and Pearse 2007). This thesis represents a collaborative effort between State Parks Managers scientists at California Polytechnic State University San Luis Obispo, and scientists at Tenera Environmental Inc. to provide sound scientific data on the 
impacts of visitors to rocky intertidal biological communities in San Luis Obispo County. A three-pronged approach was used to assess the effect of visitors to rocky intertidal communities: 1) an observational study to quantify visitor densities in publicly accessible rocky intertidal communities, 2) an experimental manipulation of visitor density to rocky intertidal communities based on the visitor densities observed in part 1 and used to identify organisms susceptible to foot traffic (access-indicator taxa), and 3) an observational study of publicly accessible rocky intertidal sites exposed to levels of foot traffic shown to cause declines in access-indicator taxa from part 2. I was involved with all three portions of the study and my thesis is focused on presenting and discussing parts 1 and 3 in detail.

Visitor counts and the observational access-indicator taxa study (parts 1 and 3) were conducted in Montaña de Oro State Park (MDO) in San Luis Obispo County from 2007-2009. There was abundant accessible rocky intertidal coastline in the park. Three popular rocky intertidal sites were chosen within the park to conduct visitor counts. Visitors were quantified from fixed locations on the bluff above each of the three observation sites on sixteen occasions during the course of three years. These counts were used to estimate the annual number of visitors to each site. The area of each intertidal observation site was also calculated and with the annual number of visitors, was used to calculate the annual density of visitors to the rocky intertidal at each site. This represents a novel approach to quantifying visitor numbers to rocky intertidal communities. Additionally, I examined whether there was a relationship between the number of cars entering the park and the density of rocky intertidal visitors or between the number of cars parked at each site and the density of rocky intertidal visitors. 
The annual density of visitors at one of the observation sites in MDO, Hazard Reef, was shown to be approximately equal to the moderate treatment level from the experimental study (part 2). This moderate level of visitor density was shown to significantly reduce the abundance of five rocky intertidal taxa: rockweed (Silvetia compressa, Hesperophycus californicus, and Fucus gardneri), Endocladia muricata, Mastocarpus papillatus, limpets, and chitons. To assess whether long-term exposure to foot traffic could impact the abundance of access-indicator taxa in MDO, the abundance of these taxa was sampled at Hazard Reef and compared to the abundance of the same taxa at two adjacent sites with much lower annual densities of visitors. A stratified random sampling design was used to assess the abundance of the five access-indicator taxa found in the mid-intertidal zone at these three sites in the spring of 2009.

My work demonstrated that visitor densities and patterns of use were variable among the three accessed intertidal sites in MDO. Annual visitor numbers to the rocky intertidal for the three observation sites within MDO were between 3,000-5,000 people. There was no relationship between the number of cars entering the park and the annual density of visitors to the rocky intertidal. The number of parked cars was significantly related to visitor density at one study site suggesting that under specific circumstances, controlling parking lot size may be a viable approach to managing impacts to intertidal areas. Significant differences in limpet density $\left(60 \mathrm{per}^{2}\right)$ were detected in a moderately accessed intertidal site relative to adjacent and less visited sites. The abundance of combined algae and limpets were lower at the moderate use site when the lower use sites were compared together against it. Patterns of rocky intertidal habitat use and the estimated annual visitor density suggest that some areas in San Luis Obispo County may 
be exposed to damaging levels of visitors. The current study identified that the abundance of one out of five experimentally identified access-indicator taxa (Rockweed, Mastocarpus papillatus, Endocladia muricata, Limpets, and Chitons) had been significantly reduced at a popular rocky intertidal site, relative to adjacent and less visited sites. 


\section{ACKNOWLEDGMENTS}

I would like to thank many people, without whom this thesis would not be the product it is today. My advisor Dr. Dean Wendt was instrumental in guiding me through graduate school and my thesis. His insight, patience, and humor are greatly appreciated. John Steinbeck of Tenera Environmental Inc. has provided an immense amount of guidance and statistical advice. Dr. John Perrine brought a critical and wise perspective; your feedback has been invaluable. Scott Kimura of Tenera Environmental Inc. was extremely patient working with me. He taught me about the organisms of the rocky intertidal, how to design and implement a field study, and how to tie a half hitch. His energy, expertise, and feedback helped make this project the comprehensive study it is. I would also like to thank Dr. Andrew Schaffner in the Cal Poly Statistics Department for assisting me on multiple occasions. I had an enormous amount of help from the DEW Lab: Corbin Hodges, Nate Hall, Lenora Brewer, Lisa Needles, Melissa Daugherty, Dave Rasmussen, and Laurel Johnston. Susan Helberg taught me how to navigate Microsoft Access. Gery Cox, Andrew Harmer, and Joel Carter were critical in the field to collect quality data while making the day interesting. Thanks to all my volunteer visitors. California State Parks and PG\&E allowed me to conduct studies on their property. Finally, this project was supported by funding from; the David and Lucile Packard Foundation, the Resource Legacy Fund Foundation, the Coastal Conservancy, Cal Poly, the California Ocean Protection Council, and The Morro Bay National Estuary Program. 


\section{TABLE OF CONTENTS}

Page \#

LIST OF TABLES

$\mathrm{X}$

LIST OF FIGURES

xi-xii

GENERAL INTRODUCTION

$1-7$

CHAPTER 1

Introduction

8-11

Methods

$12-17$

Results

$18-21$

Discussion

$21-31$

\section{CHAPTER 2}

Introduction

Methods

49-53

Results

$53-54$

Discussion

$54-58$

References

APPENDIX 1

76-126

APPENDIX 2

127-129 


\section{LIST OF TABLES}

Table

2.1. ANOVA results comparing access-indicator taxa
Page \#

70 


\section{LIST OF FIGURES}

Chapter 1 Figures

1.1. Map of study area

1.2. Annual estimates of $\mathrm{CR}$ visitors

1.3. Average hourly visitors to shore zones

1.4. Annual CR visitor density by site hourly shore visitors

1.7. Regression analysis of daily MDO cars and the hourly number of CR visitors

1.8. Regression analysis of daily parked cars and hourly shore visitors

1.9. Regression analysis of daily parked cars and hourly CR

1.10. Regression of daily parked cars and annual

1.11. Regression of daily parked cars and annual

1.12. Regression analysis of tide height and hourly 
2.1. Annual visitor density at; Hazard Reef,

Hazard Mid, and Hazard Far

2.2. Depiction of transects, quadrants, and quadrats

72

2.3. Aerial photograph of Hazard Study area

2.4. Percent cover of access-indicator algae at;

Hazard Reef, Hazard Mid, and Hazard Far

2.5. Abundance of access-indictor limpets and

chitons at; Hazard Reef, Hazard Mid, and Hazard Far 


\section{GENERAL INTRODUCTION}




\section{Introduction}

The rocky intertidal is a relatively easily accessible marine environment with a diverse community structure including many species of plants, animals, and algae. These communities have been accessed and used by humans for a variety of purposes including food, bait for fishing, sightseeing, and to collect organisms for aquaria (Hockey and Bosman 1986, Keough et al. 1993, Addessi 1994, Branch and Moreno 1994, Siegfried et al. 1994, Griffiths and Branch 1997, Lindberg et al. 1998, Castilla 1999, Crowe et al. 2000). Passive (not manipulating organisms, sight-seeing, photography, litter, and habituation behavior) and active (e.g., collecting or manipulating organisms) human disturbance has been shown to affect many natural systems (e.g., Burden and Randerson 1972, Boyle and Samson 1985, Hockey and Bosman 1986, Addessi 1994, Murray et al. 1999, Germaine and Wakeling 2000, Beale and Monaghan 2004, Stallings 2009). These effects include but are not limited to: alterations to bird activity (e.g., Beale and Monaghan 2004), terrestrial animal distribution (e.g., Boyle and Samson 1985), plant cover (e.g., Burden and Randerson 1972), and sessile rocky intertidal organism abundances (e.g., Hockey and Bosman 1986, Addessi 1994, Murray et al. 1999). The documented effects of passive and active human disturbance to rocky intertidal communities may increase as population size increases and as people move toward coastal areas (Turner et al. 1996, Department of Economic and Social Affairs Population Division 2000). It is thus critical that there is a better understanding of how human visitation impacts ecological communities of coastal areas. 
The rocky intertidal has functioned as a model community to study ecological interactions and processes such as predator/prey relationships (e.g., Paine 1969, Menge et al. 1994, Navarrete and Menge 1996, Navarrete et al. 2000, Robles et al. 2001), community structure (e.g., Paine 1969, Menge et al. 1997, Navarrete and Berlow 2006, Martins et al. 2008), keystone species (e.g., Paine 1969, Menge et al. 1994, Navarrete and Menge 1996, Salomon et al. 2006), habitat type (e.g., Sebens 1983, Hunt and Scheibling 2001, Okuda et al. 2010), global climate change (e.g., Sagarin et al. 1999, Galbraith et al. 2002, Smith et al. 2006, Firth et al. 2009), pollution (e.g., Gappa et al. 1990, Newey and Seed 1995, Medina et al. 2005, Atalah and Crowe 2012), the intermediate disturbance hypothesis (e.g., Dial and Roughgarden 1998, McClintock et al. 2007, Pfaff et al. 2010), and biological zonation (e.g., Lubchenco 1980, Johnson and Ledesma-Vasquez 1999, Boaventura et al. 2002). In addition to understanding basic ecological principles such as those cited above, it has also served as a model for studying how human disturbance can alter the structure and function of ecological communities through their actions (e.g., Addessi 1994, Keough and Quinn 1998, Lindberg et al. 1998, Crowe et al. 2000, Whitaker et al. 2010, Huff 2011).

Some forms of human disturbance previously examined include collecting and handling of organisms, impacts of pollution, and visitation (i.e., foot traffic) (e.g., Beauchamp and Gowing 1982, Ghazanshahi et al. 1983, Hockey and Bosman 1986, Povey and Keough 1991, Addessi 1994, Fletcher and Frid 1996, Brown and Taylor 1999, Murray et al. 1999, Sagarin et al. 2007, Van De Werfhorst and Pearse 2007, Atalah and Crowe 2012). My thesis focused on elucidating the effects of public access and human visitation to rocky intertidal communities. My work particularly focused on examining 
the current impact of access to rocky intertidal communities and providing resource managers with information on the effects from current levels of visitation and the potential impacts of increased access.

Prior work examining the effects of foot traffic on rocky intertidal communities has shown effects such as reductions in algal and sessile invertebrate cover and loss of diversity (e.g., Beauchamp and Gowing 1982, Ghazanshahi et al. 1983, Povey and Keough 1991, Brosnan and Cumrine1994, Fletcher and Frid 1996, Murray 1998, Keough and Quinn 1998, Brown and Taylor 1999, Clowes and Coleman 2000, Van De Werfhorst and Pearse 2007, Huff 2011, and Kimura et al. in prep., Appendix 1). Most of these studies were also intended to provide information on the impacts of access to guide management decisions about coastal resources. Studies designed to provide information specifically about the effects of foot traffic have done so using both manipulative experimental designs and observational studies (Beauchamp and Gowing 1982, Ghazanshahi et al. 1983, Bally and Griffiths 1989, Underwood and Kennelly 1990, Povey and Keough 1991, Addessi 1994, Fletcher and Frid 1996, Brown and Taylor 1999, Clowes and Coleman 2000, Tenera 2003, Van De Werfhorst and Pearse 2007). However, to date no study incorporates the following: 1) experimental manipulations of foot traffic based on observations of the levels of foot traffic occurring at publicly accessible shores and 2) using the results of an experimental manipulation to identify areas potentially impacted by public access, specifically from foot traffic.

This study was divided into three parts, two of which I designed and conducted for my thesis:1) surveys to estimate the levels of visitor use at publicly accessible shores, which were then used to guide foot traffic levels applied in a field experiment; 2) an 
experimental field study to determine effects from varying treatment levels of foot traffic derived from the visitor surveys done in collaboration with Tenera Environmental, Inc.; and 3) an observational study sampling access-indicator taxa identified in the field experiment in areas with varying levels of access to determine if impacts similar to the field experiment could be detected. The results of part two, which I helped design and implement, are introduced briefly below to provide perspective and background and covered in complete detail in Kimura et al. in preparation (hereafter cited as Appendix 1).

In summary, the results of the visitor observations discussed in Chapter One were used to set experimental visitor levels used in the field experiment (Appendix 1). The results of the field experiment identified taxa affected by foot traffic (i.e., "accessindicators"), which were then used to assess the effects of long-term public access to rocky shores in MDO (Chapter Two). The collective results of my work may help California State Parks manage the resources of rocky intertidal shores in a way that allows for access and sustainability of the resources for generations to come.

Summary of the Experimental Field Study (Appendix 1)

The effect of non-consumptive human activities on algae and sessile and mobile invertebrates in rocky intertidal communities was examined empirically by conducting a field experiment using a Before-After-Control-Impact (BACI) study design. The experiment was designed to elucidate damaging visitor levels and identify taxa affected by public access ("access-indicators"). This was achieved by simulating annual visitor levels comparable to those occurring at publicly accessible rocky intertidal communities. The visitor treatment levels were such that a pre-determined density of visitors was 
applied to fixed plots and the visitor treatments (Impact) were designed such that 'visitors' were behaving in a more realistic manner than what has been done in previous studies. This experimental approach incorporating a BACI design, utilizing visitor counts from public areas to set treatment levels, and applying visitor treatments in a manner that more accurately simulates foot traffic represents a novel and more comprehensive approach to assessing impacts from visitors to rocky intertidal communities.

A study site was chosen on Pacific Gas and Electric property in San Luis Obispo County, Ca. Pacific Gas and Electric operated the Diablo Canyon Power Plant (DCPP), and managed 12,000 acres of adjacent coastal property on the central California coast. Much of the rocky coastline was closed to public access, which was an ideal situation to conduct a controlled experiment of visitor impacts because there was no background visitation occurring in the rocky intertidal community. Experimental plots were located in the mid-intertidal community, characterized by dense stands of brown algae known as rockweed (Silvetia compressa, Fucus gardneri, and Hesperophycus califonicus). Plots were $4 \mathrm{~m} \mathrm{x} 4 \mathrm{~m}$ square. Sixteen test plots were established and the abundance of algae, sessile invertebrates, and mobile invertebrates were visually quantified for one year before the onset of experimental visitor applications (i.e., the impact).

Following one year of monthly observation, three treatment levels of visitor densities were applied to test plots based on the densities recorded in my visitor surveys in an adjacent publicly accessible area (Chapter One). The abundance of algae and sessile and mobile invertebrates continued to be sampled monthly during the 10 visitor applications spread out over eight months. The difference in organismal abundance was 
compared between the time periods before and after treatments were applied, and among the control plots and three intensities of visitor access.

The following five taxa showed significant reductions in abundance due to simulated public access in the experimental plots:

1. Rockweed: < 10\% (Silvetia compressa, Hesperophycus californicus, Fucus gardneri)

2. Mastocarpus papilllatus: $<10 \%$

3. Endocladia muricata: $<10 \%$

4. Limpets (Lottidae): $\sim 25$ individual $\mathrm{m}^{-2}$

5. Chitons (Polyplacophora): $\sim 2$ individuals $\mathrm{m}^{-2}$

The abundances of these taxa showed a gradient in the levels of change among the three treatments, with the greatest reductions in abundance occurring in the plots with the highest visitor density. The moderate experimental visitor density was comparable to densities I observed at frequently accessed public shores in MDO (Chapter One), indicating that reductions in access-indicator taxa may also be occurring at publicly accessible shores in MDO, which I tested by conducting surveys of a commonly accessed intertidal area in MDO (Chapter Two). 


\section{CHAPTER ONE}

QUANTIFYING LEVELS AND PATTERNS OF VISITOR USE IN ROCKY INTERTIDAL COMMUNITIES 


\section{Introduction}

Active and/or passive human disturbance can result in changes in community structure and organismal abundance (e.g., Beauchamp and Gowing 1982, Ghazanshahi et al. 1983, Hockey and Bosman 1986, Povey and Keough 1991, Addessi 1994, Fletcher and Frid 1996, Brown and Taylor 1999, Murray et al. 1999, Van De Werfhorst and Pearse 2007, Smith et. al 2008). For resource agencies to sustainably manage publicly accessible rocky shores and establish appropriate management actions, the threshold level of visitors leading to significant impacts needs to be determined. Although previous research aimed to assist with management decisions has shown impacts to intertidal communities, I was not able to locate and review any studies which have the critical information needed to make use of the data in a management context. Specifically, previous studies do not provide a means to correlate the observed impacts, either from experimental or observational field studies, to levels of access at public shores. One of the problems is the absence of a metric for measuring the level of 'human use' in intertidal studies that relates directly into practical management policy. Thus, managers are left knowing that there are impacts, but they have no way to relate human use metrics from intertidal studies to metrics used to manage access to public shores. This study aims to remedy that situation by providing estimates of visitor use to publicly accessible rocky intertidal communities.

In addition to providing an annual visitor use estimate to popular rocky intertidal communities in Montaña de Oro State Park (MDO) based on visitor density, visitor use values were used to set treatment levels in a controlled study examining the impact of visitor access on the rocky intertidal (Appendix 1). To derive estimates, I made visitor 
counts at three commonly accessed sites in one of the most visited state parks in San Luis Obispo (SLO) County, (MDO). The measured counts were used to calculate the density of visitors, which was then used to set the experimental visitor levels used in the impact experiment.

Visitor estimates have been made in rocky intertidal communities for both experimental and observational studies. Past experimental studies have estimated relative levels of use (Beauchamp and Gowing 1982) and footstep density (Povey and Keough 1991, Fletcher and Frid 1996, Brown and Taylor 1999) to justify applied treatments of experimental visitor levels. Observational studies have estimated relative levels of use (Ghazanshahi et al. 1983, Addessi 1994, Clowes and Coleman 2000, Tenera 2003, Van De Werfhorst and Pearse 2007), footstep density (Bally and Griffiths 1989), the annual number of visitors to a location (Underwood and Kennelly 1990, Tenera 2003), or the density of visitors (people ha ${ }^{-1}$ ) (Clowes and Coleman 2000). These use estimates then define lower use areas from higher use areas allowing for comparison of areas with differing levels of visitors. None of these experimental or observational studies have estimated visitor density at publicly accessible shores to inform a priori the levels of impact that should be tested or evaluated in experimental or observational studies.

The visitor use observations from my thesis build on previous experimental and observational work aimed to assist with resource use and protection decisions in rocky intertidal communities by providing a potentially more useful metric to estimate human impacts and set sustainable use levels. The metric I used to quantify human use in intertidal communities was visitor density (people $\mathrm{m}^{-2} \mathrm{yr}^{-1}$ ). Visitor density as defined here includes the effects from both active and passive behavior as well as the effects from 
foot traffic (trampling). This metric provides a more realistic and, more importantly, a more useful estimate of the effects from people visiting intertidal communities for management use.

Simply knowing the annual densities of people that visit particular sites and the actual impacts to the visited areas is not necessarily enough information for managers to be able to keep visitation below damaging levels. It would be helpful to resource managers if they had a mechanism to adjust the density of visitors at a particular site. To address this issue I examined whether there was a relationship between the density of visitors to these rocky intertidal areas and either the numbers of cars entering a state park or parked in lots near areas with rocky intertidal habitat. It seemed intuitive that more cars entering a park or parked in a lot near rocky intertidal habitat would correlate to higher densities of visitors in the rocky intertidal. I wanted to know if this assumption was valid and statistically significant for popular rocky intertidal areas in MDO. In doing so I aimed to discuss whether pursuing either restrictions on the total number of cars entering a park or limiting parking lot size would be potential methods to limit the effects of human access. A significant relationship between car totals and intertidal visitor density would indicate that State Parks managers may be able to predict and control damage to intertidal communities by regulating visitor densities through daily car limits to the park or by limiting parking availability adjacent to popular rocky intertidal areas. Taken together, the information from my thesis and the collaborative experiment with Tenera Environmental Inc. will provide a more concise assessment of visitor levels and impacts to rocky intertidal communities than previous work. This should enable resource managers to actively manage the impacts to these communities due to human access. 


\section{Methods}

\section{$\underline{\text { Study Site }}$}

MDO is located in San Luis Obispo County (Fig. 1.1). The park has a variety of activities, facilities, and habitats which attract approximately 700,000 visitors annually (California State Parks 2008). There is extensive rocky shore habitat along the approximate seven miles of shoreline in MDO. Several shoreline areas with rocky intertidal habitat within the park are well known to the local and visiting public and have relatively well defined trails providing access. Visitor observations were recorded at three commonly accessed sites within MDO: Hazard Reef, Spooner's Cove, and Corallina Cove (Fig. 1.1). Observation sites were chosen based on the presence of rocky intertidal habitat and information from park managers that identified these sites as a focus for visitors interested in intertidal communities.

Individual site descriptions as follows:

\section{Hazard Reef (Lat. 35.289 Long. -120.883 GCS North American Datum 1983)}

Hazard Reef is the northernmost of the three sites. The parking consists of dirt pull-outs adjacent to the road. A well-worn trail winding half a kilometer through Hazard Canyon delivers visitors from the parking area to the shore. There is no ocean view of the reef from the parking area. The shore at Hazard Reef is bordered to the north by a large stretch of sand beach and is the northernmost rocky bench in the park. Extending south from Hazard Reef by about $1 \mathrm{~km}$ is a large stretch of rocky bench. Hazard Reef has a popular surf break and is also popular with school groups. The sandy area at Hazard Reef is the smallest of the three observation sites, and there are no facilities, fire pits, or picnic tables. 


\section{Spooner's Cove (Lat. 35.274 Long. -120.888 GCS North American Datum 1983)}

Spooner's Cove is the middle site, roughly halfway between the northern entrance of the park and the border with private property owned by Pacific Gas \& Electric Co. that is part of the Diablo Canyon Power Plant property. There is a large, well-defined dirt parking lot at Spooner's Cove adjacent to Pecho Road. The site is in full view from Pecho Road as motorists approach from either the north or south. Spooner's Cove is a large sandy cove with rocky intertidal areas on the northern and southern ends of the cove. There is also a rock bench (3-5 $\mathrm{m}$ wide), which is frequently accessed by visitors near the outflow of a perennial creek at the northern end of the Cove. There are restrooms and picnic benches present at Spooner's Cove.

\section{Corallina Cove (Lat. 35.269 Long. -120.895 GCS North American Datum 1983)}

Corallina Cove is the southernmost observation site with parking provided by dirt pull outs adjacent to Pecho Road. Corallina Cove is accessed after walking over half a kilometer along a bluff trail then following a divergence that leads to the beach at Corallina Cove. The Cove is not visible from Pecho Road. Corallina Cove has a sand beach larger than Hazard Reef but smaller than the beach zone at Spooner's Cove $(\sim 125$ $\mathrm{m}$ long oriented north to south). There are large rocky intertidal platforms extending out to sea perpendicular to the shore on the northern and southern borders of the cove.

Corallina Cove is popular with educational groups and had one sign discussing tide pool etiquette at the top of the bluff where the access trail diverges from the main bluff trail. There are no facilities, fire pits, or picnic benches.

\section{$\underline{\text { Visitor Observations }}$}


Visitor observations were made consecutively at each site on the same day. Day types observed included weekdays, weekends, holidays, and non-holidays throughout the calendar year in an attempt to encompass the range of visitor levels which may be influenced by work or school breaks (holidays), weekends, or weekdays. Sample days were opportunistically chosen and were generally days with tides low enough to expose the rockweed community. Also recorded were the weather conditions (sky, temperature, and wind speed) and number of cars in the parking areas for each site at the start and finish of the observation period. Sites were sampled 16 days during 2007-2009 . Observation times primarily occurred around the low tide for that day, ideally occurring for a period starting one hour before low tide and continuing for an hour after low tide. Observations were made at each site for one hour from a location with a full view of the site. Individual site observation periods (1 hour) were divided into 10-minute segments. A visitor count was recorded at the start of each 10-minute segment. Visitors were categorized based on their vertical location (relative to sea level) on the shore and substrate: Beach (sand zone), Bare Rock (rock without significant biotic coverage), and Covered Rock (rocky substrate with significant algal and invertebrate coverage - CR). Separate 'Surfer' and 'Fisher' designations were also assigned to visitors possessing surfing or fishing gear and/or actively participating in these respective activities. Activities of shore visitors were recorded as Passive (not manipulating organisms or substrate) or Active (manipulating organisms or substrate). CR areas of special interest were delineated using landmarks, and visitors to these areas were recorded in a 'covered rock known area' category (CRKA). The size $\left(\mathrm{m}^{2}\right)$ of CRKAs were later calculated and used to estimate the visitor densities in these areas. 


\section{$\underline{\text { Area Estimates }}$}

Rocky intertidal areas with algal cover (CRKA) were estimated for each of the three observation sites. The total are of each site was estimated by walking the perimeter of each CRKA with a hand-held GPS when the tide was +0.61 m mean lower low water (MLLW), the same approximate tide level of the upper mid-intertidal community examined in the experimental field study (Appendix 1). ESRI ArcGis software was used to plot these GPS points (decimal degrees) on NOAA chart 18703 (Morro Bay). The points were connected in the order recorded to construct a polygon and to calculate the area of each polygon.

\section{Estimate of Available Tides}

The total number of hours the rocky intertidal community was exposed annually was calculated by totaling the number of hours the tide was less than or equal to $+0.61 \mathrm{~m}$ MLLW. Total tide hours per year were calculated based on the number of days with a tide less than or equal to $+0.61 \mathrm{~m}$ MLLW between 9 am and $5 \mathrm{pm}$ during the time of year not on daylight savings or between 9 am and 6 pm for days on daylight savings. Each tide-day matching the above criteria was then assigned a three hour time period available for intertidal access. Tide days were determined using the 2009 NOAA tide predictions for Port San Luis (Station ID 9412110, NOAA 2009), and were measured relative to mean lower low water (MLLW). The total number of available tide-days meeting these criteria was 201 . 


\section{$\underline{\text { Annual Covered Rock Visitor Estimates }}$}

The total annual CR zone attendance was estimated using two methods. Both methods utilized the average hourly covered rock zone visitation rates calculated from the visitor observations. The first method multiplied the hourly CR zone visitation rate by the estimated annual exposure hours (603 hrs.) for each of the three observation sites. The second method utilized the percentage of daily visitors in the CR relative to the MDO daily park visitor totals. The percentage was calculated for each of the sixteen observation days and the daily percentage was multiplied by the annual estimated number of visitors to MDO in 2007/2008 (652,943).

\section{Density of Covered Rock Visitor Use}

Annual densities of use at Hazard Reef, Spooner's Cove, and Corallina Cove were determined for the CRKA by multiplying the average hourly number of visitors in these areas by three hours (assumed tidal exposure hours per day) and by the number of CRKA exposure days per year (201). The calculated value was then divided by the covered rock area exposed when the tide level equaled +0.61 m MLLW. The units of visitor density were reported as people $\mathrm{m}^{-2}$ year $^{-1}$.

\section{$\underline{\text { Statistical Analysis }}$}

The association among the following set of variables for each observation site was examined using linear regression: hourly numbers of people at covered rocky intertidal areas (CR), daily number of cars entering the park, numbers of people at shoreline areas in the park, numbers of cars in parking lots associated with shoreline areas, and tide 
height. Sixteen observation days were analyzed for each site. The average hourly visitor rate was calculated using each of the seven counts made during the observation hour for each observation day. The significance of the above relationships was tested $(\alpha=0.05)$. $\mathrm{R}^{2}$ values were used to determine the amount of variation observed in the response variables explained by the predictor variables in the model. All analyses were done using MiniTab ver. 16.0 statistical software.

\section{$\underline{\text { Relationship Between Hazard Reef Visitor Density and Parking Lot Car Totals }}$}

To address whether controlling parking lots size may be an effective means to control impacts to rocky intertidal communities from visitor access, I further examined the association between visitors at Hazard Reef and the number of cars parked in the parking area at Hazard Reef. To do this analysis, annual visitor density was calculated from the hourly rate of CRKA visitation observed at Hazard Reef and using visitor counts made in the CRKA. However, the CRKA was not established until the third visitor observation event, so the regression between annual visitor density and cars parked in the lot at Hazard Reef was based on 14 visitor observations, instead of the 16 used to calculate hourly CR visitors. Additionally, there was an outlier visitor count observed when a large school group visited Hazard Reef but which did not park in the lot I used to make my parked car estimates. I performed a second regression with this outlier removed. Annual CRKA visitor density data were log base 10 transformed. The significance of the relationship between parking lot car totals and annual CRKA visitor density was tested $(\alpha=0.05) . R^{2}$ values were used to determine the amount of variation observed in the response variables explained by the predictor variables in the model. 


\section{Results}

$\underline{\text { Annual Estimates of Covered Rock Visitors to Montaña de Oro }}$

An estimated 4,679 (SE \pm 1,337) people annually visit the $\mathrm{CR}$ at three popular rocky intertidal sites in MDO based on a calculation multiplying the hourly $\mathrm{CR}$ visitor rate by the annual CR exposure hours. Hazard Reef experienced the greatest estimated number of visitors $(2,213 \mathrm{SE} \pm 1,356)$ followed by Corallina Cove $(1,520 \mathrm{SE} \pm 301)$ and Spooner's Cove (937 SE \pm 285) (Fig. 1.2). An estimated (3,279 SE \pm 813) people visited the $\mathrm{CR}$ at these three rocky intertidal areas in MDO using a calculation multiplying the daily percentage of CR visitors by the MDO annual visitor total.

\section{Visitor Use Estimates by Site}

Spooner's Cove had the greatest number of visitors in the beach zone (18.8 people $\left.\mathrm{hr}^{-1}, \mathrm{SE} \pm 3.9\right)$ and the fewest visitors to the $\mathrm{CR}$ zone $\left(1.7\right.$ people $\left.\mathrm{hr}^{-1}, \mathrm{SE} \pm 0.5\right)$. In contrast, Hazard Reef had the fewest beach visitors (1.4 people $\left.\mathrm{hr}^{-1}, \mathrm{SE} \pm 0.6\right)$ but the greatest number of visitors to the $\mathrm{CR}$ zone (4.2 people $\mathrm{hr}^{-1}, \mathrm{SE} \pm 2.5$ ). Corallina Cove had the least difference in hourly visitation rates between the beach and CR zones ( 4 and 2.6 people $\mathrm{hr}^{-1}$ respectively, $\mathrm{SE} \pm 0.8$ and 0.6) (Fig. 1.3). No surfers or fishers were observed at Corallina Cove, while both Spooner's Cove and Hazard Reef were utilized by surfers and fishers (Fig.1.3).

\section{Determination of Covered Rock Area}

Hazard Reef had the largest observed CRKA of the three observation sites $(1,960$ $\left.\mathrm{m}^{2}\right)$ and Spooner's Cove had the smallest $\left(462 \mathrm{~m}^{2}\right)$. The CRKA at Corallina Cove was $1152 \mathrm{~m}^{2}$ 


\section{Annual Density of CR Use}

In the CR zone, Corallina Cove had the lowest annual density of visitor use (1.00

people $\left.\mathrm{m}^{-2} \mathrm{yr}^{-1}\right)$, followed by Hazard Reef (1.21 people $\left.\mathrm{m}^{-2} \mathrm{yr}^{-1}\right)$. Spooner's Cove had the highest annual visitor density, (1.90 people $\mathrm{m}^{-2} \mathrm{yr}^{-1}$ Fig. 1.4), due to its small area.

\section{Annual Density of CRKA Use}

In the CRKA, Spooner's Cove had the lowest density of visitors $\left(1.5\right.$ people $\mathrm{m}^{-2}$ $\mathrm{yr}^{-1}$ ), Corallina Cove had 2.0 people $\mathrm{m}^{-2} \mathrm{yr}^{-1}$, and Hazard Reef had the highest at 3.9 people $\mathrm{m}^{-2} \mathrm{yr}^{-1}$ (Fig. 1.5).

$\underline{\text { Relationship between Daily Number of Cars Entering Montaña de Oro and Shore Visitors }}$

A significant relationship was not detected between daily car totals and number of shore visitors at any of the three sites: Hazard Reef $(\mathrm{p}=0.617, \mathrm{n}=16)$; Spooner's Cove $(\mathrm{p}=0.277, \mathrm{n}=16)$; and Corallina Cove $(\mathrm{p}=0.266, \mathrm{n}=16)($ Fig. 1.6).

$\underline{\text { Relationship between Daily Number of Cars Entering MDO and Hourly CR Visitors }}$

A significant relationship was not detected between daily car totals and the number of visitors to the CR zone at any of the three sites (Hazard Reef $p=0.901, n=$ 16; Spooner's Cove $\mathrm{p}=0.488, \mathrm{n}=16$; and Corallina Cove $\mathrm{p}=0.881, \mathrm{n}=16$ ) (Fig. 1.7).

$\underline{\text { Cars in Parking Areas as Predictors for Number of Total Shore Visitors }}$ 
A significant relationship between parking lot car totals and the hourly number of shore visitors was detected at all three sites: Hazard Reef $(p=0.002, n=16)$; Spooner's Cove $(\mathrm{p}=0.000, \mathrm{n}=16)$; and Corallina Cove $(\mathrm{p}=0.015, \mathrm{n}=16)$. The number of cars parked at each site was positively correlated with the hourly number of shore visitors at all three sites (Fig. 1.8). The number of cars parked at each observation site explained the following amount of variation at each site: Hazard Reef $\left(R^{2}=0.4935\right)$, Spooner's Cove $\left(\mathrm{R}^{2}=0.8800\right)$ and Corallina Cove $\left(\mathrm{R}^{2}=0.3518\right)$. At Hazard Reef and Corallina Cove the number of cars parked at each site explained more variation in the total number of shore visitors than did the daily number of cars entering MDO.

\section{Cars in Parking Areas as Predictors for the Number of CR Visitors}

A significant relationship was not detected between the number of cars parked at each site and the hourly number of CR visitors at: Hazard Reef $(\mathrm{p}=0.081, \mathrm{n}=16)$; Spooner's Cove $(\mathrm{p}=0.108, \mathrm{n}=16)$; or Corallina Cove $(\mathrm{p}=0.184, \mathrm{n}=16)($ Fig. 1.9).

The Relationship between the Number of Cars Parked at Hazard Reef and CRKA $\underline{\text { Visitors }}$

A significant relationship was detected between the annual density of CRKA visitors and the daily number of cars parked at Hazard Reef ( $\mathrm{p}=0.003, \mathrm{n}=14$; Fig 1.10). The number of cars parked at Hazard Reef explained the majority of the variation observed in the annual CRKA visitor density observations $\left(\mathrm{R}^{2}=0.526\right)$. Parking lots built to the size indicated on the $\mathrm{x}$-axis were estimated to receive the corresponding annual visitor density if that number of cars parked every available three-hour tide day for one 
year. These data contained an outlier, which was a large school group that was recorded in the CRKA but which did not park in the parking area for Hazard Reef. With the outlier removed there was still a significant relationship between the number of parked cars and the density of CRKA visitors $(\mathrm{p}=0.03, \mathrm{n}=13$; Fig 1.11). The number of cars parked at Hazard Reef explained some of the variation observed in the annual CRKA visitor density observations when the outlier was dropped from the analysis $\left(\mathrm{R}^{2}=0.34\right)$.

\section{$\underline{\text { Relationship between Tide Height and Covered Rock Visitors }}$}

A significant relationship was detected between tide height and the number of hourly CR visitors at Spooner's Cove $(\mathrm{p}=0.026, \mathrm{n}=16)$, but not at Hazard Reef ( $\mathrm{p}=$ 0.394, $\mathrm{n}=16)$ or Corallina Cove $(\mathrm{p}=0.208, \mathrm{n}=16)($ Fig. 1.12). Some variation in hourly number of CR visitors at Spooner's Cove was explained by tide height $\left(\mathrm{R}^{2}=\right.$ $0.3058)$.

\section{Discussion}

The study in this chapter was designed to provide visitor estimates in rocky intertidal communities to guide experimental treatment levels and to provide resource managers an estimate of the distribution and levels of visitation to three popular rocky intertidal sites in MDO. Three issues were addressed in this chapter and contributed to a larger research effort done in cooperation with Tenera Environmental Inc.:

1) estimates of annual rocky intertidal visitor use 
2) estimates of rocky intertidal visitor density and protocol to estimate visitor density and

3) and assessing whether parking lot car counts were related to rocky intertidal visitor density.

There are very few examples of visitor use studies which have been closely integrated with the design of experimental field studies of rocky intertidal biological communities where the results are used to guide treatment levels in the experiment, and none have used the metric of annual visitor density (Bally and Griffiths 1989, Povey and Keough 1991 Brown and Taylor 1999, Huff 2011). There are not any published studies calculating annual visitor densities, per $\mathrm{m}^{2}$, from repeated timed visitor counts. The visitor use estimates presented here were incorporated into a novel integrative study examining visitor impacts to rocky intertidal and other shoreline biological communities.

Annual visitor density estimates at three commonly accessed rocky intertidal communities were made (Figs. 1.4 and 1.5) and used to guide visitor densities applied in a manipulative field experiment (Appendix 1). The metric developed from the visitor surveys related directly to the number of visitors to an area and may be more useful to resource managers than previous metrics based on the density of footsteps. Managers are likely to find it easier to control impacts from foot traffic by regulating visitor density, and therefore more likely to incorporate results from a study of visitor density effects, because the metric is directly related to the number of people visiting an area. Visitor density estimates were made by obtaining: visitation rates based on timed visitor counts, the area of the habitat exposed at the desired tide level, and determining the annual hours of rocky intertidal exposure. In contrast, it may be more difficult to manage the impacts 
of foot traffic using information from studies incorporating foot step density as the experimental metric (Povey and Keough 1991, Keough and Quinn 1998, Ferreira and Rosso 2009, Huff 2011), for which a scale of footsteps per person would have to be calculated and, which to date, has not been calculated. For this reason, the visitor density metric and calculation methods presented here may be more valuable to resource managers addressing impacts to rocky intertidal communities than metrics used in previous studies. Additionally, the entire study may be more relevant to management decisions because the experimental applications were rigorously justified using timed visitor counts at rocky intertidal communities of defined area.

The study of visitor impacts, using the density of people as the metric of impact, may also be applicable in systems outside the rocky intertidal. For example, studies examining the effects of SCUBA diving on underwater communities often quantified the number of fin or appendage contacts with the substrate and measured whether there was a response (e.g., a reduction in organism density, an increase in damaged individuals, or fewer fish) (e.g., Barker and Roberts 2004, Worachananant et al. 2008, Di Franco et al. 2009, Poonian et al. 2010). A more applicable metric, from a resource management context, may be one less focused on these relatively specific diver contact incidents. Instead, SCUBA diving impact studies could focus on the effect from a predetermined density of divers occurring at a site. Examining the effects from divers on a per area or volume basis would capture most or all of the non-extractive events that occur when divers visit an area (e.g., contacting the reef, disturbing fish) and allow for a discussion of the impacts of diving based on a metric resource managers are familiar with, the number of divers at a given site. 
As a starting point to estimate annual visitor density to popular rocky intertidal biological communities, annual visitor numbers were estimated at the three study sites in MDO. Two methods, based on the multiplying the hourly number of CR visitors by either the annual number of rocky intertidal exposure hours or by the percentage of daily $\mathrm{CR}$ visitors to daily MDO visitors, were used to estimate the annual number of $\mathrm{CR}$ visitors. The two annual estimates of CR visitor levels were within 1400 people per year of each other. The lower estimate multiplying the percentage of daily $\mathrm{CR}$ visitors to daily MDO visitors was 70\% ( 3,300 visitors per year) of the estimate multiplying the hourly number of CR visitors by the annual number of rocky intertidal exposure hours $(\sim 4,700$ people per year). Given the $30 \%$ difference between estimation methods, further examination of these two methods is necessary to determine which is more accurate. However, the results indicated that the three popular sites in MDO State Park received between 3,000-5,000 visitors per year (Fig. 1.2). These annual visitor estimates suggest that popular rocky intertidal communities in SLO County were less heavily visited than popular areas in northern and southern California where hundreds to more than one thousand visitors have been observed on a single day (Addessi 1994, Clowes and Coleman 2000, Murray 1997, Tenera 2003, Tenera 2004, Van de Werfhorst and Pearse 2007, Whitaker et al. 2010).

Visitor counts showed that the distribution and number of visitors to rocky intertidal areas in MDO State Park was variable over the relatively short distance among the three sites (Fig. 1.3). Hazard Reef and Corallina Cove had more people in the covered rock $(\mathrm{CR})$ zone relative to the total number of visitors to the shore, while most visitors to Spooner's Cove were in the beach zone. The total number of shore visitors 
was much greater at Spooner's Cove than the other two sites (Fig. 1.3). These results seem counter-intuitive; sites with more shore visitors should also have more CR visitors (e.g., Spooner's Cove). However, differences among sites (e.g., physical features, facilities, ease of access and parking) likely contributed to the observed differences in visitor distribution along the shore. Tenera (2004) suggest that rocky intertidal communities adjacent to sandy beaches may be exposed to higher levels of visitors than those without adjacent sandy beaches in northern California. Spooner's Cove had the smallest and least accessible covered rock zone, yet had a large parking area and a large sandy beach that were visible from the road. It also had picnic facilities and restrooms. Rocky intertidal biological communities may be susceptible to damage at sites with similar access and facilities to Spooner's Cove, but with a larger and more accessible covered rock area. In contrast, Hazard Reef was not visible from the road, did not have facilities, and the majority of visitors to the site entered the covered rock zone, yet the overall density of visitors was arguably lower than if the site had easier access, more visibility, or facilities to draw visitors. Other studies suggest that the amount of visitors to rocky intertidal biological communities decreases as the distance from an access point increases (e.g., Addessi 1994). The visitor counts presented here indicate that there may be a similar trend in the total number of visitors to a site along a gradient of accessibility. As the ease of access, road visibility, or presence of facilities decreases visitors may be less inclined to explore a shoreline.

This conclusion was consistent with the assumptions made by Smith et al. 2008 to subjectively grade shore use levels as either high or low by taking into consideration the ease of parking and ease of accessing the shore. Resource managers should consider the 
site characteristics and how these characteristics influence visitor activity when managing the rocky intertidal resources of a particular site. Grading sites based on ease of access may be an effective means for resource managers to determine whether specific sites, with abundant rocky intertidal habitat, are susceptible to large numbers of visitors thereby leading to significant impacts to rocky intertidal biological communities.

My data suggest that regulating the total number of cars entering MDO would not be an effective or accurate means to control the number of visitors to rocky intertidal habitats in MDO State Park. A significant relationship was not detected between the number of cars entering MDO State Park and either the number of shore or CR visitor numbers (Figs. 1.6 and 1.7). MDO State Park was host to diverse terrestrial and marine habitats which drew visitors for a variety of recreational purposes not necessarily linked to the rocky intertidal. Visitors can participate in a variety of activities including: hiking, biking, riding horses, photography, camping, touring the historical visitor center, surfing, fishing, etc. Based on estimates of the percentage of people annually visiting the CR zone, only $0.5 \%$ of the people annually entering MDO were participating in activities in the rocky intertidal at the three observation sites. Such a small percentage would suggest that most of the people entering MDO do not visit the rocky intertidal, or at least do not visit the rocky intertidal at the three sites examined here. There was also some question as to how accurate the State Parks daily car counts were in relation to the shore visitor counts. Car counts were based on a daily total obtained from a counter placed on the road that cars drive over as they enter the park. These data did not record the time that each count was made, therefore the visitor counts could not be related to the number of cars entering the park during the three hour observation time. There do not appear to be 
any published studies examining the relationship between daily car totals and either shore or $\mathrm{CR}$ visitor numbers. Car count data including the time which cars are entering a park may be more effective at elucidating any relationship between daily car totals and the number of shore or CR visitors.

The number of cars parked at the observation sites was more strongly related to the number of shore and CR visitors than were the MDO daily car totals. This result indicates that people may be parking at sites with rocky intertidal habitat, but not necessarily visiting the $\mathrm{CR}$ zone. Shore visitor levels were significantly related to the number of cars parked at each site. However, the relationships between cars parked at each site and the number of CR visitors were not significant at any of the sites. Other observational studies of visitor distribution along rocky shores around Monterey, CA. showed that $\sim 80 \%$ of visitors do not enter the CR zone (Clowes and Coleman 2000, Tenera 2003).

Further examination of the relationship between the number of cars parked at Hazard Reef and the CRKA visitor density at Hazard Reef suggest that regulating parking lot size may be an effective means for resource managers to control visitor density to rocky intertidal communities. There was a significant relationship detected between the number of cars parked at Hazard Reef and the density of people in the CRKA zone (Fig. 1.10). Though none of the relationships between parking lot car counts and CR visitor density were significant, the relationship was the strongest at Hazard Reef (Fig. 1.9a). For this reason, the relationship between parking lot car counts and CRKA (covered rock known area) was further analyzed at that site. Visitor count data from this analysis was based on two fewer surveys than for the CR analysis because the CRKA 
was not delineated during the first two observations. The observation area for CRKA visitor counts was also smaller than for the $\mathrm{CR}$ visitor counts, possibly contributing to the significant relationship observed between parking area car totals and CRKA visitor density. The smaller CRKA observation area was closer to the Hazard Reef parking area. Visitors parking in the Hazard Reef lot may have been more likely to walk to the closer CRKA than to the CR farther from the observed parking area. The relationship between the number of cars parked at Hazard Reef and the density of CRKA visitors contained an outlier which was a large school group that did not utilize the observed parking area. With this data point removed the relationship between the number of parked cars and CRKA visitors was still significant (Fig. 1.11). This indicates both a strength and weakness of the car counts, from this study, in lots near rocky intertidal biological communities to potentially predict the density of visitors. The weakness in these observations was that the observed parking areas did not include all areas where cars could be parked for people to access the observed CRKA zones. This weakness could be addressed by using a more complete sampling design that included all possible parking areas. In addition, visitors to CR zones could be interviewed to determine exactly where they parked to access the rocky intertidal. The strength, as mentioned above, is that despite the incomplete sampling of parking areas, there was still a significant relationship between the number of cars parked at one of the major parking areas for Hazard Reef and the density of CRKA visitors. These findings were similar to those from a study assessing the recreational usage of river shoreline which found a relationship between the number of visitors and the size of the parking area (Santiago et al. 2008). This study also developed a model, incorporating among other factors the number of parking spaces, to 
predict visitor use and suggests the number of parking spaces could be used to regulate the number of visitors to recreation areas along the shore of a river.

Further experimental work manipulating parking lot size and observing CRKA visitor density may be able to provide a scale of expected CRKA visitor density based on the number of parking spaces in a lot. Determining this scale would require detecting a significant relationship between the number of parked cars and the rocky intertidal visitor density based on experimental manipulations of parking lot size. With this scale, visitor density could be predicted and controlled using the number of parking spaces. For example, to appropriately size a parking lot, managers should determine the area of the rocky intertidal they are allowing access to, calculate the ratio of the area of their reef relative to Hazard Reef $\left(1,960 \mathrm{~m}^{2}\right.$ at $+0.61 \mathrm{~m}$ MLLW), and multiply by the target annual visitor density. A more detailed hypothetical discussion of how parking lot car counts, CRKA visitor observations, and the results of an experimental manipulation of visitor densities to rocky intertidal communities could be used to manage the effects of visitor access to rocky intertidal communities is provided in Appendix 2.

A statistically significant relationship between tide height and CR visitor numbers was only detected at Spooner's Cove. This result may be due to a lack of sampling on days with higher tides, as it was assumed no CR would be exposed when the tide rose above a certain level, thereby excluding access. A significant relationship between tide height and CR visitor numbers might have been detected at Hazard Reef and Corallina Cove if more days had been sampled with higher tides, thereby excluding access to the CR at Hazard Reef and Corallina Cove. However, most of the sampling occurred when the tide level was low enough for visitors to access the rocky intertidal habitat. This 
finding also indicates that at Hazard Reef and Corallina Cove, the amount of people visiting the rocky intertidal community was not strongly dependent on extremely low tides, but that people visited these areas equally when the tide was low enough to allow access (Fig. 1.11). Again, site differences likely contributed to the observed relationships between tide height and CR visitor numbers. The rocky intertidal habitat at Spooner's Cove was more difficult to access as the tide height increased than the CR habitat at either Hazard Reef or Corallina Cove (pers. obs.). Therefore, a strong correlation between tide height and visitor numbers would not be expected. Tide height was incorporated in the calculation estimating the annual exposure hours of rocky intertidal habitat. Based on the results above indicating that visitors would go to these areas when they were exposed and not only on the lowest tides, the tide value used to calculate annual exposure hours was $\leq+0.61 \mathrm{~m}$ MLLW .

In summary, this study presents another metric of rocky intertidal use was provided which may be easier for resource managers to integrate into policy than other metrics, such as foot step density. The results of these surveys indicated that regulating the number of cars entering MDO State Park would not be an effective means to control access to rocky intertidal biological communities. A stronger relationship was detected between the number of cars parked near rocky intertidal communities and the annual number of rocky intertidal visitors. Further controlled manipulation of parking lot size may clarify whether parking lot size could accurately be used to predict and control visitor access to rocky intertidal communities. Finally, estimates of visitor levels to rocky intertidal communities suggest that impacts are much less in SLO County than what occurs in areas of northern and southern California, but future studies should be 
conducted to elucidate any relationships among shores with differing levels of visitor density and the abundance of organisms in rocky intertidal communities. 


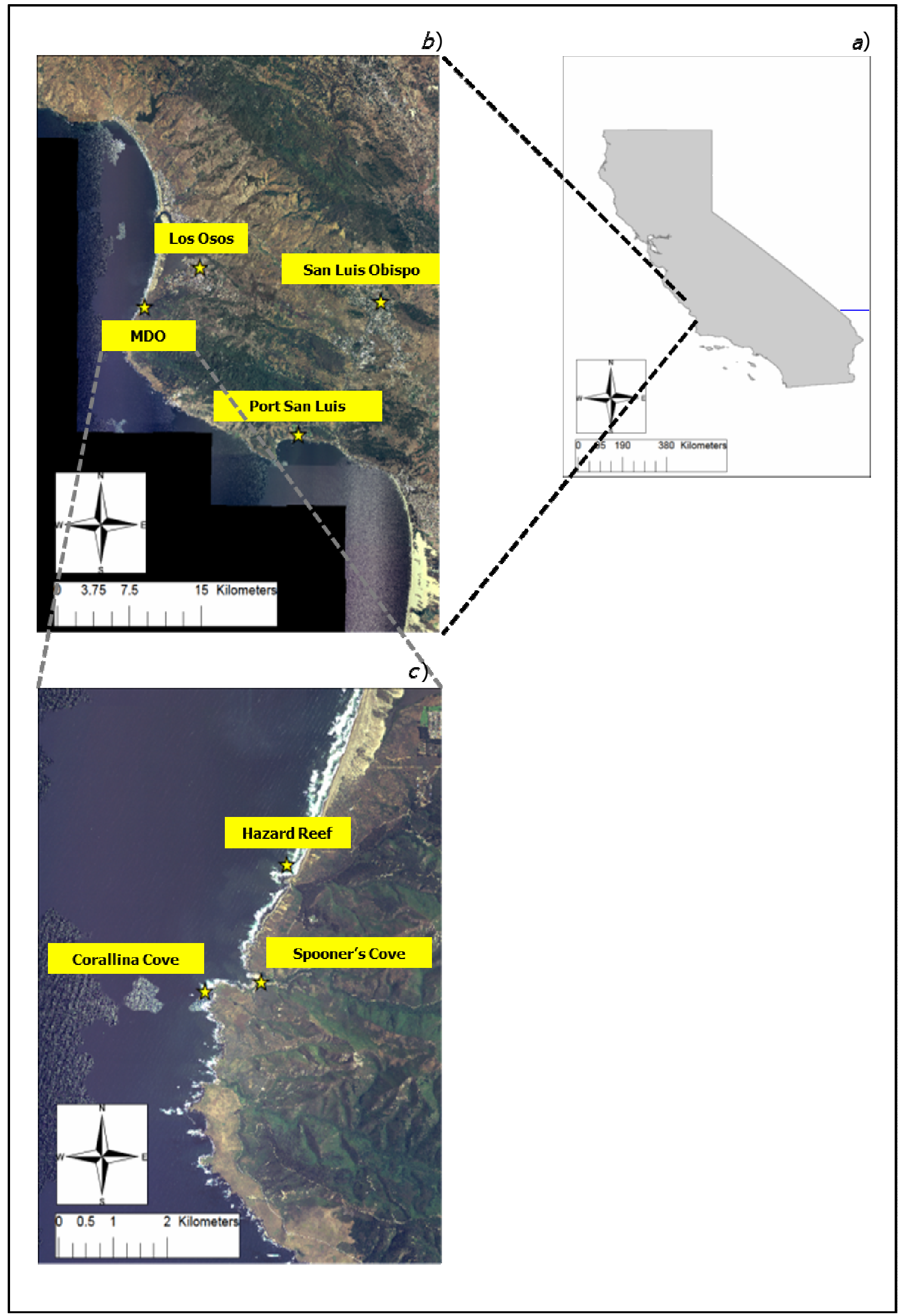

Figure 1.1 Map displaying the position of the visitor use study area in $a$ ) California, $b$ ) San Luis Obispo County, and $c$ ) specific observation sites in Montaña de Oro State Park. 


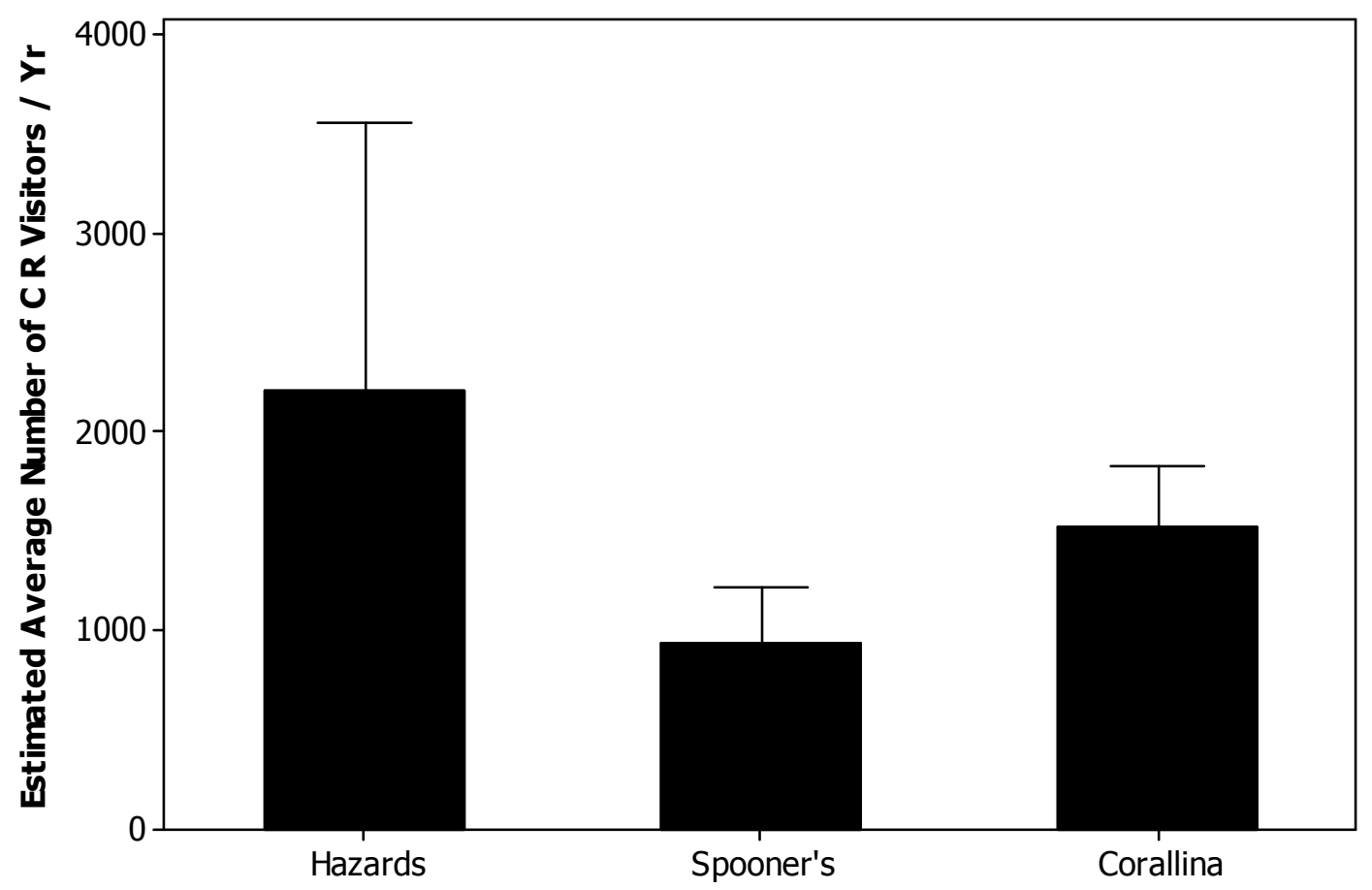

Figure 1.2. Annual estimates of total covered rock (CR) attendance by site (error bars are one standard error of the mean). Annual attendance was calculated by multiplying the average hourly visitor rate by the estimated number of hours each area is exposed to foot traffic per year (603 hours). 


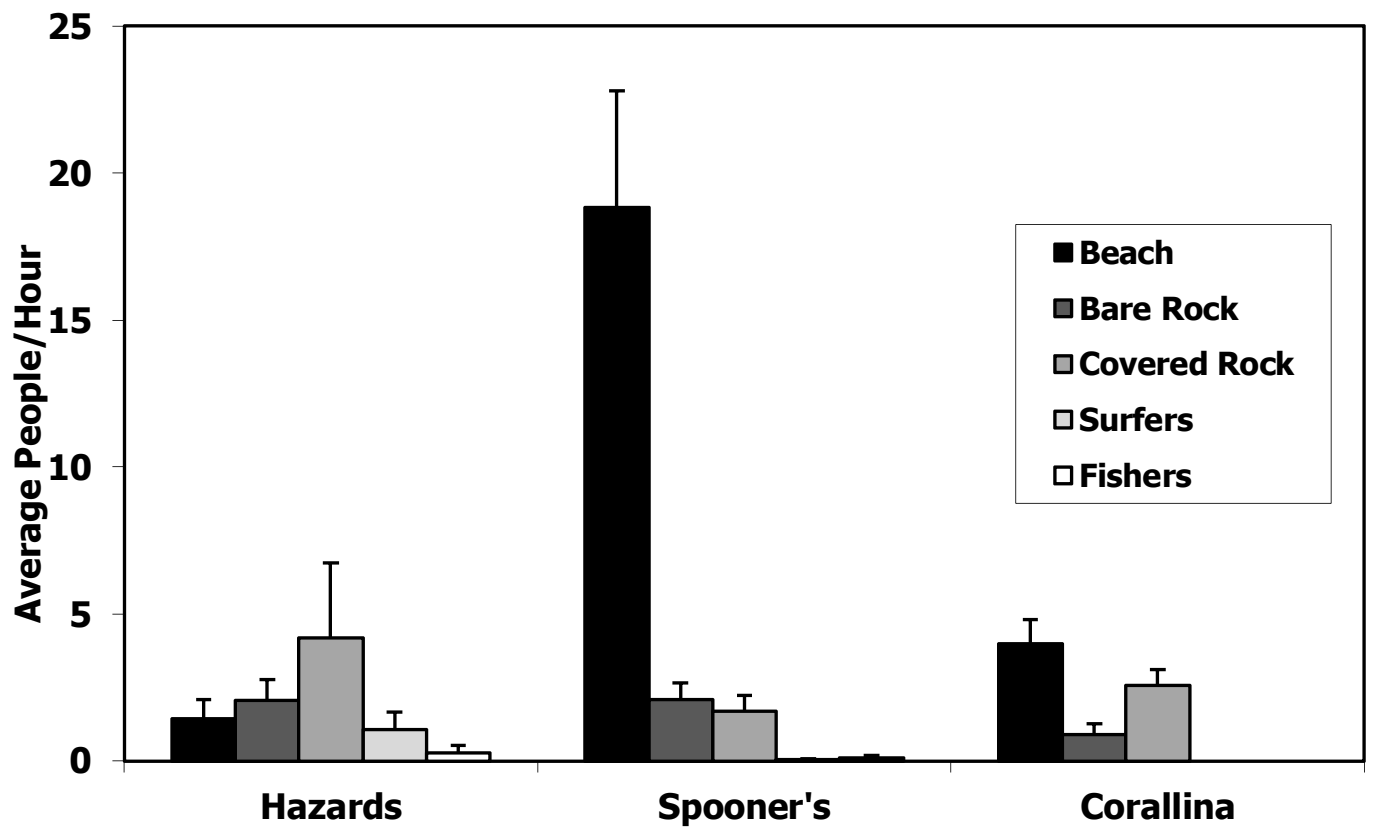

Figure 1.3. Average hourly visitation rates (error bars represent one standard error) of visitation to different shore zones at three observation sites within Montaña de Oro state park. Hourly estimates were the average number of visitors recorded from counts made every ten minutes over the course of an hour. Sixteen observations were used to calculate average hourly visitor rates. 


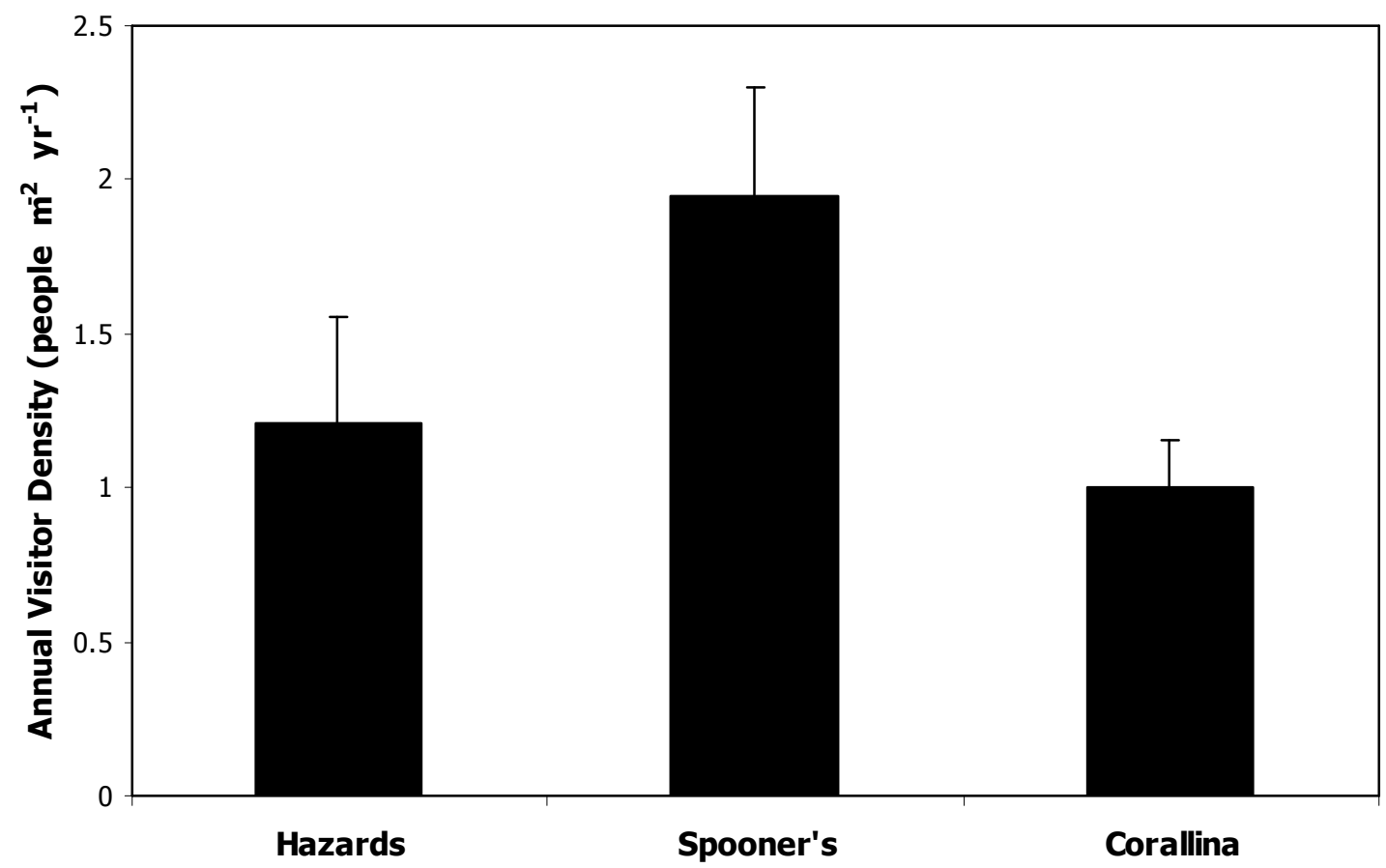

Figure 1.4. Annual density of visitation per $\mathrm{m}^{2}$ (error bars represent one standard error) in the covered rock zone (CR) at three popular sites within Montaña de Oro State Park. Density was calculated by multiplying the average hourly visitor rate by 603 available visitation hours per year. That value was then divided by the area of the respective observation site to determine annual visitor density. 


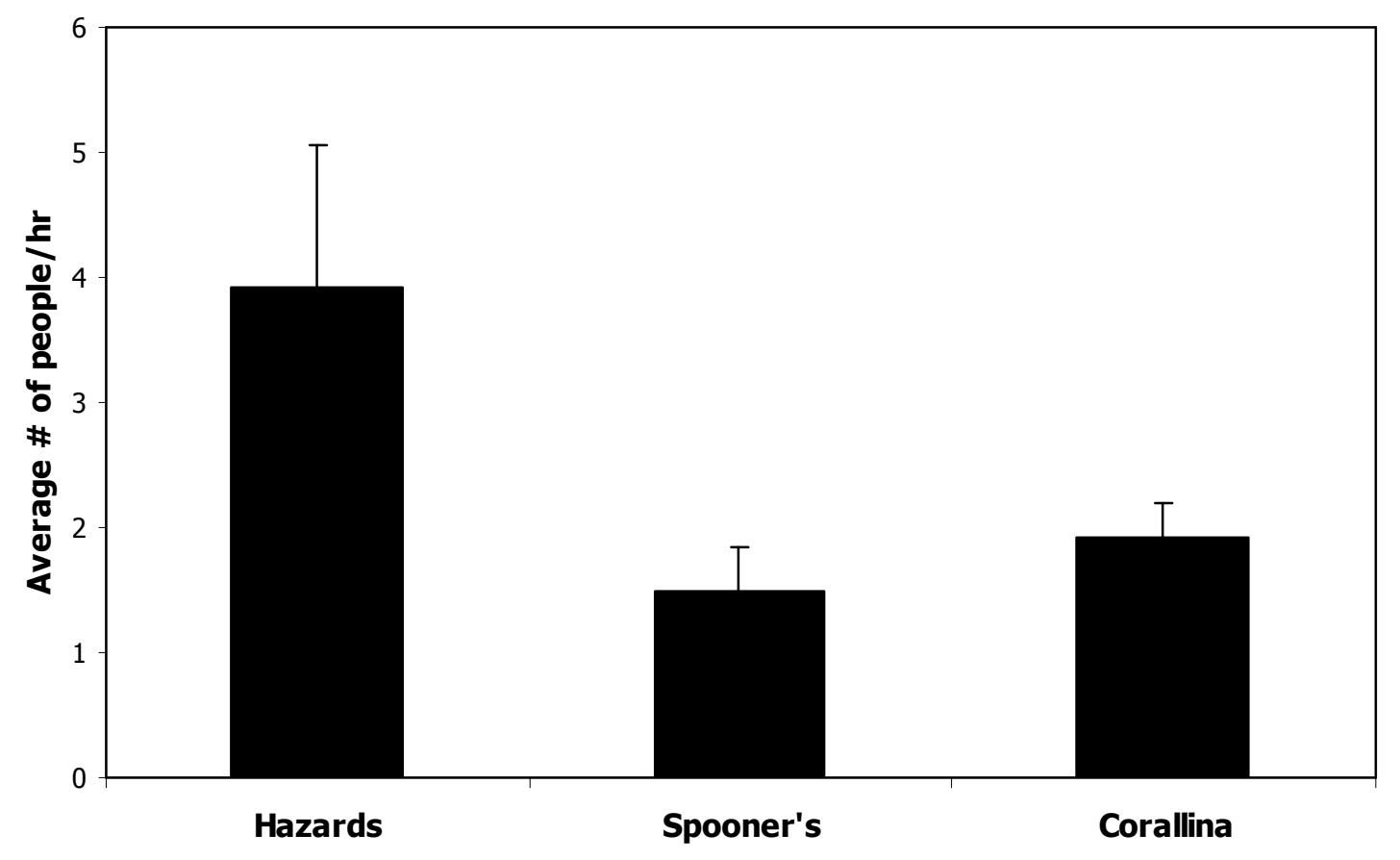

Figure 1.5. The average hourly number of people visiting the covered rock known area (CRKA) (error bars represent one standard error). Rates were calculated by combining the hourly average 'covered rock known area passive' and 'covered rock known area active' to provide a single covered rock known area rate. Visitation rates were based on the average CRKA hourly rates from 16 observation days. Note: rates are different than those listed in Table 1 due to restricting the calculation to only 'covered rock known area' observations. 
a)

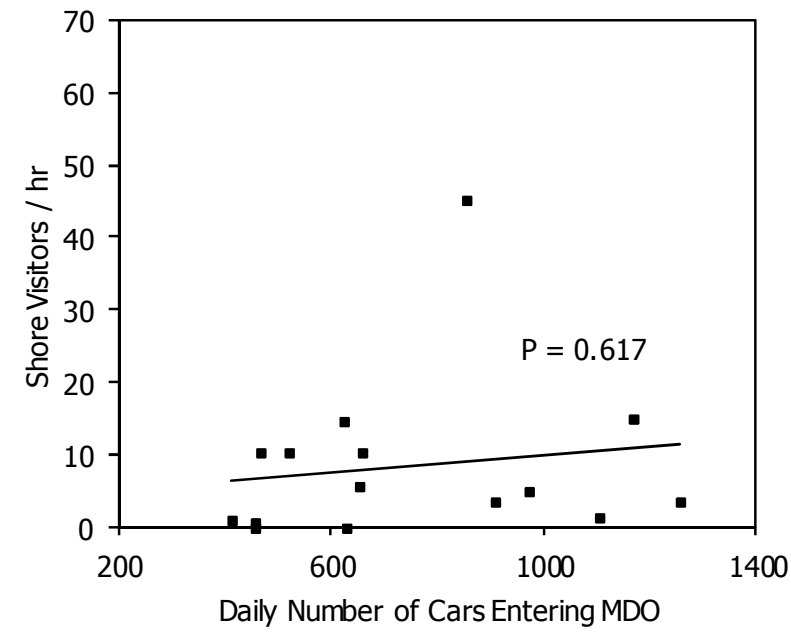

b)

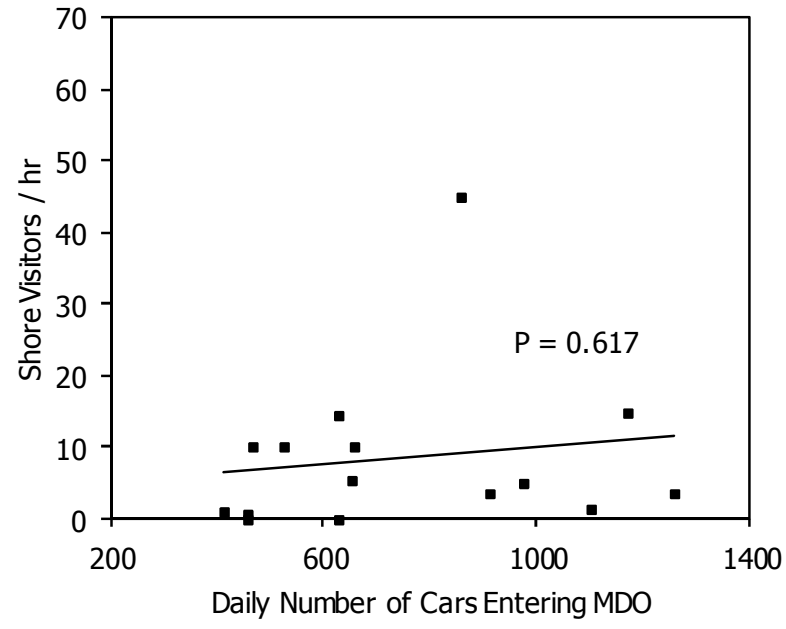

c)

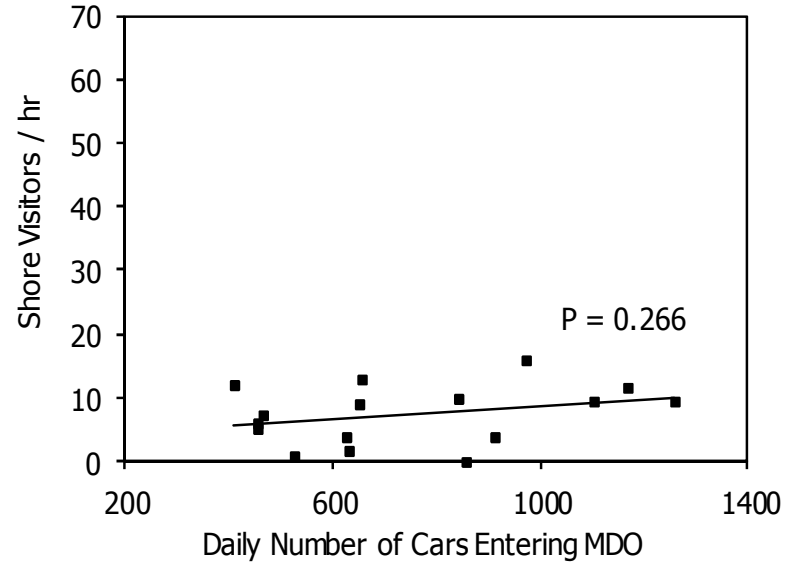

Figure 1.6. Regression analysis of the daily number of cars recorded by California State Parks staff entering MDO State Park and the average hourly number of shore visitors at: a) Hazard Reef, b) Spooner's Cove, and c) Corallina Cove. Total shore visitors were quantified as all people recorded in the beach, bare, and covered rock zones. 
a)

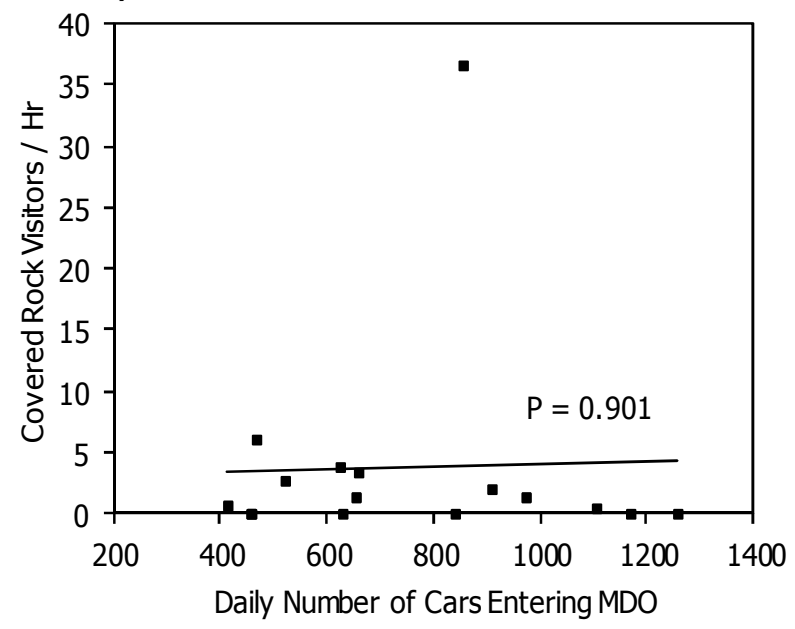

b)

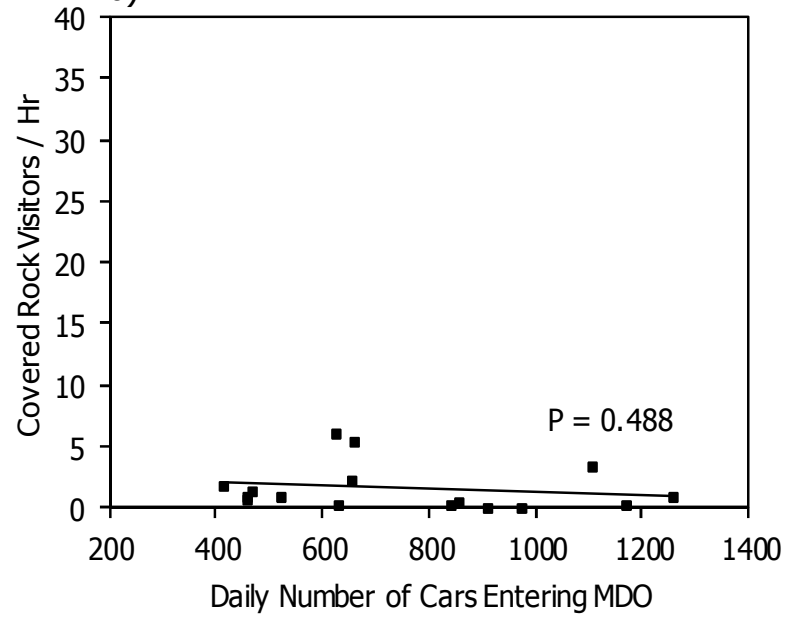

c)

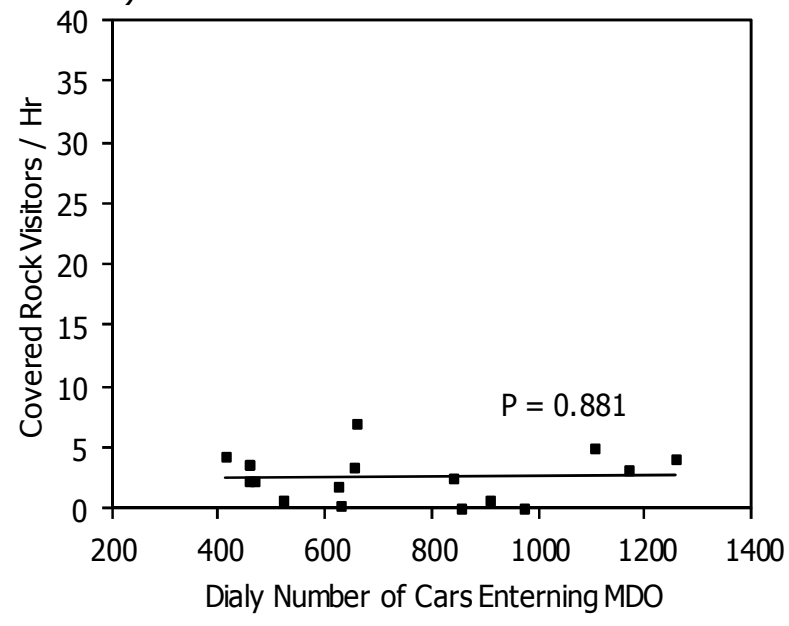

Figure 1.7. The relationship between the daily number of cars entering MDO State Park recorded by California State Parks and the hourly number of visitors to the covered rock zone at: a) Hazard Reef, b) Spooner's Cove, and c) Corallina Cove. Each covered rock visitor rate data point represents the average number of visitors recorded in the covered rock zone every 10 minutes for one hour. 
a)

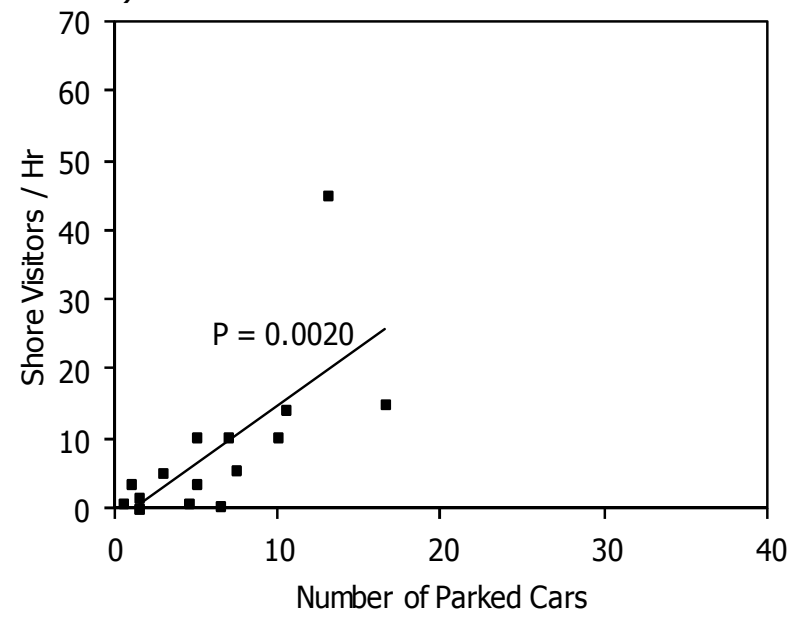

b)

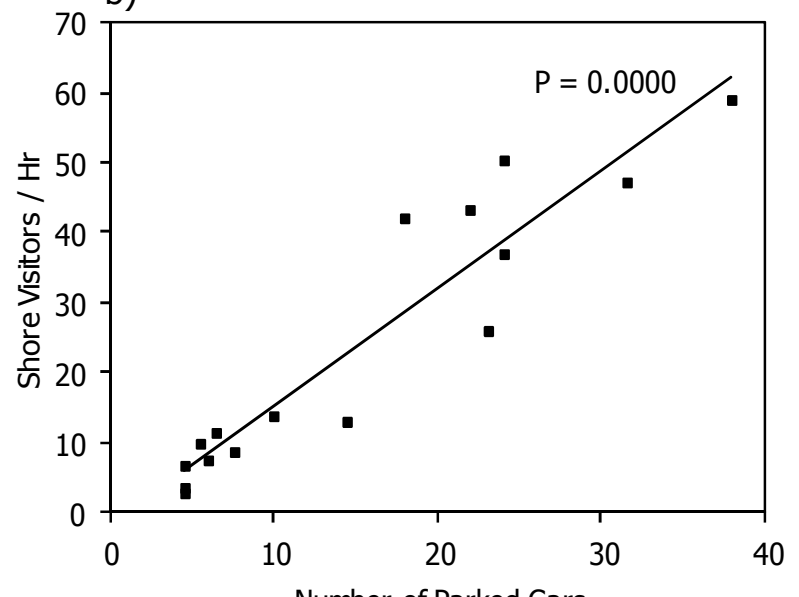

c)

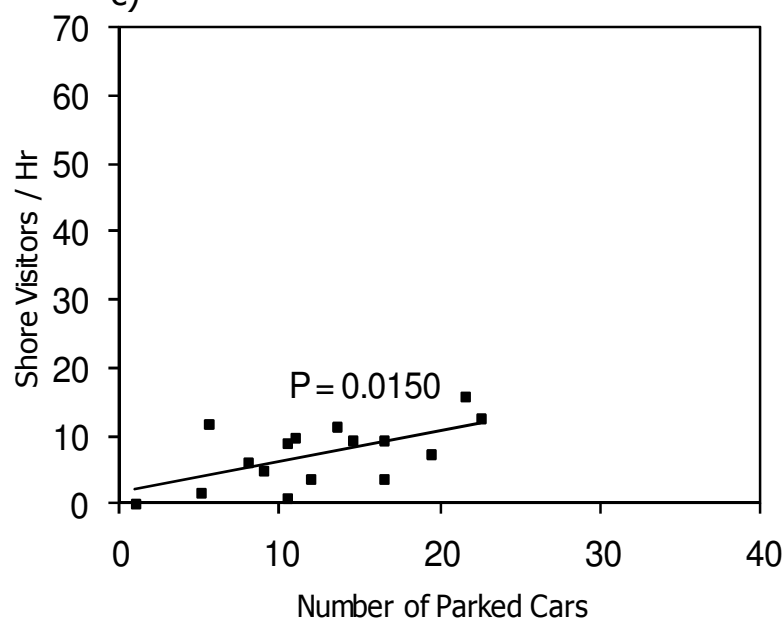

Figure 1.8. The relationship between the daily numbers of cars parked adjacent to observation sites and the hourly rate of total shore visitation at: a) Hazard Reef, b) Spooner's Cove, and c) Corallina Cove. Total shore visitors were quantified as all people recorded in the beach, bare, and covered rock zones. Each total shore visitor rate data point represents the average number of visitors recorded in the covered rock zone every 10 minutes for one hour. Car counts are the average number of cars parked at each site at the start and finish of the one hour observation period. 
a)

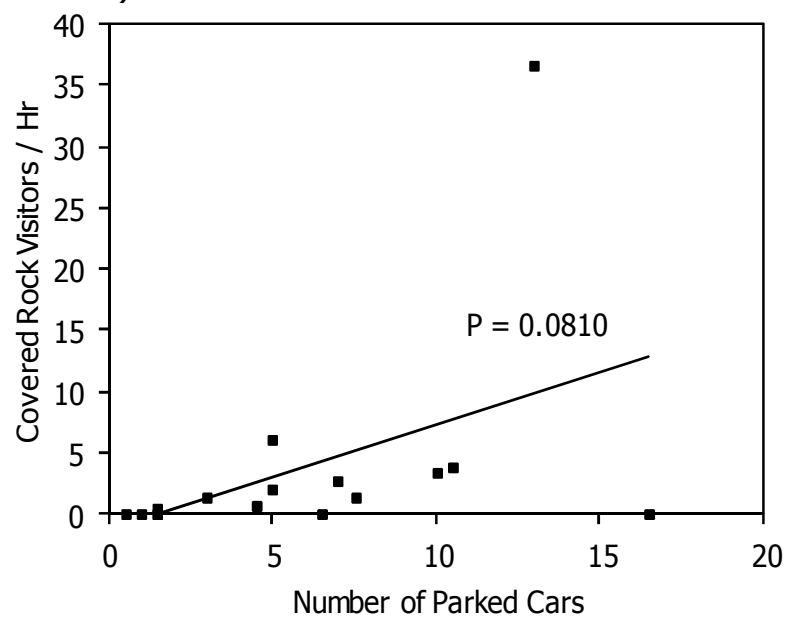

b)

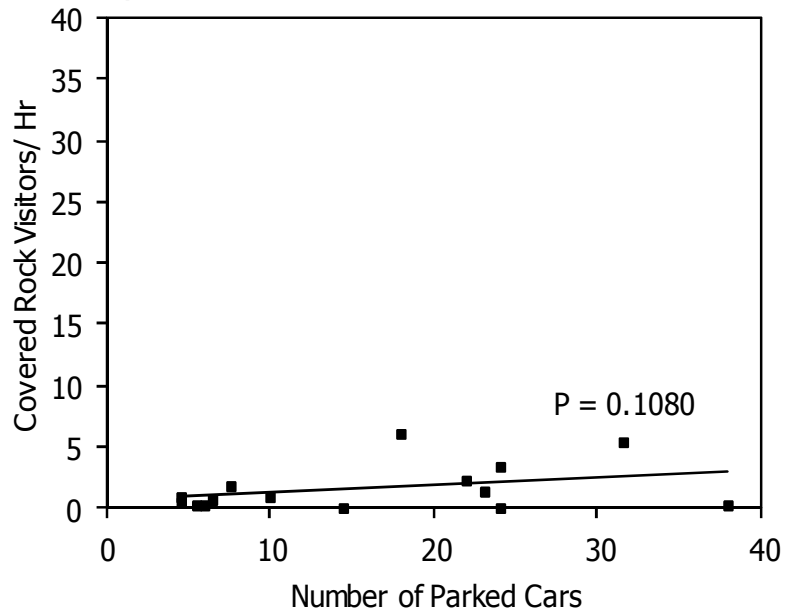

c)

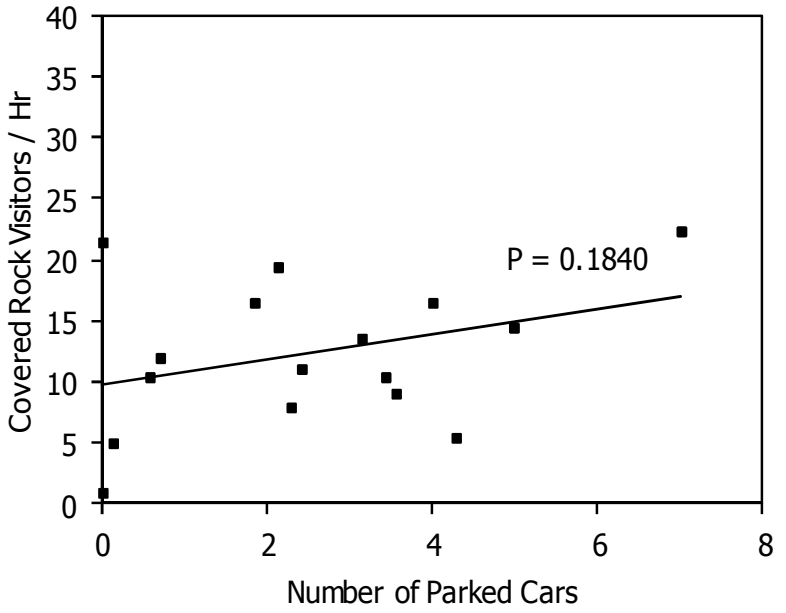

Figure 1.9. The relationship between the daily numbers of cars parked adjacent to observation sites and the hourly number of visitors to the covered rock zone at: a) Hazard Reef, b) Spooner's Cove, and c) Corallina Cove. Each covered rock visitor rate data point represents the average number of visitors recorded in the covered rock zone every 10 minutes for one hour. 


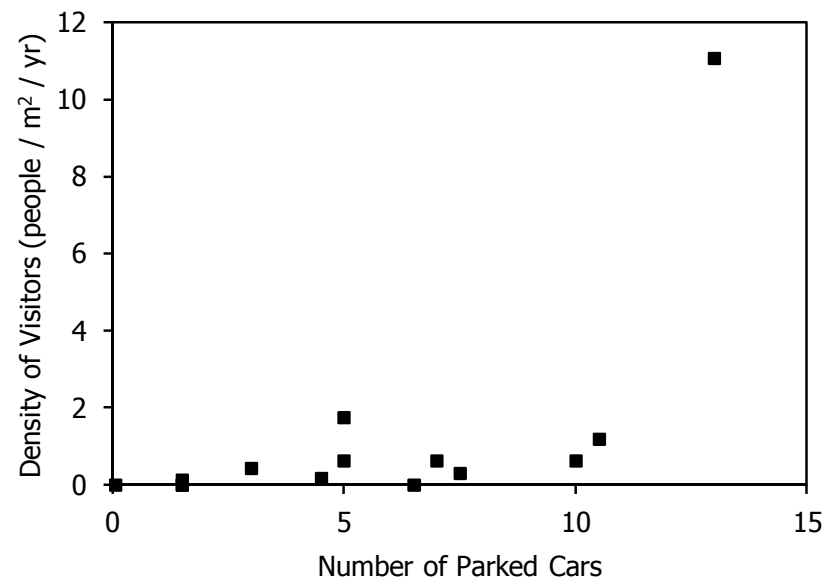

Figure 1.10. The relationship between the average numbers of cars recorded at the start and end of each one-hour observation period and the annual density of covered rock visitors at Hazard Reef. Note: figure represents the non-transformed values of annual CRKA visitor density, not the log transformed values used in the regression analysis. 


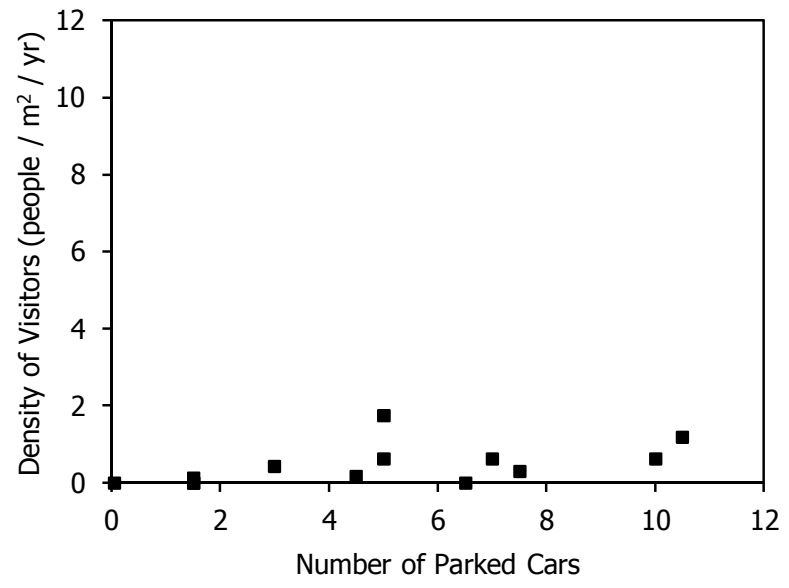

Figure 1.11. Relationship between the average numbers of cars recorded at the start and end of each onehour observation period and the annual density of covered rock visitors at Hazard Reef without the school group outlier. Note: figure represents the non-transformed values of annual CRKA visitor density, not the $\log$ transformed values used in the regression analysis. 
a)

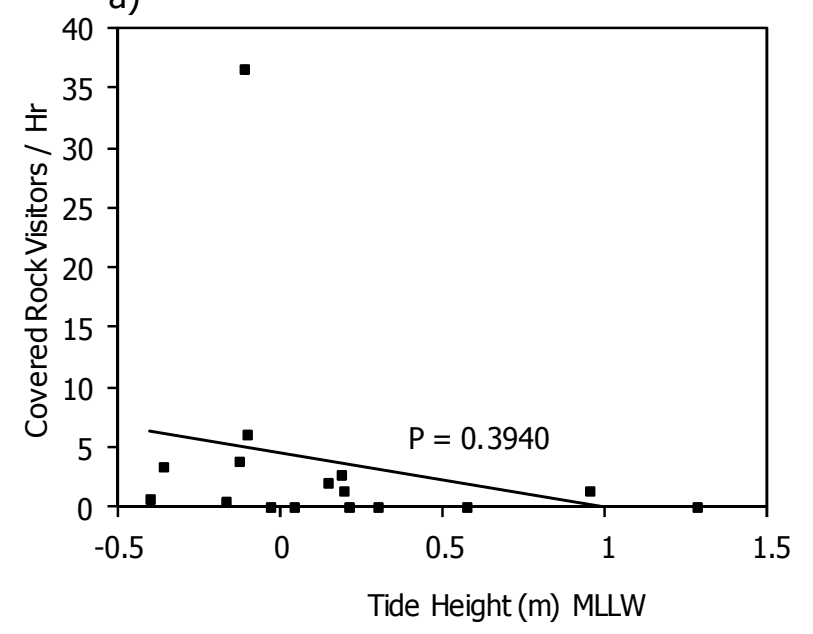

b)

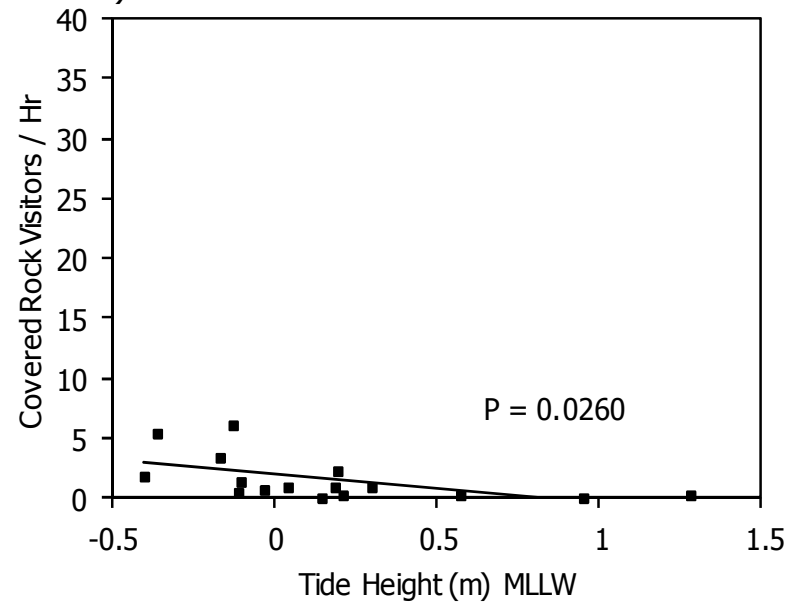

c)

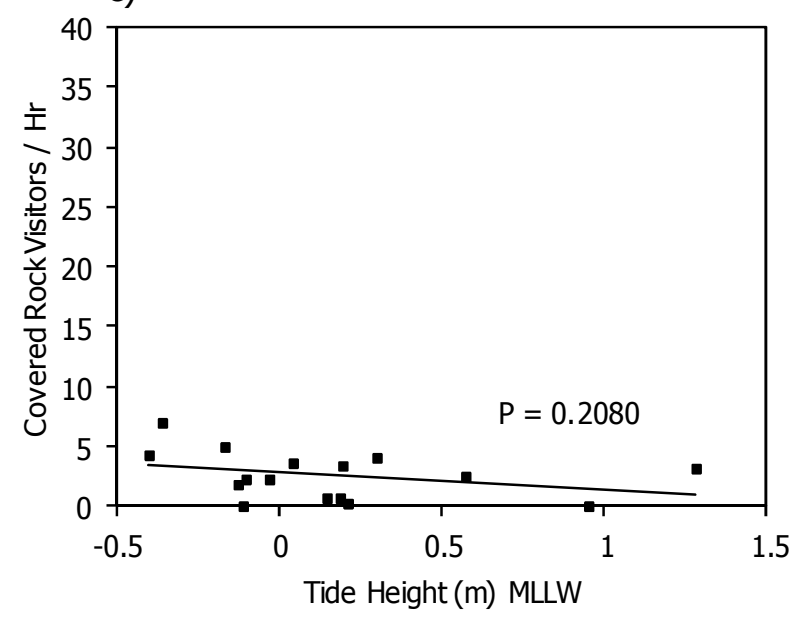

Figure 1.12. The relationship between tide height and the hourly rate of covered rock visitors at: a) Hazard Reef, b) Spooner's Cove and c) Corallina Cove. Each covered rock visitor rate data point represents the average number of visitors recorded in the covered rock zone every 10 minutes for one hour. Tide height was based on NOAA predictions for Port San Luis. 


\section{CHAPTER 2}

ASSESSING THE ABUNDANCE OF ACCESS INDICATOR TAXA ON PUBLIC ROCKY SHORES IN MONTAÑA DE ORO STATE PARK 


\section{Introduction}

Human visitation to natural areas can lead to changes in behavior, abundance, and distribution of individual organisms as well as to changes in community structure (e.g. Dale and Weaver 1974, Addessi 1994, Lindberg et al. 1998, Blair 1999, Niemelä et al. 2000, Cahill et al. 2002, Fernández-Juricic 2002, Berger 2007). Temperate rocky intertidal ecosystems are subject to human disturbance, both directly and indirectly. Direct disturbances are impacts resulting from people visiting the intertidal, whereas indirect disturbances result from human activity in areas spatially removed from the affected intertidal community (e.g., sewage outflow, global climate change, and oil spills). Direct human disturbance can generally be defined as affecting intertidal communities in two ways: consumptive (harvesting) and non-consumptive (e.g., foot traffic) activities.

A body of literature exists examining the effects of foot traffic using both experimental applications (trampling) as well as observational studies comparing communities among areas with varying levels of visitation. Experimental and observational studies have detected significant reductions in algal and invertebrate taxa caused by or related to foot traffic. Affected algal taxa include: algae in the order Fucales (Povey and Keough 1991, Brosnan and Cumrine 1994, Fletcher and Frid 1996, Murray 1997, Keough and Quinn 1998, Schiel and Taylor 1999, Clowes and Coleman 2000, Van De Werfhorst and Pearse 2007, Appendix 1), non-coralline fleshy and turf species (Brosnan and Cumrine 1994, Fletcher and Frid 1996, Murray 1997, Clowes and Coleman 2000, Huff 2011, Appendix 1), and coralline species (Fletcher and Frid 1996, Murray 1997, Keough and Quinn 1998, Brown and Taylor 1999, Schiel and Taylor 1999, Clowes 
and Coleman 2000). Affected invertebrate taxa include: tube forming polychaetes (Murray 1997), mussels and other bivalves (Brosnan and Cumrine 1994, Murray 1997, Brown and Taylor 1999, Van de Werfhorst and Pearse 2007), barnacles (Brosnan and Cumrine1994 and Murray 1997), limpets (Povey and Keough 1991, Murray 1997, Keough and Quinn 1998, Appendix 1) and other mollusks (Keough and Quinn 1998, Brown and Taylor 1999, Appendix 1). Bare space has also been shown to increase with increased foot traffic (Schiel and Taylor 1999, Clowes and Coleman 2000, Van De Werfhorst and Pearse 2007). In addition to impacting individual taxa, foot traffic can also decrease the diversity (Beauchamp and Gowing 1982) and abundance of algal and/or invertebrate taxa in rocky intertidal communities (Beauchamp and Gowing 1982, Ghazanshi 1983, Addessi 1994, Brown and Taylor 1999).

This study focused on describing the direct impacts of foot traffic upon rocky intertidal communities at a location open to public access. Instead of quantifying all or the majority of taxa in these communities, I restricted my sampling to five focal taxa previously identified as susceptible to experimental foot traffic (e.g., Povey and Keough 1991, Brosnan and Cumrine1994, Keough and Quinn 1998, Appendix 1), which I call access-indicator taxa. I quantified access-indicator taxon abundance at three rocky intertidal sites with various densities of foot traffic (Fig. 2.1). The visitor density at three adjacent rock benches in MDO State Park was estimated using similar methods to those from Chapter 1, but the observation time was reduced from 60 minutes to 30 minutes. The most densely visited shore had an estimated annual visitor density of 1.2 people $\mathrm{m}^{-2}$ $\mathrm{yr}^{-1}$, which was between the moderate and high experimental densities shown to affect the 
five access-indicator taxa in Appendix 1. The less visited shores had estimated annual visitor densities near zero.

Similar observational studies on the effects of foot traffic have been conducted, but this study was unique in the approach and purpose. The approach relied on the results from a controlled field study to focus sampling on taxa previously identified as susceptible to impacts, and the purpose was to determine if similar levels of impacts could be detected in intertidal areas open to public access. Since the treatments in the field experiment were selected based on levels of visitor access at the same areas used for the observational study, I was assured that the treatment levels bracketed the levels of access at the observational site. While there is always uncertainty associated with the results of most observational studies, the focus on already identified access-indicator taxa and the ability to verify results with the field experiment provided additional support that impacts detected in the access indicator taxa were the result of human access. Focusing on access-indicator taxa was also critical in providing evidence to resource managers that the levels of impacts detected in the field experiment were occurring in MDO.

My sampling focused on three algal and two invertebrate access-indicator taxa, previously identified in Appendix 1 and other experimental and observational studies as being significantly impacted by visitor levels similar to those observed at MDO. I expected the abundance of access-indicator taxa to be greater in areas with lower densities of visitors (i.e., Hazard Mid and Hazard Far). Reductions in the abundance of these taxa would provide evidence that foot traffic was having a significant impact on the rocky intertidal communities at this location. The sampled algal taxa were: rockweed in the family Fucaceae (Silvetia compressa, Fucus gardneri, and Hesperophycus 
californicus), Endocladia muricata, and Mastocarpus papillatus. Algae in the order Fucales, which includes the family Fucacea, have been identified by several studies as being sensitive to foot traffic (Beauchamp and Gowing 1982, Povey and Keough 1991, Fletcher and Frid 1996, Keough and Quinn 1998, Murray 1999, Schiel and Taylor 1999, Clowes and Coleman 2000, Van De Werfhorst and Pearse 2007) and also provide important overstory cover (Dayton 1971 and Lilley and Schiel 2006). Endocladia muricata is a turfy red alga that has been implicated as important for understory communities (Dayton 1971). Mastocarpus papillatus is a fleshy red alga that can provide both overstory or understory cover in the rocky intertidal (Dayton 1971). In addition to algae, I sampled the abundance of two herbivorous mollusk groups: limpets (Lottia digitalis, L. gigantea, L. limatula, L. pelta, L. scabra, and Tectura scutum) and chitons (Lepidochitona dentiens, Lepidochitona hartwegii, Tonicella lineata, Mopalia muscosa, and Nuttalina californica).

The study site was located in Montaña de Oro Sate Park (MDO), one of the most visited state parks in San Luis Obispo County. One particular rocky area in the park was unique because it was exposed to relatively high densities of visitors and was also adjacent to two sites with similar swell exposure, relief, and geology (pers. obs.) that had fewer visitors (Fig. 2.2). The orientation of the study site allowed for sampling along a defined difference of visitor density at three areas, each separated by less than $600 \mathrm{~m}$ of sandy shore. Considering the results from Appendix 1, I hypothesized that the change in abundance for these taxa between Hazard Reef (high visitor density) and Hazard Mid and Hazard Far (low visitor density) would be similar to the change detected between control and treatment plots in Appendix 1. Because the annual moderate experimental visitor 
densities in Appendix 1 were similar to the densities observed at Hazard Reef, it seemed logical to assume that the reductions in algal and invertebrate abundance observed in that study might be comparable to reductions at a similar rocky intertidal community, but exposed to years of public access. These reductions were 10-15 percent cover for Silvetia compressa (Fuciod algae), 5 percent cover for Endocladia muricata, 2-3 percent cover for Mastocarpus papillatus, 2-6 limpets $/ \mathrm{m}^{2}$, and $<1 \mathrm{chiton} / \mathrm{m}^{2}$ (Appendix 1).

\section{Methods}

\section{$\underline{\text { Site Description }}$}

The comparison of access-indicator taxon abundance at an area with high levels of visitor access to areas that have lower levels of access was conducted in MDO at Hazard Reef (described in Chapter 1) and two adjacent rock benches (Hazard Mid and Hazard Far). Hazard Reef (Fig. 2.3) is one of the areas in MDO that receives large numbers of visitors due to the rocky intertidal habitat, but also due to other activities such as surfing and fishing. This access path at Hazard Reef results in the area being exposed to higher concentrations of visitors than less known or more difficult to access rocky shoreline areas, such as Hazard Mid and Hazard Far. Visitor density to the intertidal habitat present at Hazard Reef was estimated at 1.2 people $\mathrm{m}^{-2} \mathrm{yr}^{-1}$ (Chapter 1$)$, which fell between the moderate and high experimental treatment densities that were shown to affect the abundance of access-indicator taxa in Appendix 1. The five access-indicator taxa identified in Appendix 1 were found in the intertidal zone at Hazard Reef and the rocky habitat extending south from Hazard Reef as a nearly continuous stretch of 
relatively flat rocky intertidal bench habitat, which was similar in geology and vertical relief to that of Hazard Reef. This adjacent flat rock bench included the comparison sites Hazard Mid and Hazard Far. Hazard Mid and Hazard Far are also visited by individuals and educational groups, though the density of visitation was lower than that of Hazard Reef.

\section{$\underline{\text { Visitor Observations }}$}

Observations were made on five occasions to quantify visitors at the three survey sites at Hazard Reef between June and September 2009. Observation days were opportunistically chosen and included weekdays and weekends. Observations occurred at a time of day around the low tide. The visitor count methodology was the same as that used in Chapter One, except that observations were made for 30 minutes, not 60 . The average hourly visitor rate was extrapolated from the 30 minute observation periods and used to calculate the annual visitor density using the same methodology as Chapter One.

\section{Field Sampling}

The survey transect location was determined by laying a transect tape parallel to shore through the middle of the 'rockweed' zone (Fig. 2.2a). The rockweed zone (community of the upper-mid intertidal characterized by the brown algae collectively known as rockweed) location was defined as the rocky shore and accompanying organisms between the upper extent of rockweed (onshore) and the lower extent of rockweed (offshore) relative to vertical location on the rock bench. The transect start location was at Hazard Reef (Lat. 35.28729 Long. -120.88413 GCS North American 
Datum 1983) and terminated $1 \mathrm{~km}$ south at Hazard Far (Lat. 35.28021 Long. -

120.88854 GCS North American Datum 1983). GPS coordinates were recorded at numerous locations along the transect to later locate the transect on a georeferenced satellite image of the coastal habitat (Fig. 2.3).

The survey transect was broken into $20 \mathrm{~m}$ sample segments (Fig. 2.2b). These segments were visually sampled for the abundance of the five access-indicator taxa as well as the percent cover of bare rock. The $20 \mathrm{~m}$ sample segments were further divided into $25 \mathrm{~m}^{2}$ sample quadrants. The transect tape in each sample segment was treated as an $\mathrm{x}$-axis beginning at the zero meter mark and ending at $20 \mathrm{~m}$. A y-axis center point was determined by randomly picking a number between 3 and 17 using a Texas Instruments TI 83 graphing calculator. Numbers were chosen between 3 and 17 to prevent overlapping sampling between adjoining $20 \mathrm{~m}$ sample segments. One y-axis was chosen for each $20 \mathrm{~m}$ sample segment. The $5 \mathrm{~m}$ perpendicular $\mathrm{y}$-axis transect tape was laid at the number randomly chosen for each sample segment (Fig. 2.2c) and was used to define a 5 $\mathrm{m} \times 5 \mathrm{~m}$ quadrant (Fig. 2.2c) centered where the $5 \mathrm{~m}$ perpendicular transect crossed the $20 \mathrm{~m}$ transect line. Due to the variable nature of the rocky intertidal habitat, not all $20 \mathrm{~m}$ segments were sampled along the entire kilometer of the transect. Segments were not sampled if they did not contain $>25 \mathrm{~m}^{2}$ of continuous suitable rockweed habitat. Unsuitable habitat included large, deep channels, elevated geology (platforms, boulders, and ridges), tidepools, and sand. GPS coordinates were recorded at the start and end points of each sample segment.

Within the $25 \mathrm{~m}^{2}$ sample quadrant, (3) one square meter sample quadrats were placed at randomly selected $\mathrm{x}$ - and $\mathrm{y}$-coordinates. The percent cover of the algal 
indicator taxa and bare rock were visually estimated using methodology described in Appendix 1. To assist in the estimation of cover the quadrats were divided into $25 \mathrm{~cm} \mathrm{x}$ $25 \mathrm{~cm}$ sub-quadrats $(\mathrm{n}=16)$, each of which was further subdivided into 9 sub-units. Cover was estimated and recorded in the field as the number of large sub-quadrats and smaller sub-units (Fig. 2.2d). These numbers were converted to percentage cover for analysis. The three algal taxa were: rockweed, Mastocarpus papillatus, and Endocladia muricata. Bare rock was defined as exposed base substrate lacking any sessile algal or animal growth. The numbers of two taxa of motile invertebrates were counted in each 1 $\mathrm{m}^{2}$ quadrat: limpets (Lottidae) and chitons (Polyplacophorans).

\section{The Number of $20 \mathrm{~m}$ Sample Segments:}

There were (8) $20 \mathrm{~m}$ sample segments at_Hazard Reef, (9) $20 \mathrm{~m}$ sample segments at Hazard Mid, and (16) $20 \mathrm{~m}$ sample segments at Hazard Far.

\section{$\underline{\text { Statistical Analyses }}$}

The abundance of access-indicator taxa was compared across sites using a nested analysis of variance (ANOVA), which was analyzed using a general linear model (GLM) constructed with the PROC GLM procedure in SAS (Ver. 9.3). The analysis was designed to test the hypothesis that there were no differences among the three areas or 'Sites' (Hazard Reef, Hazard-Mid, and Hazard-Far). Sites were the main factor in the analysis and the $20 \mathrm{~m}$ sample segments nested within sites was the error term. The $1 \mathrm{~m}^{2}$ sample quadrat values composed the data in the nested 'Segments(Site)' error term. As the primary interest was to detect any differences between the heavily visited Hazard 
Reef site and the two sites with low levels of visitors, an a priori linear contrast was constructed to test this hypothesis. Both the main effects and the linear contrasts were tested using Segment(Site) as the error term using a probability level of $95 \%(\mathrm{p} \leq 0.05)$ to determine statistical significance. The assumption of homogeneity of variance was assessed prior to ANOVA with Levene's Test and data were transformed when appropriate to comply with the assumptions of the test. Percent cover data for combined algae and rockweed were natural $\log$ transformed $(\ln x+1)$. The data for Silvetia compressa, Endocladia muricata, Mastocarpus papillatus, Lottidae, and Polyplacaphora data were not transformed.

\section{Results}

\section{$\underline{\text { Visitor Surveys }}$}

Visitor density was highest at Hazard Reef. The annual visitor density to the covered rock zone (intertidal habitat covered with a significant amount of organisms) at Hazard Reef was 0.91 people $\mathrm{m}^{-2} \mathrm{yr}^{-1}$ (Fig. 2.1). There were no covered rock zone visitors observed at Hazard Mid or Hazard Far (Fig. 2.1). The density of visitors observed from five observations at Hazard Reef was similar to the visitor density (1.2 people $\mathrm{m}^{-2} \mathrm{yr}^{-1}$ ) for the same area calculated in Chapter One.

\section{Access-Indicator Taxon Abundance:}

Algal percentage cover was lower at Hazard Reef relative to Hazard Mid and Hazard Far for all sampled taxa (Fig. 2.4), while abundances were lower at Hazard Reef 
for Lottidae, but not for Polyplacaphora (Fig. 2.5). A significant difference in the abundance of Lottidae was detected among the three study sites using the nested ANOVA ( $p=0.004$, Table 2.1). A significant difference was also detected for Lottidae using the a priori contrast $(\mathrm{p}=0.019$, Table 2.1). Limpets were most abundant at Hazard Mid. No other significant differences were detected among sites for the other taxa, but a significant difference between Hazard Reef and Hazard Mid and Hazard Far was detected using the linear contrast for combined algal coverage $(\mathrm{p}=0.023$, Table 2.1). Combined algal cover was more abundant at Hazard Mid and Hazard Far than Hazard Reef.

\section{Discussion}

I compared the abundance of access-indicator taxa at publicly accessible shores receiving annual visitor densities approximately equal to the 'moderate' experimental level applied in Appendix 1 (Hazard Reef MDO) with two adjacent areas exposed to minimal densities of visitors (Hazard Mid and Hazard Far). I wanted to determine whether similar changes in these access indicator taxa, due to experimental applications of foot traffic, could be detected in the adjacent State Park.

Significantly fewer limpets were present at Hazard Reef than Hazard Mid or Hazard Far. Additionally, combined algal cover was significantly lower at Hazard Reef when compared to the combined percent cover at Hazard Mid and Hazard Far. I observed differences between $10 \%-15 \%$ in the percent cover of algae and $10-40$ individuals $/ \mathrm{m}^{2}$ of limpets among Hazard Reef and Hazard Mid and Hazard Far. Two separate studies, one experimental the other observational, found similar The trends in the percent cover (algae) or density (mobile invertebrates) of access-indicator taxa were 
similar to the results from the field experiment (Appendix 1) and to results from another study of rocky intertidal disturbance along a gradient of visitor access (Van de Werfhorst and Pearse 2007). The magnitude of the differences in abundance of combined algal cover at Hazard Reef versus Hazard Mid and Hazard Far was similar to the magnitude of the difference between control and experimental plots from Appendix 1. The experimental plots located on PG\&E Diablo Canyon Power Plant property from Appendix 1 showed comparable reductions in the percent cover, relative to controls, of total algae (10-20\%). Van de Werfhorst and Pearse (2007) also observed similar patterns of reduced algal abundance along a gradient of visitor density of 0.0 people $\mathrm{m}^{-2} \mathrm{yr}^{-1}, 0.5$ people $\mathrm{m}^{-2} \mathrm{yr}^{-1}$, and 18.7 people $\mathrm{m}^{-2} \mathrm{yr}^{-1}$ at three rock benches in Santa Cruz, California. The results from both the experimental and observational studies indicate that visitor densities between 0.91-1.2 people $\mathrm{m}^{-2} \mathrm{yr}^{-1}$ can significantly reduce the abundance of certain taxa.

Additionally, these results show that increased visitor density may lead to larger reductions in important habitat-forming algae such as rockweed, which was the most abundant access-indicator algal taxon sampled at the Hazard sites (12-22\%). It was also the dominant algal taxon in most of the survey segments. Rockweed provides shaded and moist habitat which a variety of marine organisms may use during a low tide. Removal or reductions in rockweed may cause other algae to die off (Keough and Quinn 1998), invertebrates will have fewer places to take shelter during low tide (Brown and Taylor 1999), and changes in the community composition may occur (Beauchamp and Gowing 1982, Brosnan and Cumrine 1994, and Clowes and Coleman 2000). In addition to functioning as habitat, rockweed recruit dispersal distance has been shown to be limited 
from the parent plant, which may limit the ability of rockweed to recover from disturbance (Williams and Di Fiori 1996, Coleman and Brawley 2005, Pearson and Serrão 2006). Rockweed has been shown to be sensitive to foot traffic, leading to reductions in cover, in multiple studies (Beauchamp and Gowing 1982, Povey and Keough 1991, Fletcher and Frid 1996, Keough and Quinn 1998, Murray 1999, Schiel and Taylor 1999, Clowes and Coleman 2000, and Van De Werfhorst and Pearse 2007, Appendix 1). Assuming foot traffic had contributed to the significantly lower abundances in combined algal cover (primarily composed of rockweed) between Hazard Reef and Hazard Mid and Hazard Far, and considering the results of Appendix 1, these results suggest that resource managers should monitor and actively manage visitor densities to rocky intertidal biological communities. Monitoring and active management could prevent a significant reduction in the abundance of important habitat-forming algae in the rocky intertidal.

The observational design of this study does not allow other biotic and abiotic factors to be eliminated as explanatory factors when discussing the differences in accessindicator taxa abundance observed among the sites in MDO State Park. However, in this study other factors were not closely linked, a priori, to reductions in the abundance of the access-indicator taxa as was done with foot traffic. Additionally, these taxa were specifically predicted to decrease in abundance by levels comparable to the reductions observed in Appendix 1. The fact that reductions in the abundance of combined algal taxa and limpets were observed, the reductions were comparable to those observed in Appendix 1, and the visitor densities in MDO were similar to those applied in experimental plots provides support that foot traffic at Hazard Reef was the most likely 
cause of the differences in access-indicator taxa abundance at Hazard Reef relative to Hazard Mid and Hazard Far.

A limited sub-set of the species found in the rockweed zone was sampled in this study. Sampling was restricted to these access-indicator species because experimental results indicated that these were the species which would most likely decline in the presence of the visitor densities occurring at Hazard Reef (Appendix 1). This does not mean that other species in the community were not affected by foot traffic. Previous experimental and observational studies have shown impacts to temperate rocky intertidal species from foot traffic (Povey and Keough 1991, Brosnan and Cumrine1994, Fletcher and Frid 1996, Murray 1997, Keough and Quinn 1998, Brown and Taylor 1999, Schiel and Taylor 1999, Clowes and Coleman 2000, Huff 2011). These changes were based on quantifying footstep density or relative levels of use. It would be interesting to determine a scale of footstep density based on the observed visitor density at Hazard Reef and determine if there may be other taxa, identified from the above studies, which would show a reduction in cover or abundance from the density of footsteps at Hazard Reef. The abundance of any other access-indicator species could then be sampled to determine potential impacts due to foot traffic on other taxa at Hazard Reef and the implications for other less visited or soon to be open rocky intertidal areas.

While the level of foot traffic observed at MDO State Park did not appear to cause declines greater than $15 \%$ in the abundance of any access-indicator taxa, further declines in the abundance of species in the rockweed zone may have more noticeable impacts on the community. If the majority of the differences in abundance among the accessindicator taxa observed in this study at Hazard Reef relative to Hazard Mid and Hazard 
Far was primarily from human access, it would seem to suggest that certain areas in San Luis Obispo County should be considered susceptible to impacts from human access leading to foot traffic. The information from this study, coupled with the visitor use estimates and the experimental results of Appendix 1 may prove useful to resource managers in the County, as well as other areas, when developing management plans for current and future levels of rocky intertidal access and use. 


\section{References}

Addessi, Loana. Human disturbance and long-term changes on a rocky intertidal community. Ecological Applications 4.4 (1994): 786-797.

Atalah, Javier, and Tasman P. Crowe. Nutrient enrichment and variation in community structure on rocky shores: the potential of molluscan assemblages for biomonitoring. Estuarine, Coastal and Shelf Science 99.0 (2012): 162-170.

Bally, R, and C.L. Griffiths. Effects of human trampling on an exposed rocky shore. International Journal of Environmental Studies 34.1/2 (1989): 115-125. Print.

Barker, Nola H.L., and Callum M. Roberts. Scuba diver behaviour and the management of diving impacts on coral reefs. Biological Conservation 120.4 (2004).

Beale, Colin M., and Pat Monaghan. Human disturbance: people as predation-free predators? Journal of Applied Ecology 41.2 (2004): 335-343.

Beauchamp, K.A., and M.M. Gowing. A quantitative assessment of human trampling effects on a rocky intertidal community. Marine Environmental Research 7.4 (1982): 279-293.

Berger, Joel. Fear, human shields and the redistribution of prey and predators in protected areas. Biology Letters 3.6 (2007): 620-623.

Blair, Robert B. Birds and butterflies along an urban gradient: surrogate taxa for assessing biodiversity? Ecological Applications 9.1 (1999): 164-170.

Boaventura, Diana, P. Ré, L. Cancela de Fonseca, S.J. Hawkings. Intertidal rocky shore communities of the continental portuguese coast: analysis of distribution patterns. Marine Ecology 23.1 (2002): 69-90.

Boyle, Stephen A., and Fred B. Samson. Effects of nonconsumptive recreation on 
wildlife: a review. Wildlife Society Bulletin 13.2 (1985).

Branch, G, and C.A Moreno. Intertidal and subtidal grazers. Ecological Studies 103 (1994).

Brosnan, Deborah M., and Lana L. Crumrine. Effects of human trampling on marine rocky shore communities. Journal of Experimental Marine Biology and Ecology 177.1 (1994): 79-97.

Brown, Pam J., and Richard B. Taylor. Effects of trampling by humans on animals inhabiting coralline algal turf in the rocky intertidal. Journal of Experimental Marine Biology and Ecology 235.1 (1999): 45-53.

Burden, R. F., and P. F. Randerson. quantitative studies of the effects of human trampling on vegetation as an aid to the management of semi-natural areas. Journal of Applied Ecology 9.2 (1972): 439-457.

Cahill, James F., Jeffrey P. Castelli, and Brenda B. Casper. Separate effects of human visitation and touch on plant growth and herbivory in an old-field community. American Journal of Botany 89.9 (2002): 1401-1409.

Castilla, Juan Carlos. Coastal marine communities: trends and perspectives from humanexclusion experiments. Trends in Ecology \& Evolution 14.7 (1999): 280-283.

Clowes, Sarah W., and Brownen S. Coleman. A quantative analysis of human activity at Point Pinos rocky intertidal (Unpublished MS. on File at Hopkins Marine Station Library). 2000.

Coleman, Melinda A., and Susan H. Brawley. Are life history characteristics good predictors of genetic diversity and structure? A case study of the intertidal alga Fucus spiralis (Heterokontophyta; Phaeophyceae). Journal of Phycology 41.4 
(2005): 753-762.

Crowe, T.P., R.C. Thompson, S. Bray, S.J. Hawkings. Impacts of anthropogenic stress on rocky intertidal communities. Journal of Aquatic Ecosystem Stress and Recovery (Formerly Journal of Aquatic Ecosystem Health) 7.4 (2000): 273-297.

Dale, D., and T. Weaver. Trampling effects on vegetation of the trail corridors of north Rocky Mountain forests. Journal of Applied Ecology 11.2 (1974): 767.

Dayton, Paul K. Competition, disturbance, and community organization: the provision and subsequent utilization of space in a rocky intertidal community. Ecological Monographs 41.4 (1971).

Department of Economic and Social Affairs Population Division. Long-Range World Population Projections: Based on the 1998 Revision. New York: United Nations, 2000.

Dial, Roman, and Jonathan Roughgarden. Theory of marine communities: the intermediate disturbance hypothesis. Ecology 79.4 (1998): 1412-1424.

Fernández-Juricic, Esteban. Can human disturbance promote nestedness? a case study with breeding birds in urban habitat fragments. Oecologia 131.2 (2002): 269-278.

Ferreira, M. N., and S. Rosso. Effects of human trampling on a rocky shore fauna on the Sao Paulo coast, southeastern Brazil. Brazilian Journal of Biology 69.4 (2009): 993-999.

Firth, Louise B., T.P. Crowe, P. Moore, R.C. Thompson, S.J. Hawkins. Predicting impacts of climate-induced range expansion: an experimental framework and a test involving key grazers on temperate rocky shores. Global Change Biology 15.6 (2009): 1413-1422. 
Fletcher, H., and C. L. J. Frid. Impact and management of visitor pressure on rocky intertidal algal communities. Aquatic Conservation: Marine and Freshwater Ecosystems 6.4 (1996): 287-297..

Di Franco, Antonio, M. Milazzo, P. Baiata, A. Tomasello, R. Chemello. Scuba diver behaviour and its effects on the biota of a Mediterranean marine protected area. Environmental Conservation 36.01 (2009): 32-40.

Galbraith, H., R. Jones, R. Park, J. Clough, S Herrod-Julius, B. Harrington, G. Page. Global climate change and sea level rise: potential losses of intertidal habitat for shorebirds. Waterbirds 25.2 (2002): 173-183.

Gappa, J. J. Lopez, A. Tablado, and N. H. Magaldi. Influence of sewage pollution on a rocky intertidal community dominated by the Mytilid Brachidontes rodriguezi. Marine Ecology Progress Series 63 (1990): 163-175.

Germaine, S.S., and B.F. Wakeling. Lizard species distributions and habitat occupation along an urban gradient in Tucson, Arizona, USA. Biological Conservation 97.2 (2001): 229-237.

Ghazanshahi, J., T. D. Huchel, and J. S. Devinny. Alternation of Southern California rocky shore ecosystems by public recreational use. Journal of Environmental Management 16.4 (1983): 379-394.

Griffiths, C.L., and G.M. Branch. The exploitation of coastal invertebrates and seaweeds in South Africa: historical trends, ecological impacts and implications for management. Transactions of the Royal Society of South Africa 52.1 (1997): 121148.

Hockey, Philip A. R., and Alison L. Bosman. Man as an intertidal predator in transkei: 
disturbance, community convergence and management of a natural food resource. Oikos 46.1 (1986): 3-14.

Huff, Tonya M. Effects of human trampling on macro- and meiofauna communities associated with intertidal algal turfs and implications for management of protected areas on rocky shores (Southern California). Marine Ecology 32.3 (2011): 335345.

Hunt, Heather L., and Robert E. Scheibling. Patch dynamics of mussels on rocky shores: integrating process to understand pattern. Ecology 82.11 (2001): 3213-3231.

Johnson, Markes E., and Jorge Ledesma-Vazquez. Biological zonation on a rocky-shore boulder deposit; upper Pleistocene Bahia San Antonio (Baja California Sur, Mexico). PALAIOS 14.6 (1999): 569-584.

Keough, Michael J., Gerald P. Quinn, and Alice King. correlations between human collecting and intertidal mollusc populations on rocky shores. Conservation Biology 7.2 (1993): 378-390.

Kimura, Scott, Grant T. Waltz, John R. Steinbeck, Dean E. Wendt. A comprehensive approach for understanding the impacts of visitation to temporally variable ecological systems. In Preparation n. pag.

Lilley, Stacie, and David Schiel. Community effects following the deletion of a habitatforming alga from rocky marine shores. Oecologia 148.4 (2006): 672-681.

Lindberg, David R, James A. Estes, and Kenneth I. Warheit. Human influences on trophic cascades along rocky shores. Ecological Applications 8.3 (1998): 880890.

Lubchenco, Jane. Algal zonation in the New England rocky intertidal community: an 
experimental analysis. Ecology 61.2 (1980): 333-344.

Martins, Gustavo M., R.C. Thompson, S.J. Hawkings, A.I. Neto, S.R. Jenkins. Rocky intertidal community structure in oceanic islands: scales of spatial variability. Marine Ecology Progress Series 356 (2008): 15-24.

McClintock, J.B., R.A. Angus, and F.E. McClintock. Abundance, diversity and fidelity of macroinvertebrates sheltering beneath rocks during tidal emersion in an intertidal cobble field: does the intermediate disturbance hypothesis hold for less exposed shores with smaller rocks? Journal of Experimental Marine Biology and Ecology 352.2 (2007): 351-360.

Medina, M., S. Andrade, S. Faugeron, N. Lagos, D. Mella, J.A. Correa. Biodiversity of rocky intertidal benthic communities associated with copper mine tailing discharges in northern Chile. Marine Pollution Bulletin 50.4 (2005): 396-409.

Menge, Bruce A., B,A. Daley, P.A. Wheeler, T.P. Strub. Rocky intertidal oceanography: an association between community structure and nearshore phytoplankton concentration. Limnology and Oceanography 42.1 (1997): 57-66.

Menge, Bruce A., E.L. Berlow, C.A. Blanchette, S.A. Navarrete, S.B. Yamada. The keystone species concept: variation in interaction strength in a rocky intertidal habitat. Ecological Monographs 64.3 (1994): 249-286.

Murray, Steven N. Effectiveness of Marine Life Refuges on Southern California Shores. Taking a Look at California's Ocean Resources: An Agenda for the Future. Vol. 2, pp. 1453-1465. 1998.

Murray, Steven N., Teri Gibson Denis, and Jayson R. Smith. human visitation and the frequency and potential effects of collecting on rocky intertidal populations in 
southern California marine reserves. CalCOFI Rep. 40 (1999): 100-106.

Navarrete, Sergio A., and Eric L. Berlow. Variable interaction strengths stabilize marine community pattern. Ecology Letters 9.5 (2006): 526-536.

Navarrete, Sergio A., and Bruce A. Menge. Keystone predation and interaction strength: interactive effects of predators on their main prey. Ecological Monographs 66.4 (1996): 409-429.

Navarrete, Sergio A., Bruce A. Menge, and Bryon A. Daley. Species interactions in intertidal food webs: prey or predation regulation of intermediate predators? Ecology 81.8 (2000): 2264-2277.

Newey, S., and R. Seed. The effects of the Braer Oil Spill on rocky intertidal communities in South Shetland, Scotland. Marine Pollution Bulletin 30.4 (1995): 274-280.

Niemelä, Jari, J. Kotze, A. Ashworth, P. Brandmayr, K. Desender, T. New, L. Penev, M. Samways, J. Spence. The search for common anthropogenic impacts on biodiversity: a global network. Journal of Insect Conservation 4.1 (2000): 3-9.

NOAA. 2009 NOAA Tide Table Predictions Port San Luis, California. 2009. Web. 13 Feb. 2009.

Okuda, Takehiro, T. Noda, T. Yamamoto, M. Hori, M. Nakaoaka. Contribution of environmental and spatial processes to rocky intertidal metacommunity structure. Acta Oecologica 36.4 (2010): 413-422.

Paine, Robert T. The Pisaster-Tegula interaction: prey patches, predator food preference, and intertidal community structure. Ecology 50.6 (1969): 950-961.

Pearson, Gareth A., and Ester A. Serrão. Revisiting synchronous gamete release by 
Fucoid algae in the intertidal zone: fertilization success and beyond? Integrative and Comparative Biology 46.5 (2006): 587-597.

Pfaff, M. C., C. Hiebenthal, M. Molis, G.M. Branch, M. Wahl. Patterns of diversity along experimental gradients of disturbance and nutrient supply — the confounding assumptions of the intermediate disturbance hypothesis. African Journal of Marine Science 32.1 (2010): 127-135.

Poonian, Chris, Patricia Z. R. Davis, and Colby Kearns McNaughton. Impacts of recreational divers on palauan coral reefs and options for management. Pacific Science 64.4 (2010): 557-565.

Povey, Anna, and Michael J. Keough. Effects of trampling on plant and animal populations on rocky shores. Oikos 61.3 (1991): 355-368.

Robles,, Carlos D., Mario A. Alvarado, and Robert A. Desharnais. The shifting balance of littoral predator-prey interaction in regimes of hydrodynamic stress. Oecologia 128.1 (2001): 142-152.

Sagarin, R.D., Barry, J.P., Gilman, S.E. \& Baxter, C.H. Climate related changes in an intertidal community over short and long time scales. Ecological Monographs, 69 (1999), 465-490.

Sagarin, Raphael, R.F. Ambrose, B.J. Becker, J.M. Engle, J. Kido, S.F. Lee, C. Melissa Miner, S.M. Murray, P.T. Raimondi, D. Richards, C. Roe. Ecological impacts on the limpet; Lottia gigantea; populations: human pressure over a broad scale on island and mainland intertidal zones. Marine Biology 150.3 (2007): 399-413.

Salomon, Anne K., Jennifer L. Ruesink, and Robert E. DeWreede. Population viability, ecological processes and biodiversity: valuing sites for reserve selection. 
Biological Conservation 128.1 (2006): 79-92.

Santiago, Luis, Armando Gonzalez-Caban, and John Loomis. A model for predicting daily peak visitation and implications for recreation management and water quality: evidence from two rivers in Puerto Rico. Environmental Management 41.6 (2008): 904-914.

Schiel, David and D.I. Taylor. Effects of trampling on a rocky intertidal algal assemblage in southern New Zealand. Journal of Experimental Marine Biology and Ecology. 235.2 (1999): 213-235.

Sebens, Kenneth P. Population dynamics and habitat suitability of the intertidal sea anemones Anthopleura elegantissima and A. xanthogrammica. Ecological Monographs 53.4 (1983): 405-433.

Siegfried, W.R., Philip A. R. Hockey, and G.M. Branch. The exploitation of intertidal and subtidal biotic resources of rocky shores in Chile and South Africa -- an overview. Ecological Studies 103 (1994): 1-16.

Smith, Jayson, Peggy Fong, and Richard Ambrose. The impacts of human visitation on mussel bed communities along the california coast: are regulatory marine reserves effective in protecting these communities? Environmental Management 41.4 (2008): 599-612.

Smith, Jayson R., Peggy Fong, and Richard F. Ambrose. dramatic declines in mussel bed community diversity: response to climate change? Ecology 87.5 (2006): 11531161.

Stallings, Christopher D. Fishery-independent data reveal negative effect of human population density on Caribbean predatory fish communities. PLoS ONE 4.5 
(2009): e5333.

Tenera Environmental Inc. San Luis Obispo, CA. A Comparative Study and User Survey, Point Pinos, California. Monterey Bay National Marine Sanctuary: Monterey Bay National Marine Sanctuary, 2003.

Tenera Environmental Inc. San Luis Obispo, CA. James V. Fitzgerald Marine Reserve: Resource Assessment. James V. Fitzgerald Marine Reserve: San Mateo County Environmental Services Agency, 2004.

Turner, R. K., S. Subak, and W. N. Adger. Pressures, trends, and impacts in coastal zones: interactions between socioeconomic and natural systems. Environmental Management 20.2 (1996): 159-173.

Underwood, AJ, and SJ Kennelly. Pilot studies for designs of surveys of human disturbance of intertidal habitats in NSW. Mar. Freshwater Res. 41.1 (1990): $165-173$.

Van De Werfhorst, Laurie C., and John S. Pearse. Trampling in the rocky intertidal of central California: a follow-up study. Bulletin of Marine Science 81.2 (2007): $245-254$.

Whitaker, Stephen G., Jayson R. Smith, and Steven N. Murray. Reestablishment of the Southern California rocky intertidal brown alga, Silvetia compressa: an experimental investigation of techniques and abiotic and biotic factors that affect restoration success. Restoration Ecology 18 (2010): 18-26.

Williams, S. L., and R. E. Fiori. Genetic diversity and structure in Pelvetia fastigiata; (Phaeophyta: Fucales): Does a small effective neighborhood size explain finescale genetic structure? Marine Biology 126.3 (1996): 371-382. 
Worachananant, Suchai, R.W. Carter, M. Hockings, P. Reopanichkul. Managing the impacts of SCUBA divers on Thailand's coral reefs. Journal of Sustainable Tourism 16.6 (2008): 645-663. 
Table 2.1 Results of ANOVA comparing a) test of abundances of access-indicator taxa among Hazard Reef, Hazard Mid and Hazard Far study sites using nested ANOVA, and b) a priori contrast comparing abundances at Hazard Reef with the average abundances at the Hazard Mid/Far sites. Significant differences $(\mathrm{p}<0.05)$ either indicating a difference in abundance among sites (Sites) or between Hazard Reef and the Hazard Mid/Far sites are displayed in bold.

\begin{tabular}{|c|c|c|c|c|c|c|}
\hline & & \multicolumn{5}{|c|}{ Combined Algae } \\
\hline & & $\mathrm{DF}$ & Type III SS & MS & $\mathrm{F}$ & $P$ \\
\hline & Site & 2 & 6.706 & 3.353 & 3.000 & 0.065 \\
\hline & Contrast & DF & Contrast SS & MS & $\mathrm{F}$ & $P$ \\
\hline & & 1 & 6.420 & 6.420 & 5.750 & 0.023 \\
\hline & & \multicolumn{5}{|c|}{ Silvetia compressa } \\
\hline & & $\overline{D F}$ & Type III SS & MS & $\bar{F}$ & $P$ \\
\hline & Site & 2 & 1259.206 & 629.603 & 1.660 & 0.208 \\
\hline & Contrast & DF & Contrast SS & MS & $\mathrm{F}$ & $\mathrm{P}$ \\
\hline & & 1 & 1173.612 & 1173.612 & 3.090 & 0.089 \\
\hline & & \multicolumn{5}{|c|}{ Rockweed } \\
\hline & & $\mathrm{DF}$ & Type III MS & MS & $\mathrm{F}$ & $\mathrm{P}$ \\
\hline & Site & 2 & 4.954 & 2.477 & 1.200 & 0.316 \\
\hline & Contrast & DF & Contrast SS & MS & $\mathrm{F}$ & $P$ \\
\hline & & 1 & 4.712 & 4.712 & 2.28 & 0.142 \\
\hline & & \multicolumn{5}{|c|}{ Endocladia muricata } \\
\hline & & $\mathrm{DF}$ & Type III SS & MS & $\mathrm{F}$ & $\mathrm{P}$ \\
\hline & Site & 2 & 1092.074 & 546.037 & 1.191 & 0.166 \\
\hline & Contrast & $\mathrm{DF}$ & Contrast SS & MS & $\mathrm{F}$ & $\mathrm{P}$ \\
\hline & & 1 & 435.706 & 435.706 & 1.520 & 0.227 \\
\hline & & \multicolumn{5}{|c|}{ Mastocarpus papillatus } \\
\hline & & DF & Type III SS & MS & $\mathrm{F}$ & $P$ \\
\hline & Site & 2 & 10.628 & 5.314 & 0.510 & 0.603 \\
\hline & Contrast & DF & Contrast SS & MS & $\mathrm{F}$ & $\mathrm{P}$ \\
\hline & & 1 & 9.318 & 9.318 & 0.900 & 0.350 \\
\hline & & \multicolumn{5}{|c|}{ Lottidae } \\
\hline & & $\mathrm{DF}$ & Type III SS & MS & 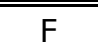 & $P$ \\
\hline & Site & 2 & 40713.448 & 20356.724 & 6.690 & 0.004 \\
\hline & Contrast & DF & Contrast SS & MS & $\mathrm{F}$ & $\mathrm{P}$ \\
\hline & & 1 & 18561.386 & 18651.386 & 6.100 & 0.019 \\
\hline & & \multicolumn{5}{|c|}{ Polyplacaphora } \\
\hline & & $\mathrm{DF}$ & Type III SS & MS & $\mathrm{F}$ & $\mathrm{P}$ \\
\hline & Site & 2 & 27.182 & 13.591 & 3.080 & 0.061 \\
\hline & Contrast & DF & Contrast SS & MS & $\mathrm{F}$ & $P$ \\
\hline & & 1 & 3.705 & 3.705 & 0.84 & 0.367 \\
\hline
\end{tabular}




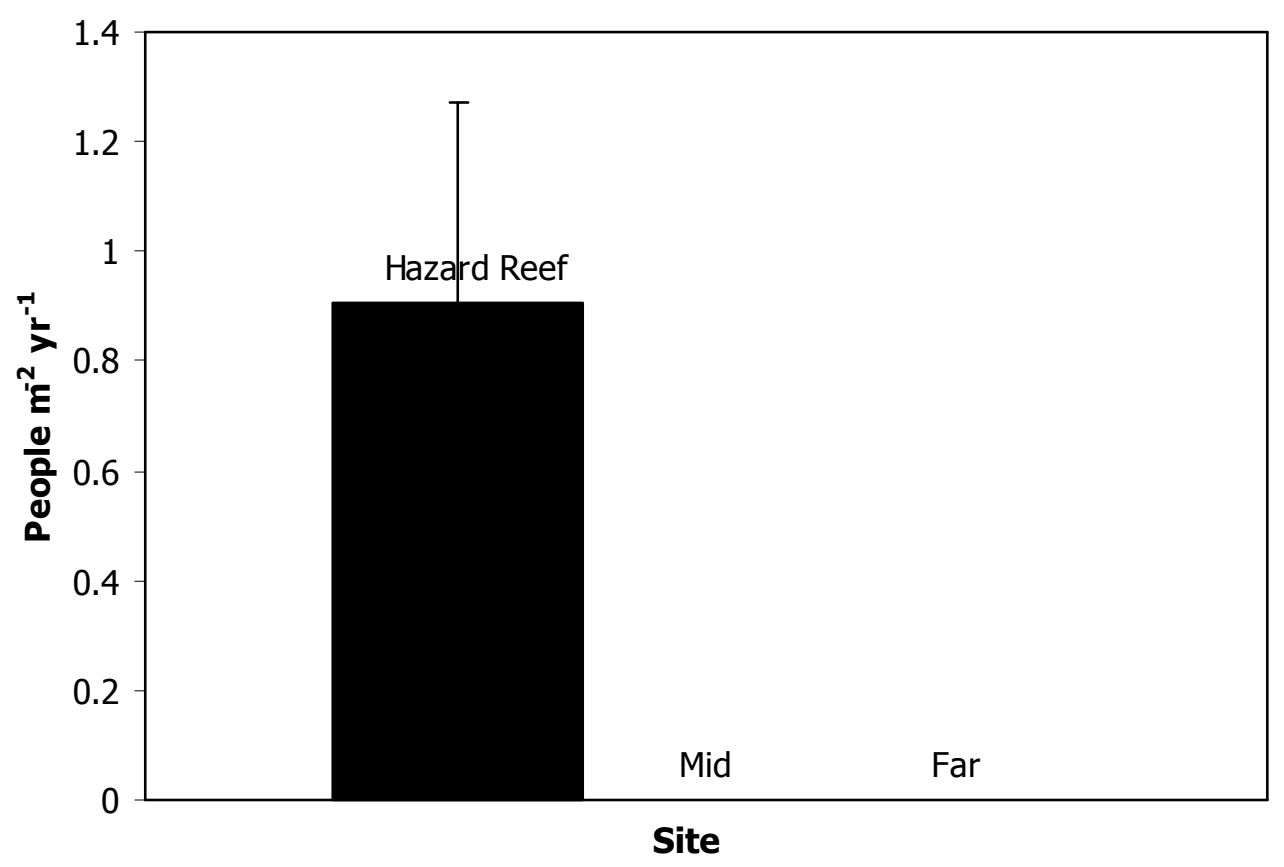

Figure 2.1. The annual visitor density (+ standard error of the mean) in the covered rock zone at three adjacent rocky intertidal areas in MDO State Park. 

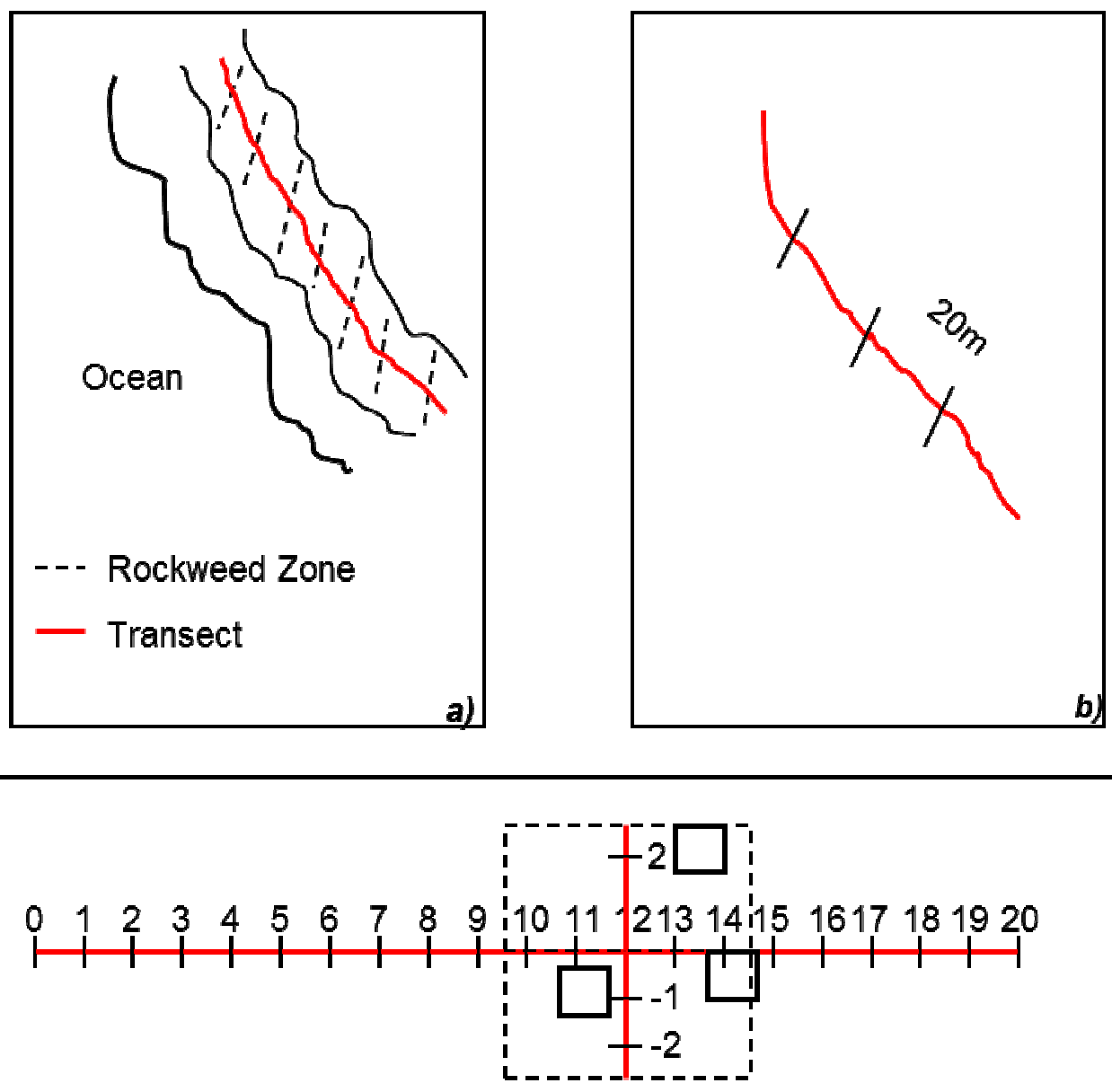

- - $25 \mathrm{~m}^{2}$ Sample Quadrant

c)

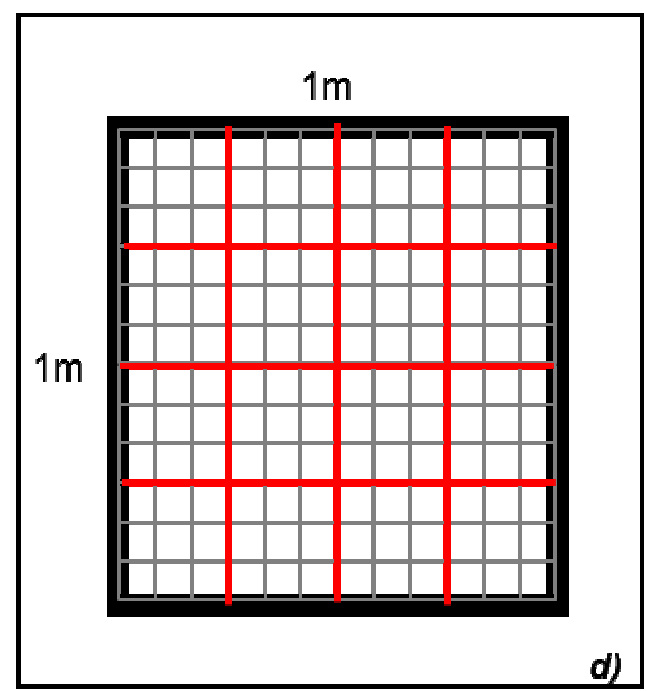

Figure 2.2. Representation of: a) the transect placement through the study community, b) division of the $1 \mathrm{~km}$ transect into $20 \mathrm{~m}$ sample segments, c) placement of the $5 \mathrm{~m}$ perpendicular transect to form a $25 \mathrm{~m}^{2}$ sample quadrant, and c) division of the $1 \mathrm{~m}^{2}$ sample quadrat into $25 \mathrm{~cm} \mathrm{x} 25 \mathrm{~cm}$ sub-squares ( $\left.\mathrm{n}=16\right)$, each of which was further divided visually into ninths (gray grid). Images b), c), and d) are subsets if image a). 


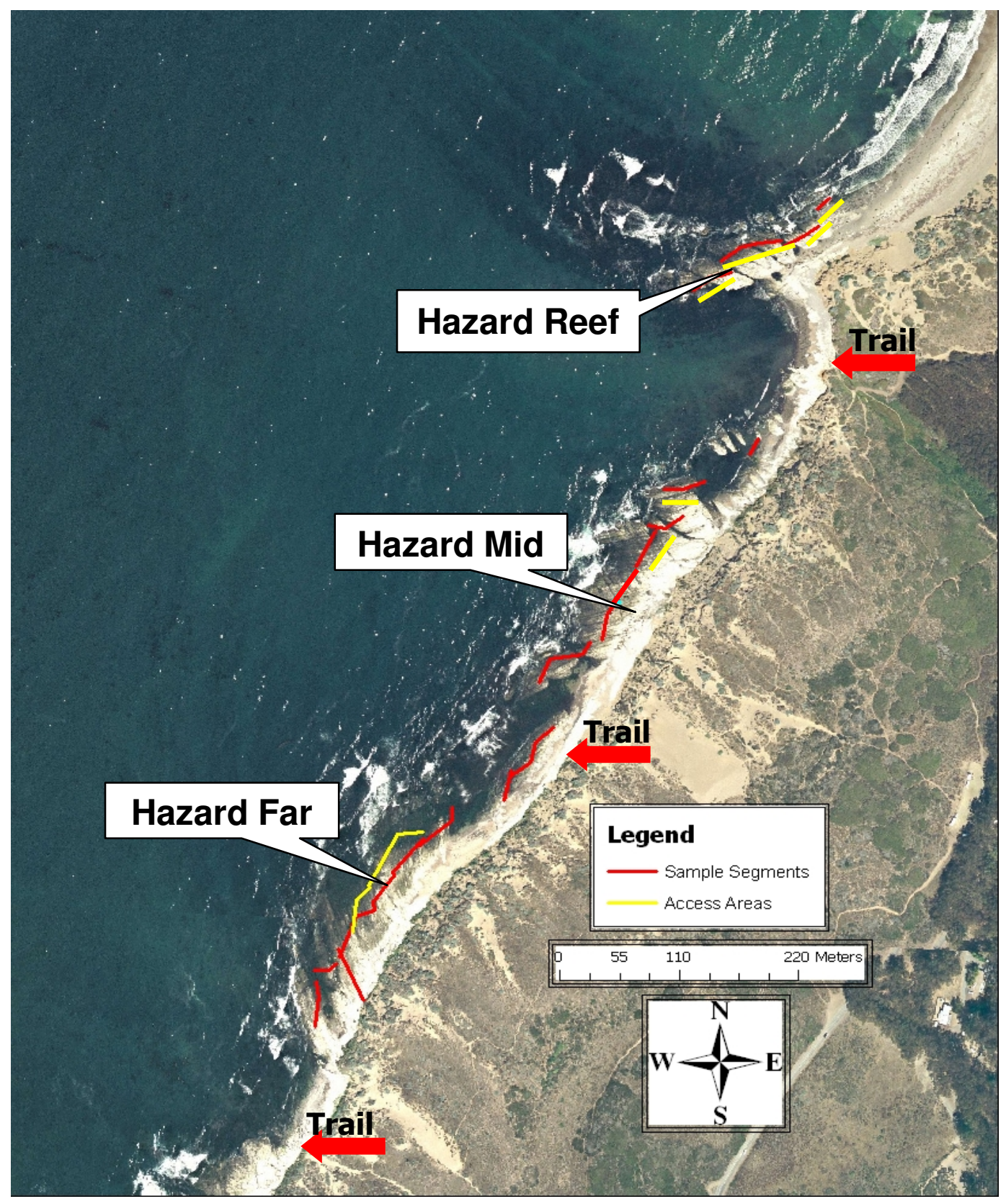

Figure 2.3. Aerial photograph showing sample transect labeled by red lines. Transect start point was the northern end of Hazard Reef. Transect end point was southern end of Hazard Far bench. Yellow lines indicate independently identified access areas where individuals and educational groups have been observed. Trail locations connecting the shore with a dune hiking trail are indicated by red arrows. 


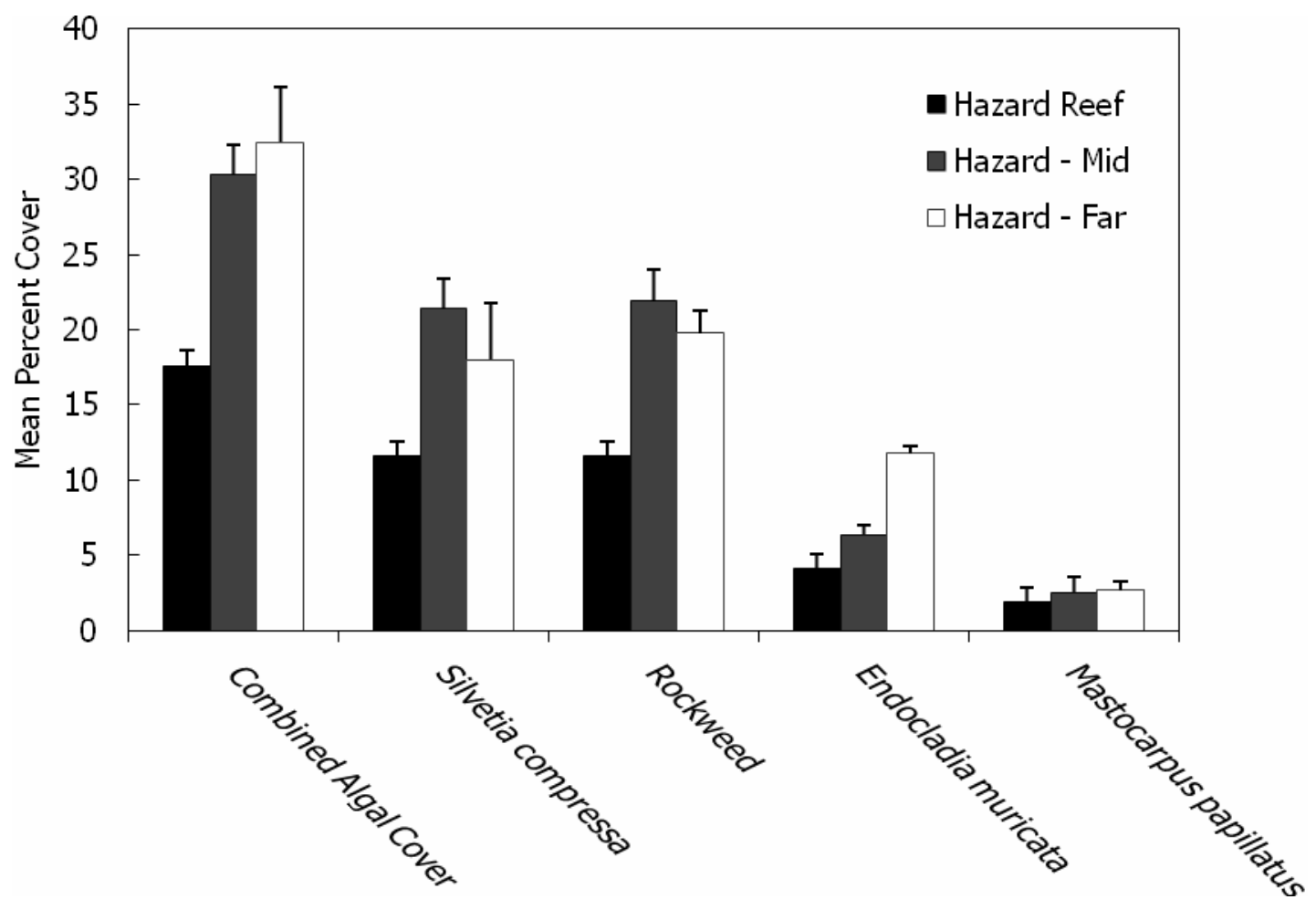

Figure 2.4. A comparison of the percentage cover $(\mathrm{SE}+1)$ for access-indicator algal taxa. Abundance was calculated as the percent cover $\mathrm{m}^{-2}$. 

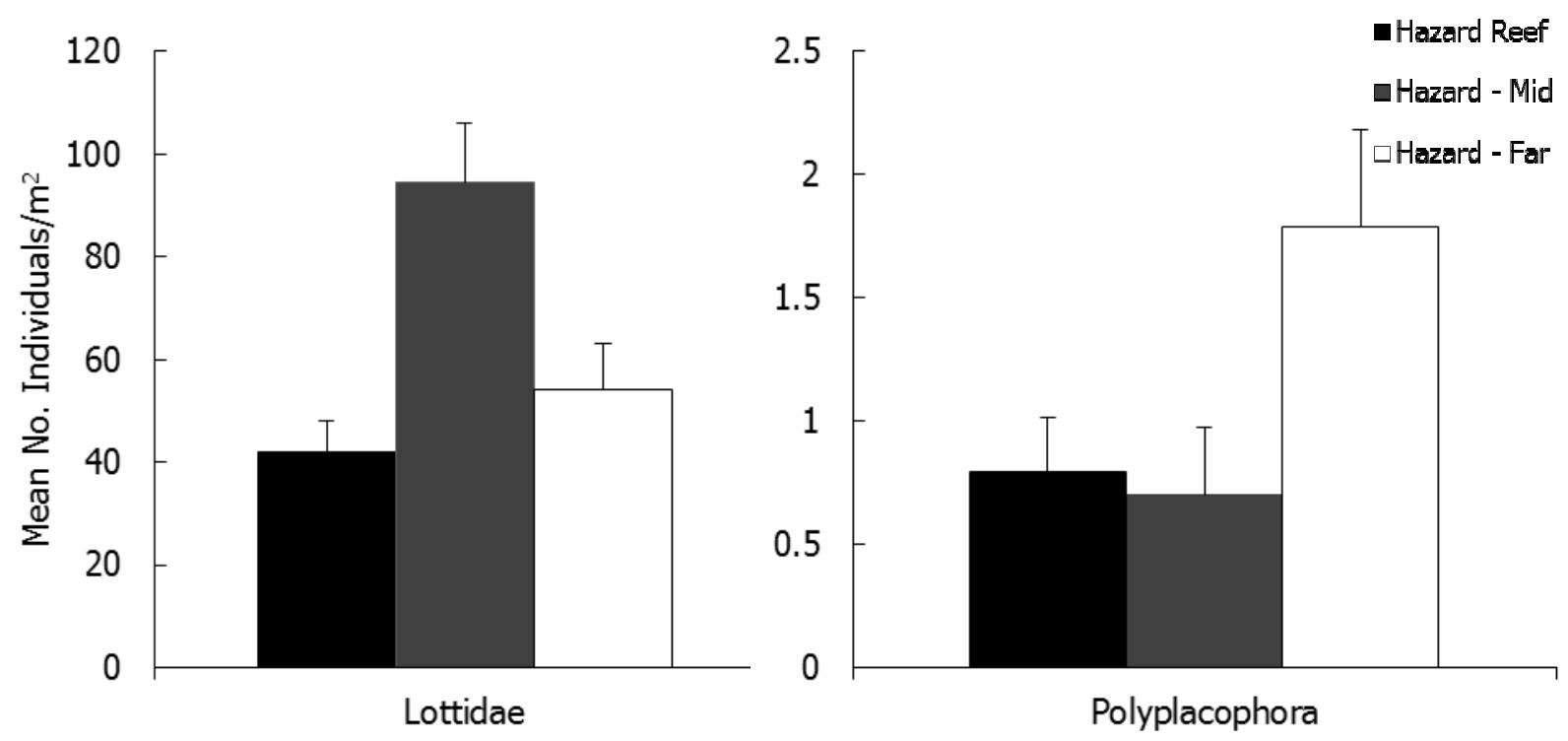

Figure 2.5 A comparison of Lottidae (limpets) and Polyplacophora (chitons) density (number of individuals $\mathrm{m}^{-2}$ ) among study sites. Density was calculated as the mean number of individuals $\mathrm{m}^{-2}$ for all $20 \mathrm{~m}$ segments in each site. Error bars represent one standard error of the mean 


\title{
Appendix 1
}

A comprehensive approach for understanding the impacts of visitation to temporally variable ecological systems: A model study of the rocky intertidal community

\author{
Scott Kimura ${ }^{1}$, Grant T. Waltz ${ }^{2}$, John R. Steinbeck ${ }^{1}$, Dean E. Wendt ${ }^{2}$ \\ 1 Tenera Environmental Inc., San Luis Obispo, California, 93401 \\ USA \\ 2 Center for Coastal Marine Sciences, California Polytechnic State \\ University, San Luis Obispo, California, 93407 USA
}

\begin{abstract}
Connecting changes in ecological communities to impacts from human visitation can be difficult, especially in temporally variable systems whose stressors are also variable. High variability inherently obscures our understanding of systems and ultimately limits our ability to take management actions to protect many marine and terrestrial ecological systems (e.g., coral reefs, kelp forests, salt marshes, dessert communities, coastal dunes). Here we report a novel approach to demonstrate how to understand the real impact of visitation in highly variable ecological communities, and then how to determine if commonly visited areas are being compromised by visitation. Our methodology involves three essential elements: 1) quantification of visitation levels through visitor surveys in the ecological community of interest; 2) a controlled field experiment to identify species that are affected by visitation (i.e., "access indicator taxa" (AIT)) using a before-aftercontrol-impact design (BACI); importantly the impact activities and levels are realistic
\end{abstract}


because they are based entirely on observations and data from visitor surveys; and, lastly 3) field sampling of currently open areas to identify changes in abundance of identified access indicator species. In our study we focused on the rocky intertidal zone in central California as a model system. We first completed surveys on the number of visitors to areas of rocky shoreline at a popular California State Park to determine visitor densities over time. We then tested exposure levels determined from the visitor surveys using a BACI design field experiment on a rocky shoreline area with no public access. Lastly, we sampled rocky shoreline in the State Park with low levels of visitors and compared that area to areas with higher visitor levels similar to those that we tested in our experiment. We found in the field experiment that our high exposure treatment of ca. three people per hour per $\mathrm{m}^{2}$ resulted in statistically significant reductions in abundances of marine algae over ten treatment applications. Although the visitor densities in the high exposure area sampled in the field study in the Park (ca. two people per hour per $\mathrm{m}^{2}$ ) were estimated to be slightly less than the high exposure treatment used in the field experiment, the differences in algal abundance with the area with lower visitor use were similar to the changes detected in our experiment. The results of the field study confirmed that the results of the field experiment were realistic and could be used to help manage visitor levels in the area. We feel that our three-pronged approach serves as a model with study design fundamentals that can be adapted for other studies aimed at determining impacts from human visitation.

Key words: BACI analysis, carrying capacities, management implications, resource stewardship, rocky intertidal zones, trampling effects, visitor access 


\section{INTRODUCTION}

Resource managers are often faced with the problem of balancing the potentially conflicting goals of resource protection and public access even though many studies (e.g. Liddle 1975, Liddle and Kay 1987, Andres-Abellan et al. 2006, Baines and Richardson 2007, Leujak and Ormond 2008, Remacha and Delgado 2011) have shown that public access can result in negative impacts to the resources that these agencies are tasked to protect. In fact, the stated missions of resource agencies such as the California Coastal Commission (http://www.coastal.ca.gov/strategy.html) and California State Parks (http://www.parks.ca.gov/?page_id=91) clearly include both resource conservation and public access. The competing demands of access and resource protection require robust information on the impacts of access to natural resources. Unfortunately, management decisions to balance resource protection and access are often made based on anecdotal information or data gathered from field studies that may not fully account for the variability inherent in natural systems. These shortcomings are especially problematic when resource managers need to defend decisions that are controversial or in need of support by stakeholder and user groups.

Our study resulted from a collaborative effort among scientists, resource managers, and stakeholder groups in San Luis Obispo County, California to identify research needs for protecting coastal resources. One of the agencies involved in the collaboration was California State Parks, which has jurisdiction for nearly half (45\%) of the open coastal shoreline in the county (Figure 1). Due to recent acquisition of several new large coastal areas to become open to public access, State Park managers became interested in 
determining, as a baseline, if the current level of public access in Montaña de Oro State Park (MDO), one of the more popular coastal parks in the County, was affecting the biological resources along the shore. The result of any studies used to determine sustainable levels of visitor use could then be used to assess whether public access should be better controlled in this and other new coastal parks.

The comprehensive research program we describe here was designed to provide park managers with information that could be used in determining the sustainable levels of visitor use in rocky intertidal areas by studying the effects of trampling or foot traffic. To fully understand the impacts and then to provide useful information for decision making on public access we designed a research program with three components: 1) surveys of the current levels of visitor access along shoreline areas; 2) a manipulative field experiment to determine the potential effects of the levels of visitor access observed in the visitor surveys; and, 3) an observational study that used results of the manipulative experiment to predict impacts in a commonly visited area. The general approach we outline is applicable to any ecosystem or habitat where managers need quantitative assessment of impacts in an effort to balance public access with resource protection.

While this comprehensive approach was to provide greater support for park management decisions on resource protection, it was also designed and executed to overcome some of the shortcomings of previous studies of human disturbance in natural areas that have been the subject of considerable previous research (e.g., Chan 1970, Beauchamp and Gowing 1982, Ghazanshahi et al. 1983, Underwood and Kennelly 1990, Addessi 1994, Keough and Quinn 1998, Schiel and Taylor 1999, Murray et al. 1999, Ambrose and Smith 2004, Van De Werfhorst and Pearse 2007). Effects of human disturbance to vegetation and 
wildlife from people simply visiting areas have been detected in many communities and ecosystems (e.g. Liddle 1975, Liddle and Kay 1987, Andres-Abellan et al. 2006, Baines and Richardson 2007, Leujak and Ormond 2008, Remacha and Delgado 2011). The presence of people and accompanying noise can disturb species behaviors and alter species abundance and distribution patterns (Chan 1970, Bally and Griffiths 1989, Ferreira and Rosso 2009). Changes in species abundance levels and distribution can also result from illegal collecting and from trampling. Detecting species changes that may result from human activities can be difficult, however, especially in spatially and temporally variable ecological systems such as the rocky intertidal or coral reefs. The inherent variability was addressed in our study through the use of a field experiment using a before-after-control-impact (BACI) design that controlled for natural variation by concurrently sampling plots with and without foot traffic both before and after/during the application of the treatments (Stewart Oaten, et al. 1986). Although BACI designs have typically been used for analysis of data from observational studies with unreplicated impacts, the designs are also applicable to controlled field experiments where data are not independent, due to repeated sampling of the experimental units (Stewart-Oaten and Bence 2001). Although problems of independence can also be addressed by using repeated measures analysis (Green 1993), the use of BACI is a robust alternative approach (Steinbeck et al. 2005).

We chose to focus on the rocky intertidal community for our study because of the interest of California State Park managers and the prevalence of this habitat at many of the coastal park areas in central California. Rocky intertidal areas have also become increasingly popular places to visit for education and recreation, and are often where 
people are exposed to 'hands-on' marine biology for their first time. Visiting rocky shores, however, comes with the potential for impacts to occur from collecting (Chan 1970, Ghazanshahi et al. 1983, Underwood and Kennelly 1990, Addessi 1994, Schiel and Taylor 1999, Murray et al. 1999, Ambrose and Smith 2004). Effects from trampling can also occur (Beauchamp and Gowing 1982, Brosnan and Crumrine 1994, Keough and Quinn 1998, Van De Werfhorst and Pearse 2007, Huff 2011). While restrictions on collecting are intended to prohibit or limit people from removing organisms, there are generally no restrictions controlling where and how much people can walk once down on the shore.

Understanding the shortcomings of previous studies on visitor impacts to natural areas was a core element in the design of our research as we wanted to ensure that knowledge from our work would provide a foundation for making decisions on coastal access. The primary shortcomings of previous empirical studies are twofold: 1) experimental impact levels do not reflect the intensity of impact found in real-world situations (impact levels are often much higher in experiments); and, 2) the nature of the emulated impact in experimental treatments does not often reflect the nature of impact in natural conditions. For example, many studies have applied pre-specified footsteps in a uniform fashion in relatively small test plots (e.g, <1 m2) (Bally and Griffiths 1989, Povey and Keough 1991, Brosnan and Crumrine 1994, Keough and Quinn 1998, Brown and Taylor 1999, Denis 2002, Clowes 2002, Huff 2011). Using this approach, the test subjects (people) end up stepping repeatedly on organisms in the same small spaces with the applications repeated in the same fashion in subsequent trials. Our observations, however, of people visiting rocky intertidal areas indicate this approach does not accurately represent normal 
behavior of people on the shore and the subsequent impacts to which rocky intertidal organisms are exposed. Although many previous studies utilized control plots to account for natural variation that can otherwise confound the interpretation of results, the interpretation of the results may consequently be hampered by the application of treatment levels that were not representative of the type and intensity of actual foot traffic under normal visitation conditions.

Although a few previous experimental studies of trampling impacts on rocky intertidal communities have used control plots to account for natural variation (Bally and Griffiths 1989, Povey and Keough 1991, Brosnan and Crumrine 1994, Keough and Quinn 1998, Brown and Taylor 1999, Denis 2002, Clowes 2002, Huff 2011), several other studies have used strictly observational comparisons of species abundances between areas with high and low/no numbers of visitors (Addessi 1994, Ambrose and Smith 2004; Tenera 2003, 2004). The later approach, may result in ambiguous results, as the areas being compared may have inherent physical or habitat differences that result in differences in species composition or abundance among observed plots. We addressed this issue by using the data from our BACI experiment to predict shifts in abundance of a suite of "access indicator taxa" among areas open to the public with different levels of visitation. Thus, the results from our observational study were based a priori on our BACI study. We believe the integration of results from our three interrelated studies (visitor surveys, controlled field experiment, and observational field study) provides a useful framework for quantifying the impacts of visitation in highly variable ecological communities and it provides useful data to resource managers charged with balancing public access and resource protection. 


\section{METHODS}

Our study was in three parts: 1) visitor counts in several intertidal areas to determine visitor densities and duration; 2) a manipulative field experiment testing those exposure and concentration levels for impacts; and 3) a field observational study to ground-truth the results of the field experiment and determine whether differences between high and low use areas could be attributed to visitor traffic, based on how well the differences between areas of similar foot traffic exposure matched the changes detected in the experiment.

\section{Visitor Surveys}

The foot traffic exposure levels chosen to be tested in our experiment were based on visitor observations and counts completed along rocky shoreline areas inside Montaña de Oro (MDO) State Park, a coastal State Park in San Luis Obispo County, California that experiences the highest numbers of visitors to State Parks in the county with rocky shorelines (Figure 1). Over 500,000 people visit MDO State Park each year (California State Parks 2008), and a portion of these people visit several specific, rocky intertidal areas in the park for education and recreation.

Timed counts of people on rocky shorelines in the park were completed in areas of known sizes at two popular places known locally as Hazard Canyon and Corallina Cove (Figure 1). The visitor survey area was the upper mid-intertidal zone at both locations, which other studies have shown is the zone where people exploring rocky shores spend most of their time (Clowes 2002; Tenera 2003, 2004). Counts of people in both areas were made every 10 minutes for one hour from cliff top locations, similar to the method 
used by Murray et al. (1999). The counts at both locations were made on the same day, and 14 days were sampled, which included weekdays, weekends, holidays, and nonholidays. The counts were completed during daytime low-tide periods (within 2-3 hours before and after low tides of $+0.6 \mathrm{~m}$ mean lower low water [MLLW] and lower) and when weather conditions were conducive to visitor activity. The size of each visitor area was delineated using GPS. ESRI ArcGIS software was used to plot the GPS data and to calculate the intertidal area where people were counted.

We calculated annual visitation (visitor exposure levels) that occurs at Hazard Canyon and Corallina Cove based on the equation: annual visitor exposure = average person hours $\mathrm{m}^{-2} \times 945$ hours $\mathrm{yr}^{-1}$ (Table 1$)$. Person $\mathrm{hrs} \mathrm{m}^{-2}$ values were the averages of our timed visitor counts. The 945 hours value was the total hours in 2007 (the year of our study) when tide levels were equal to or less than +0.6 m MLLW between 10:00 am and sunset; tide levels low enough to access the visitor areas and within the assumed daily period when most people visit the shore.

The hourly exposure times were derived from Tides \& Currents V2.00 (Nautical Software Inc.) and based on NOAA tide predictions for Port San Luis, California, the nearest tide station to the experiment site (approximately $13.7 \mathrm{~km}$ south of the experiment site). The tidal curve for each day in 2007 was plotted, and the number of hours (to the nearest half hour) that the tide level was below +0.6 m MLLW between 10:00 am and sunset each day for the year were totaled.

\section{Field Experiment}


The site of our field experiment $\left(35^{\circ} 13^{\prime} 53.46^{\prime \prime} \mathrm{N}, 120^{\circ} 52^{\prime} 52.01^{\prime \prime} \mathrm{W}\right)$ was on a bench rock platform $3.4 \mathrm{~km}$ south of MDO State Park and surrounded by private land owned by Pacific Gas and Electric Company (PG\&E) (Figure 1). Completing our experiment in an area closed to public access was important, as it provided assurance that no unaccounted foot traffic occurred in the test plots. The bench rock platform (tidal elevation approximately $+0.9 \mathrm{~m}$ MLLW) at the experiment site extended approximately 50-75 m seaward from the base of a $10 \mathrm{~m}$ tall shore cliff.

Like MDO State Park where we completed our visitor counts, the bench rock platform of the experiment site had large areas covered with the rockweed species Silvetia compressa. The platform with $S$. compressa was appropriate for our study because $S$. compressa, like many rockweed species, is sensitive to trampling effects (Murray and Gibson 1979, Fletcher and Frid 1996, Denis 2002). In addition, S. compressa provides important habitat and shelter for invertebrates and smaller algae, particularly during low tide when the intertidal is exposed to air and direct sunlight (Gunnill 1982, 1984; Jenkins et al. 1999).

Other algae characteristic of the upper mid-intertidal zone and with rockweed in central California (Abbott and Hollenberg 1976, Sparling 1977) were also abundant on the bench rock experimental site. These included the red algae Mastocarpus papillatus and Endocladia muricata. Common invertebrates were limpets (Lottiidae), acorn barnacles (Chthamalus fissus), chitons (Cyanoplax hartwegii), and black turban snails (Chlorostoma funebralis). 
The manipulative experiment portion of our study was designed as a before-after-controlimpact (BACI) study (Stewart Oaten, et al. 1986, Stewart-Oaten and Bence 2001). We established 19 plots of $8 \mathrm{~m}^{2}$ size $(2 \mathrm{~m} \mathrm{x} 4 \mathrm{~m}$ ) on the bench rock site, intentionally avoiding areas of sand, deep tidepools, surge channels, turnable substrate, and high relief rocks. The $2 \mathrm{~m}$ x $4 \mathrm{~m}$ plot size was chosen because it was the largest size that could be accommodated on the bench rock site and in the rockweed zone without having plots overlap one another. The corners of the plots were marked with stainless steel anchor bolts.

\section{Sampling}

Non-destructive biological sampling was done in three $1 \mathrm{~m}^{2}$ quadrats positioned end-toend and centered longitudinally in each $8 \mathrm{~m}^{2}$ plot. The percent cover of each algal and sessile invertebrate species, including bare substrates, was visually estimated using crossstring grids in the quadrats to help estimate cover. Overstory species were sampled first, and then their blades and branches were moved to expose and tally the coverage of the understory species and to count all motile invertebrates.

\section{$\underline{\text { Pre-Treatment and Treatment Applications }}$}

Species abundances in the 19 plots were first sampled monthly for 13 months (February 2007-February 2008) before any experimental trampling was conducted. The data were analyzed using a Tukey test for additivity (Tukey 1949) to determine if the abundances of numerically dominant taxa had similar patterns of abundance among surveys. This test was done to ensure the data met the assumption of additivity for the BACI analysis model (Stewart-Oaten et al. 1986), which in some taxa required square root or log 
transformation of the data. We also calculated the Bray-Curtis dissimilarity among plots to help identify plots with the greatest differences in species composition. The additivity and Bray Curtis analyses were used to identify three plots that had patterns of species changes and species composition that differed from the other quadrats. These three plots were not included in the experimental treatments in order to minimize the variation among the plots and to better meet the assumptions of the BACI model. The remaining 16 plots were randomly divided into three different visitor exposure level groups (treatments) and a control group, each group having four plots.

Instead of treatment exposures being based on pre-determined numbers of footsteps, our treatment exposures were: 1) low-2 people in each plot for 10 minutes; 2) medium-2 people in each plot for 20 minutes; and 3) heavy-4 people in each plot for 40 minutes. Control plots were not exposed to any visitor traffic. Our visitor exposures were repeated 10 times over the next 8 months to bracket the visitor exposure levels that we estimated occur on MDO State Park rocky shores in a year (Figure 2). Biological sampling continued monthly during this period (March-October 2008); the sampling was scheduled independent of when the experimental trampling exposures were applied.

Our test subjects were student volunteers from two local colleges. We initially intended the treatments to be applied as 'blind trials', in which our volunteers would be unaware that they were the subjects of a trampling study. However, this became unworkable, due to the difficulty of finding a new set of volunteers unfamiliar with the study for each trial. We overcame this by having our returning volunteers complete various activities in the test plots that simulated visitors exploring the intertidal zone. Volunteers were given a list of activities to do at any pace and order, which included matching species to pictures, 
taking pictures, counting species, comparing counts, and sharing observations. The volunteers were also told they did not have to constantly walk around in the plots during the experiment or complete all of the activities. Our volunteers were instructed to behave as if visiting the shore with friends, family, or school. Consequently, time was spent walking, talking, standing still, kneeling, and squatting. Organisms were touched and picked up on occasion to emulate that commonly observed activity as well. Although our study was based on numbers of people in the test plots for specific periods of time, we also counted how many steps our test subjects took while inside the test plots during one of the surveys. Eight people were watched for 10 minutes while they were inside the plots, and their footsteps were counted.

\section{$\underline{\text { Analysis Methods }}$}

The data analyzed from the field experiment focused on the most abundant algae and invertebrates, based on the average abundances from all of the plots prior to the treatment period. This consisted of seven taxonomic groups of algae that together comprised almost $97 \%$ of the total non-crustose algal cover and nine invertebrate taxa that together comprised $97 \%$ of the total invertebrate counts. The acorn barnacle (C. fissus) and mussel (Mytilus spp.) were recorded as percent cover, and were also analyzed.

The Before-After-Control-Impact (BACI) design for the experiment used the data collected in the before (B) period to estimate the average differences between the control (C) and treatment (or impact [I]) plots, which were then compared to estimates of the average differences in the period after (A) the application of the treatments. In BACI designs, the sampling events provide the replication for the average differences or 
'deltas' between the treatment and control abundances. The deltas from each survey from the BACI design were calculated as the difference in the mean abundance from the three quadrats within each $8 \mathrm{~m}^{2}$ plot for each survey using the formula $\mathrm{x}_{i-\mathrm{I}}-\bar{x}_{i-\mathrm{C}}$ (the abundance for each treatment plot $\left(\mathrm{x}_{i-\mathrm{I}}\right)$ minus the mean abundance from the control plots $\left(\bar{x}_{i-\mathrm{C}}\right)$ for each survey $i$ ). The calculated deltas were analyzed using ANOVA.

Analysis using the BACI model requires the data to conform to certain statistical assumptions that are generally the same as those for analysis of variance (ANOVA), and are described in detail by Schroeter et al. (1993). The deltas for the treatment plots were tested for additivity, serial correlation, and homogeneity of variances prior to analysis to determine if they met appropriate assumptions using the original data and the data transformed using a range of transformations and constants, as described in Steinbeck et al. (2005). The data were analyzed using the "Proc Mixed" procedure in SAS (Littell et al. 1996). This program analyzes mixed-model ANOVAs that include random and fixed factors, and can accommodate autoregressive error structures that may occur with serially-correlated data.

The following ANOVA model was used to test the hypothesis that treatment plots were unaffected by trampling:

$$
\mathrm{X}_{i j k}=u+\mathrm{T}_{i}+\mathrm{P}_{j}+\mathrm{TP}_{i j}+\mathrm{S}_{k(j)}+\mathrm{TS}_{i k(j)}
$$

where $\mathrm{X}_{i j k}=$ the delta value for a treatment $(\mathrm{T})$ for a given survey $(\mathrm{S})$ within a period $(\mathrm{P})$ (transformed as appropriate); $u=$ the mean difference across all treatment, period, and survey effects; $\mathrm{T}_{i}=$ the effect of the $i^{\text {th }}$ treatment; $\mathrm{P}_{j}=$ the effect of the $j^{\text {th }}$ Period; $\mathrm{TP}_{i j}=$ 
the effect of the Treatment $x$ Period interaction; $S_{k(j)}=$ the effect of the $k^{\text {th }}$ Survey within the $j^{\text {th }}$ Period; and $\mathrm{TS}_{i k(j)}=$ the effect of the Treatment $\mathrm{x}$ Survey within Period interaction.

The main effects and interaction terms were not relevant to identifying thresholds of visitor use that might result in impacts. Therefore, the hypothesis that there was no significant difference in mean deltas between periods was tested using a set of preplanned comparisons between periods for each treatment using a significance level of 95\%. Test power was calculated based on the main period effect, in order to determine the power of the data to detect a difference among periods, if one was present. A test power of $80 \%$ was used to determine which data sets were capable of detecting a difference among periods.

The multivariate technique of non-metric multidimensional scaling (MDS) was used to examine patterns of variation in the treatments over time, relative to the average control abundances, separately for algae and invertebrates. This technique analyzed delta values, as used in the BACI ANOVA, for the algal and invertebrate taxa that occurred in at least 6 of the 21 surveys, regardless of occurrence with respect to treatment type. Delta values were used to reduce variation caused by seasonal abundance changes and to focus on differences among surveys between periods. Since the deltas used in the analysis had both positive and negative values, the mean character difference, or Czekanowski distance (Legendre and Legendre 1998), was computed using the average of the delta values from the four plots for each of the survey-treatment combinations. The MDS analysis was done using PRIMER Version 6 (Clarke and Gorley 2001).

\section{Observational Field Study}


Our observational field study (ground-truth study) was completed on three bench rock platforms in MDO State Park differing in the amount of visitor traffic (Figure 1). One bench area was Hazard Reef, which was also an area used to calculate visitor traffic levels to test in our experiment. The other areas (Hazard-Mid, Hazard-Far) were located as far as $1 \mathrm{~km}$ down coast from Hazard Reef where visitor traffic was largely absent. All three areas were characterized by a high abundance of $S$. compressa and other species similar to our experimental site. The purpose of sampling Hazard Reef was to describe species abundances exposed to long-term continuous levels of visitor traffic, and in sampling the Hazard-Mid and Hazard-Far study areas, to determine if differences in species abundances could be detected among areas with high and low levels of visitors that might be due to the differences in foot traffic. The changes in species and relative magnitude of change were also compared with the changes detected in our BACI experiment.

Stratified random sampling was used in each area. A transect line was deployed parallel to the shoreline on each bench platform and through the middle of the rockweed zone. The transect line was divided into $20 \mathrm{~m}$ segments, and three random $1 \mathrm{~m}^{2}$ quadrats were sampled in each segment. The three bench areas differed in shoreline length, such that Hazard Reef, Hazard-Mid, and Hazard-Far had 8, 9, and 16 transect segments, respectively.

Algal cover and invertebrate densities were sampled using the same methods used in the field experiment. The species/taxa that were sampled were only those that significantly declined in the experiment and which were present in the field study: S. compressa, 
Hesperophycus californicus, M. papillatus, E. muricata, and the invertebrate groups Lottiidae (limpets) and Polyplacophora (chitons).

The abundance of each taxon was compared across areas using ANOVA (GLM procedure in MiniTab Ver. 16). 'Sites' (Hazard Reef, Hazard-Mid, and Hazard-Far) were the main factor and the $20 \mathrm{~m}$ sample segments were random factors nested within sites. Similar to the field experiment, the level of probability in determining significance for the observational field study was $95 \%$. When a significant difference was detected among areas, Tukey pairwise comparison tests were used a posteriori to determine which areas were significantly different from each other. Data were transformed when appropriate to comply with the assumptions of ANOVA. S. compressa, H. californicus, E. muricata, and M. papillatus were log transformed (log base e). Combined algae were not transformed. Lottidae and polyplacophorans were square root transformed.

\section{RESULTS}

\section{Visitor Surveys}

The levels of visitor traffic tested in our field experiment were from visitor counts extrapolated over a year based on the estimated period of accessible tides (Table 1). Hazard Canyon and Corallina Cove had estimates of annual visitor traffic of 1.9 and 1.6 person hrs $\mathrm{m}^{-2}$ year $^{-1}$, respectively. Our observed levels were bracketed by the cumulative amount of visitor exposure levels that we applied in 10 treatments in the heavy and low exposure treatments (3.3 and 0.4 person $\mathrm{hrs} \mathrm{m}^{-2}$, respectively) (Figure 2).

\section{Experiment}




\section{$\underline{\text { Algae and Seagrass }}$}

We sampled over 30 algal taxa and one seagrass species in the experimental treatment and control plots. All plots remained characterized by the rockweed S. compressa, Fucus distichus, and H. californicus, and the red algae E. muricata and M. papillatus. All of these species remained thoroughout the experiment, but with shifting abundances over time. These five algal species accounted for over $90 \%$ of the total non-crustose algal cover throughout the experiment. Excluding crustose algae, no single algal species was greater than $40 \%$ cover on average in the plots. Species rank order of abundance remained largely unchanged over time.

Statistically significant declines in algal cover, primarily in the heavy exposure treatment plots, were detected between the pre-treatment and treatment periods, relative to controls, in S. compressa, E. muricata, and M. papillatus (Figure 3, Table 2). The decline in cover, relative to controls, for each of these species was less than $10 \%$ cover. A significant decline in total algal cover (all non-crustose species combined) of approximately $20 \%$, relative to controls, was detected in the heavy exposure treatment (Figure 4 and Table 2).

Statistically significant changes, relative to controls, that were smaller in magnitude and involved fewer species were detected in the moderate and low exposure treatments (Figure 3). The low exposure treatment had mixed results with both increases and decreases in algal cover, relative to controls, and had species changes that were opposite in direction to the changes in the same species in the other treatments.

The MDS configuration of the Czekanowski distances among the average differences from the control plots for the three treatments shows considerable variation among 
surveys before and during the treatment exposures, particularly in the low and moderate treatment exposures (Figure 5). The large variation in the array of survey scores for the low and moderate treatments in the MDS plot indicates the absence of a defined shift in algal community composition over time in those treatment plots. In contrast, the later surveys for the heavy visitor exposure treatment show a greater difference from the earlier surveys, indicating a shift in algal community composition and abundance from the heavier visitor exposures.

\section{$\underline{\text { Invertebrates }}$}

The two most abundant motile invertebrate taxa in the study of the 70 that were enumerated were black turban snails (Chlorostoma funebralis, formerly Tegula funebralis) followed by limpets as a group (Lottiidae). Several hundred C. funebralis and up to 50 Lottiidae in a $1 \mathrm{~m}^{2}$ quadrat were common occurrences. Aggregating anemones (Anthopleura elegantissima) were also very common in the quadrats. The acorn barnacle (C. fissus) was the most common sessile invertebrate species sampled. Mussels (Mytilus spp.), however, which tend to be locally abundant on outer coastal rocky shores, were not very common in our study plots.

Compared to the algae, the invertebrates had more variable changes both within and among the treatments (Table 2, Figure 6). The greater variation in invertebrate abundances is reflected in the lower test power for all of the taxa analyzed (Table 2). The acorn barnacle ( $C$. fissus) in the heavy exposure treatment was the only invertebrate with a statistically significant increase in abundance. 
Unlike the algae, the MDS analysis of the deltas for the invertebrates did not indicate any gradient in changes from the high to low treatment levels that would be indicative of foot traffic effects (Figure 7). All treatment level scores were highly variable over time with many of the surveys in the pre-treatment and treatment periods being more similar to each other than surveys more closely linked in time.

\section{Observational Ground-Truth Field Study}

The results showed that algal abundances were generally lowest at Hazard Reef, compared to Hazard-Mid and Hazard-Far, but the differences among individual species and areas were not consistent, and not statistically significant for most taxa (Figure 8 and Table 3). A statistically significant difference, however, was detected for combined algal cover between Hazard Reef and Hazard-Far. Combined algal percent cover was approximately $15 \%$ lower at Hazard Reef as compared to the less accessed sites. Combined algal cover at Hazard-Mid was not significantly different from the other two areas. The results for Lottiidae and Polyplacophora (chitons) were mixed and not similar between the two taxa (Figure 8 and Table 3).

\section{DISCUSSION}

Resource management of rocky shores is complicated in areas such as National Parks, State Parks, National Marine Sanctuaries, and marine protected areas where the goal of maintaining natural resources needs to be balanced with the goal of allowing for and providing coastal access in many cases. Our study in San Luis Obispo County, central California, was done to provide California State Park managers with information on the effects caused by current levels of visitor access to rocky intertidal shoreline areas in 
State Parks in San Luis Obispo County. We collected this information to also help in planning for new coastal State Parks that are not presently open to public access.

We focused our study on the effects of foot traffic (trampling) on rocky shores, as all activities to the shore involve walking, and there are generally no limitations on how many people are allowed in areas with public access. We further restricted our study to the rockweed community, as rockweed are susceptible to trampling effects, they are common in the upper mid-intertidal in San Luis Obispo County, and the upper midintertidal is the zone where rocky shore visitors tend to spend most of their time (Clowes and Coleman 2000, Tenera 2003, 2004).

The results from our field experiment are consistent with previous experiments that found rockweed communities to be negatively affected by foot traffic (Murray and Gibson 1979, Brosnan et al. 1996, Fletcher and Frid 1996, Denis 2002). While it is clear from these studies that intertidal communities are negatively affected by trampling, it is less clear on how much impact actually occurs from foot traffic at popular shoreline areas. Results from many trampling experiments fall short of describing the actual magnitude of impact, particularly when uncertainties exist on whether the trampling levels used in the experiments were a good representation of normal foot traffic in those areas.

We altered our study approach from previous studies in an attempt to provide a more realistic assessment of impacts from foot traffic. First of all we used data from visitor surveys to determine the appropriate levels of treatment used in our field experiment. We also applied our foot traffic as time spent in test plots, which was consistent with the data we collected in the visitor surveys, rather than subjecting plots to set numbers of 
footsteps. We also used larger plots to encompass more heterogeneous habitat so that the experiment was more representative of the general habitat and not of small, selected, pure stands of species. Again this was consistent with observations from our visitor surveys and other surveys (Tenera 2004, 2005) showing that people move actively around the intertidal. Finally, we verified the results of the field experiment using a field study comparing areas with varying levels of visitor traffic that was similar to the areas studied in the field experiment. We felt that an approach that provided consistent results from several studies would have a greater chance of being used in managing public access to similar rocky intertidal areas at local State Parks.

The most important aspect of our study was ensuring that the treatment levels used in the field experiment were representative of the levels of visitor traffic to equivalent rocky intertidal areas in MDO State Park. Specifically, we hoped to bracket the levels of exposure observed in our visitor surveys. To do this, we determined the area with colonized rock in the two rocky intertidal areas at MDO State Park, counted the numbers of people in those areas over a given time period, and estimated the number of hours those zones are exposed for access in a year period. From this, we determined that we needed to repeat our treatment applications at least 10 times, in order to ensure that the treatment applications bracketed the cumulative amount of visitor exposure we estimated occurs per square meter in a year period in the study areas at MDO State Park (Figure 2). This ensured that the results of the field experiment would be representative of the visitor traffic at MDO State Park. 
One of the issues addressed in the treatment levels used in our field experiment was how the results can be used to describe actual impacts. In this study, the treatments were based on the same units of measurement used in our visitor surveys. Past studies have focused treatment levels on the numbers of footsteps applied per unit area which when standardized for comparison show that many of the treatments represent extreme levels of trampling, which not surprisingly lead to large impacts (Figure 9). For example, assuming that a footprint represents an area of $0.03 \mathrm{~m}^{2}$ and assuming footsteps were distributed evenly in the test plots each visit, the same spot on the ground (footprint) in the Brosnan and Crumrine (1994) study, was contacted close to 2,500 times. The footsteps were applied monthly for 12 months. Test plots have also been as small as 0.09 $\mathrm{m}^{2}$ (Brown and Taylor 1999, Huff 2006), which focused the footsteps in an area equivalent to three footprints side-by-side. In general, the studies do not provide sound reasoning on the selection of the various treatment levels. While there are locations on the shoreline that receive high levels of trampling such as the base of a stairway to the shore, we feel it is difficult to use results from these experiments to manage access, especially because people tend to avoid walking over slippery algae and stepping on invertebrates (Bally and Griffiths 1989). We have seen that people will tend to step on bare rocks whenever possible for safer footing, and will go around densely covered areas to avoid slipping and falling. These observations indicate that treatments based on repeatedly stepping in the same location on pure stands of algae or other organisms probably overestimate the actual impacts from the equivalent number of steps taken by the average person visiting the intertidal. Finally, we feel that managed access mainly looks to regulate numbers of visitors and frequency of visits, not numbers of footsteps. 
Consistent with this approach our observations of people in the intertidal resulted in the use larger plots of more heterogeneous habitat that included bare rock. This was so our visitors had more options on where to walk and stand that more closely simulated the behavior we observed in our visitor surveys. As a result of the larger plots we did not confine our volunteers to a specific area and had them perform activities that would result in movement through the plots. The scripted activities were intended to simulate how a person, family, or school would behave when exploring the intertidal zone.

Consequently, the treatment time was spent not only walking about, but also squatting, kneeling, and standing still, on areas of colonized rock and on bare rock. Although our treatment plots were exposed to much fewer footsteps than largely all other studies of trampling effects (Figure 9), we were still able to detect impacts.

Having relatively large plots containing more heterogeneous habitat was also important in that none of our plots started with close to $100 \%$ coverage, as was the case in other studies (Povey and Keough 1991, Keough and Quinn 1998, Schiel and Taylor 1999, Smith and Murray 2005, Denis 2002). Due to plot size, the average abundance of any given algal species in our plots at the beginning of the study was no greater than about $40 \%$ cover, and the plots had exposed bare rock areas between the algal patches. Consequently, species abundances could increase, decrease, or remain unchanged over time. In contrast, experiments that begin with near-full coverage of the test species can only decline in abundance, as all footsteps have to occur on the test species.

The design of the field experiment was unique in its use of a BACI design which is typically used for observational studies that have an unreplicated treatment such as a 
thermal discharge (Schroeter et al. 1993, Steinbeck et al 2005). BACI designs have not generally been used for field experiments where replication of treatments is generally possible. The use of a BACI design is an effective approach for dealing with repeated sampling that may result in autocorrelated data that are not independent (Stewart-Oaten and Bence 2001). The BACI design is also effective at controlling for natural variation since the data analyzed are the differences between the experimental and control plots which effectively controls for the natural variation in the study area. The potential for differences among plots was decreased by eliminating plots prior to the treatment period that were not exhibiting the same overall patterns of species changes as other plots. This is a practice that has large benefits in its potential to reduce variation among experimental plots but is rarely included in the original design of a study. Our use of a BACI design in this study shows that it is more widely adaptable than its prior use in observational impact assessments (Stewart Oaten, et al. 1986, Schroeter et al. 1993, Stewart-Oaten and Bence 2001, Steinbeck et al. 2005).

We are confident that the field experiment detected changes resulting from foot traffic and not from other causes, based on the pattern of treatment responses, particularly in the algae. The fewest statistically significant changes were detected in the lowest exposure treatment, more changes were detected in the moderate treatment, and the largest number of changes were detected in the heavy exposure treatment. The ability to detect a gradient of responses and differences in the magnitude of effects were largely the result of the BACI design that controlled natural variation resulting in high statistical power to both detect impacts and conclude that the lack of significant changes at the lower treatment levels was not an artifact of a poor design or highly variable results. These help 
substantiate that the experiment detected changes due to the foot traffic exposures. The MDS results for the algae also indicate the changes in the experiment were due to the foot traffic exposures over other causes, as the greatest differences in algal composition and abundance between the pre-treatment and treatment periods occurred in the heavy exposure treatment.

The changes detected in the experiment were largely confined to the algae, with the changes in the individual species being less than about $10 \%$ cover. These small levels of change support the use of controlled field experiments as the preferred approach for assessing the effects of trampling (Bally and Griffiths 1989, Povey and Keough 1991, Brosnan and Crumrine 1994, Keough and Quinn 1998, Brown and Taylor 1999, Schiel and Taylor 1999, Clowes 2002, Denis 2002, Smith and Murray 2005, Huff 2006). It is unlikely that the low levels of change in our study could have been detected in a purely observational comparison study where natural variation can easily mask differences between areas with different levels of visitor exposure (Tenera 2003, 2004; Van De Werfhorst and Pearse 2007).

Our experiment also detected a decrease of approximately $20 \%$, relative to controls, in total algal cover (all non-crustose species combined). This was roughly equivalent to the difference ( $15 \%$ cover) in total algal cover detected in our field study between Hazard Reef and the other two study areas. The consistent results between the field experiment and observational study implies that the differences between areas along the Hazards Canyon shoreline were most likely the result of visitor traffic. One explanation on why we did not see larger differences between high and low use areas in our Hazards Canyon 
shoreline study and in our experiment is that impacts related to visitor traffic in our locale are probably not extraordinarily large, in comparison to areas with large numbers of visitors, such as southern California.

Currently, there is little guidance, no standard protocols, and few criteria to help resource managers decide what are significant levels of impacts and when intervention measures are needed to minimize or reverse impacts (Liddle 1975, Milazzo et al. 2002). As such, resource managers often have to acknowledge that impacts are probably occurring with unknown consequences, but have to accept them to allow continued shoreline access (Underwood and Kennelly 1990). Similarly, allowing shore access to continue is often the priority until it can be demonstrated that access should not be allowed to continue. Unfortunately, many decisions on balancing resource protection with continued shore access are largely based on professional judgment, taking into account social perceptions, values, benefits, and politics which are not quantitative (Liddle 1975, Hirst 1984, Underwood and Kennelly 1990, Keough and Quinn 1998, Endter-Wada et al. 1998, Tenera 2003). Management decisions should be based on strong quantitative information and direct evidence as much as possible, in order to minimize speculation and help support the often difficult trade-offs (Underwood and Kennelly 1990).

Our findings appear to provide support that the present levels of visitor access in the rocky intertidal areas of MDO State Park do not result in impacts that exceed normal levels of natural disturbance as total algal cover was only reduced by approximately $15 \%$ near the main access at Hazard Canyon in MDO State Park, and we found no barren 
zones or worn pathways in the intertidal zone near access points. We are continuing to monitor the treatment plots at the site of the field experiment for recovery.

\section{ACKNOWLEDGEMENTS}

This project was developed and completed as part of the initiatives of the San Luis Obispo Science and Ecosystem Alliance at the Center for Coastal Marine Sciences at Cal Poly San Luis Obispo (see: www.slosea.org), a consortium of central California resource managers and stakeholders with the shared interest and purpose to foster innovative research that can be applied to resource and conservation. Funding was provided by the David and Lucile Packard Foundation, the Resource Legacy Foundation, the California Coastal Conservancy, and the California Ocean Protection Council, and the research was completed under contract to the California Polytechnic State University (Cal Poly), San Luis Obispo, California. Mr. Nicholas Franco, California State Park Superintendent, Central Coast Region, was especially encouraging and in need of the information for understanding impacts from visitor traffic on existing State Park shores and for planning new coastal access points at newly acquired California State Park coastal properties. Mr. Franco also provided valuable input on the visitor surveys. In addition, this study required numerous people to help in the field with the visitor treatments of the experiment. The treatment applications were done by a pool of over 30 volunteer students from Cal Poly and Cuesta College, San Luis Obispo, California, all who spent long hours in the field without complaint. We are also very appreciative of the help provided by Dr. Andrew Schaffner of Cal Poly's statistics department. We especially want to thank Ms. Sally Krenn and Mr. Michael Fry of Pacific Gas and Electric Company’s Land 
Stewardship Program for enabling us to complete our controlled foot traffic experiment on a shore of no public access.

\section{LITERATURE CITED}

Abbott, I. A. and G. J. Hollenberg. 1976. Marine algae of California. Stanford University Press. Stanford, California.

Addessi, L. 1994. Human disturbance and long-term changes on a rocky intertidal community. Ecological Applications 4(4):786-797.

Ambrose, R. F. and J. Smith. 2004. Restoring rocky intertidal habitats in Santa Monica Bay. Draft. Submitted to the Santa Monica Bay Restoration Commission. June 2004.

Andrés-Abelláan, M., F. R. López-Serrano, F. A. García Morote, and A. Del Cerro-Barja. 2006. Assessment of trampling simulation impacts on native vegetation in Mediterranean sclerophyllous forest. Environmental monitoring and assessment 120: 93-107.

Baines, D. and M. Richardson. 2007. An experimental assessment of the potential effects of human disturbance on Black Grouse Tetrao tetrix in the North Pennines, England. Ibis 149 (Suppl. 1) 56-64.

Bally, R. and C. L. Griffiths. 1989. Effects of human trampling on an exposed rocky shore. International Journal of Environmental Studies 34: 155-125. 
Beauchamp, K. A. and M. M. Gowing. 1982. A quantitative assessment of human trampling effects on a rocky intertidal community. Marine Environmental Research 7: 279-293.

Becker, B. J. 2006. Status and trends of ecological health and human use of the Cabrillo National Monument rocky intertidal zone (1990-2005). Natural Resource Technical Report NPS/PWR/CABR/NRTR—2006/03. National Park Service. June 2006.

Brosnan, D. M. and L. L. Crumrine. 1994. Effects of human trampling on marine rocky shore communities. Journal of Experimental Marine Biology and Ecology 177: 79-97.

Brosnan, D., J. Elliott, and I. Quon. 1996. The effect of trampling on marine rocky shores in southern California. California Sea Grant Biennial Report 92-96, California, USA.

Brown, P. J. and R. B. Taylor. 1999. Effects of trampling by humans on animals inhabiting coralline algal turf in the rocky intertidal. Journal of Experimental Marine Biology and Ecology 235: 45-53.

California State Parks. 2008. Montaña de Oro State Park visitation records. Hearst Castle State Park, San Simeon, California, USA.

Castilla, J. C. and L. R. Durin. 1985. Human exclusion from the rocky intertidal zone of central Chile:the effects on Concholepacs oncholepas( Gastropoda). Oikos 45: 391399 
Castilla, J. C. and R. H. Bustamante. 1989. Human exclusion from rocky intertidal of Las Cruces, central Chile: effects on Durvillaea antarctica (Phaeophyta, Durvilleales). Marine Ecology Progress Series 50: 203-214.

Chan, G. L. 1970. Analysis of the effects of public and educational school field trips on a marine environment, Duxbury Reef. Ph.D. Dissertation, University of California, Berkeley, California, USA.

Clarke, K. R and R. N. Gorley. 2001. PRIMER v5: User Manual/Tutorial. PRIMER-E: Plymouth, England.

Clowes, S. W. 2002. Temporal change in algal communities at Point Pinos rocky intertidal as potential indicators of human and natural disturbance. M. S. Thesis, Hopkins Marine Station, Stanford University, California, USA.

Denis, T. G. 2002. Effects of human foot traffic on the standing stocks, size structures, and reproduction of southern California populations of the intertidal rockweed Silvetia compressa (O. Fucales). M. S. Thesis, California State University Fullerton, California, USA.

Endter-Wada, J., D. Blahna, R. Krannich, and M. Brunson. 1998. A framework for understanding social science contributions to ecosystem management. Ecological Applications 8(3): 891-904.

Fletcher, H. and C. L. J. Frid. 1996. Impact and management of visitor pressure on rocky intertidal algal communities. Aquatic Conservation: Marine and Freshwater Ecosystems 6: 287-297. 
Ghazanshahi, J., T. D. Huchel, and J. S. Devinney. 1983. Alteration of southern

California rock shore ecosystems by public recreational use. Journal of Environmental Management 16: 379-394.

Griffiths, C. L. and G. M. Branch. 1997. The exploitation of coastal invertebrates and seaweeds in South Africa: historical trends, ecological impacts and implications for management. Transactions of the Royal Society of South Africa 52(1):121-148.

Gunnill, F. C. 1982. Effects of plant size and distribution on the numbers of invertebrate species and individuals inhabiting the brown alga Pelvetia fastigiata (Fucaceae): effects of plant size and distribution. Marine Biology 73: 115-130.

Gunnill, F.C. 1984. Differing distributions of potentially competing amphipods, copepods and gastropods among specimens of the intertidal algal Pelvetia fastigiata. Marine Biology 82: 277-291.

Hirst, S. M. 1984. Applied ecology and the real world II. resource management and impact assessment. Journal of Environmental Management 18: 203-213.

Huff, T. M. 2011. Effects of human trampling on macro- and meiofauna communities associated with intertidal algal turfs and implications for management of protected areas on rocky shores (Southern California). Special topic, Marine Ecology 1: (11) ISSN 0173-9565. 
Jenkins, S. R., S. J. Hawkins, and T. A. Norton. 1999. Interaction between a fucoid canopy and limpet grazing in structuring a low shore intertidal community. Journal of Experimental Marine Biology and Ecology 233: 41-63.

Keough, M. J. and G. P. Quinn. 1998. Effects of periodic disturbances from trampling on rocky intertidal algal beds. Ecological Applications 8 (1): 141-161.

Kaustuv, R., A. G. Collins, B. J. Becker, E. Begovic, and J. M. Engle. 2006. Anthropogenic impacts and historical decline in body size of rocky intertidal gastropods in southern California. Ecology Letters 6: 205-211.

Legendre, P. and L. Legendre. 1998. Numerical Ecology, Second Edition. Elsevier Science B.V., Amsterdam, Netherlands.

Leujak, W. and R. F.G. Ormond, 2008. Quantifying acceptable levels of visitor use on Red Sea reef flats. Aquatic Conservation: Marine Freshwater Ecosystems. 18: 930944.

Liddle, M. J. 1975. A selective review of the ecological effects of human trampling on natural ecosystems. Biological Conservation 7: 17-36.

Liddle, M. J. and A. M. Kay. 1987. Resistance, survival and recovery of trampled corals on the Great Barrier Reef. Biological Conservation 42 (1): 18.

Lindberg, D. R., J. A. Estes, and K. I. Warheit. 1998. Human influences on trophic cascades along rocky shores. Ecological Applications 8(3): 880-890. 
Littell, R. C., G. A. Milliken, W. W. Stroup, and R. D. Wolfinger. 1996. SAS System for mixed models. SAS Institute, Cary, NC.

Milazzo, M., R. Chemello, F. Badalamenti, R. Camarda, and S. Riggio. 2002. The impact of human recreational activities in marine protected areas: What lessons should be learnt in the Mediterranean Sea? Mar. Ecol. 23 Supplement 1: 280-290.

Moreno, C. A., J. P. Southerland, and H. F. Jara. 1984. Man as a predator in the intertidal zone of southern Chile. Oikos. 42: 155-160.

Murray, S. N. and T. A. Gibson. 1979. Vulnerability of the rockweed Pelvetia compressa to anthropogenic disturbance on southern California rocky shores. Phycologia 36: $75-76$.

Murray, S. N., T. G. Denis, J. S. Kido, and J. R. Smith. 1999. Human visitation and the frequency and potential effects of collecting on rocky intertidal populations in southern California marine reserves. CalCOFI Reports 40: 100-106.

Povey, A. and M. J. Keough. 1991. Effects of trampling on plant and animal populations on rocky shores. Oikos 61: 355-368.

Remacha, C, J. Pérez-Tris, and J. Antonio Delgado. 2011. Reducing visitors' group size increases the number of birds during educational activities: Implications for management of nature-based recreation. Journal of Environmental Management 92 $1564-1568$ 
Schiel, D. R. and D. I. Taylor. 1999. Effects of trampling on a rocky intertidal algal assemblage in southern New Zealand. Journal of Experimental Marine Biology and Ecology 235: 213-235.

Schroeter, S. C., J. D. Dixon, J. Kastendiek, and R. O. Smith. 1993. Detecting the ecological effects of environmental impacts: a case study of kelp forest invertebrates. Ecological Applications 3(2): 331-350.

Smith, J. R. and S. N. Murray. 2005. The effects of experimental bait collection and trampling on a Mytilus californianus mussel bed in southern California. Marine Biology 147: 699-706.

Sparling, R. 1977. An annotated list of the marine algae (Chlorophyta, Phaeophyta, Rhodophyta) of San Luis Obispo County, California with keys to genera and species. Blake Printery, San Luis Obispo, California, USA.

Steinbeck, J. R., D. R. Schiel, and M. S. Foster. 2005. Detecting long-term change in complex communities: a case study from the rocky intertidal zone. Ecological Applications 15: 1813-1832.

Stewart-Oaten, A. and J. R. Bence. 2001. Temporal and spatial variation in environmental impact assessment. Ecological Monographs 71: 305-339.

Stewart-Oaten, A. 1996. Problems in the analysis of environmental monitoring data. Pages 109-132 in R.J. Schmitt and C.W. Osenberg, editors. Detecting ecological impacts. Academic Press, New York, New York, USA. 
Stewart-Oaten, A., W. M. Murdoch, and K. R. Parker. 1986. Environmental impact assessment: "pseudoreplication" in time? Ecology 67: 929-940.

Tenera Environmental. 2003. A comparative intertidal study and user survey, Point Pinos, California. Prepared for the Monterey Bay Sanctuary Foundation. Monterey, California, USA.

Tenera Environmental. 2004. James V. Fitzgerald Marine Reserve: resource assessment. Prepared for the San Mateo County Environmental Services Agency, Redwood City, California, USA.

Tenera Environmental. 2011. S/S Cape Mohican Restoration Program, Duxbury Reef, Gulf of the Farallones National Marine Sanctuary, Baseline Study and Resource Stewardship Assessment. February 2011.

Thompson, R. C. T. P. Crowe, S. J. Hawkins. 2002. Rocky intertidal communities: past environmental changes, present statusand predictions for the next 25 years. Environmental Conservation. 29 (2): 168-191

Tukey, J. W. 1949. One degree of freedom for non-additivity. Biometrics 5: 232-242.

Underwood, A. J. and S. J. Kennelly. 1990. Pilot studies for designs of surveys of human disturbance of intertidal habitats in New South Wales. Australian Journal of Marine and Freshwater Research. 41:165̃-173.

Van De Werfhorst, L. C. and J. S. Pearse. 2007. Trampling in the rocky intertidal of central California: a follow-up study. Bulletin of Marine Science 81(2): 245-254. 
Table 1. Summary of visitor counts in MDO State Park.

\begin{tabular}{|c|c|c|c|c|c|c|}
\hline Location & $\begin{array}{l}\text { Mean number } \\
\text { people hour }\end{array}$ & $\begin{array}{c}\text { Number of } \\
\text { surveys }\end{array}$ & $\begin{array}{c}\text { Rock } \\
\operatorname{area}\left(\mathrm{m}^{2}\right)\end{array}$ & $\begin{array}{l}\text { Total hours } \\
\text { year }^{-1} \text { of tides to } \\
\text { access shores }\end{array}$ & $\begin{array}{l}\text { Total days year }{ }^{-1} \\
\text { of tides to access } \\
\text { shores }\end{array}$ & $\begin{array}{l}\text { Person hours } \mathrm{m}^{-2} \\
\text { year }^{-1} \text { in rock zone }\end{array}$ \\
\hline Hazard Canyon & 3.9 & 14 & 1,960 & 945 & 275 & 1.9 \\
\hline Corallina Cove & 1.9 & 14 & 1,154 & 945 & 275 & 1.6 \\
\hline
\end{tabular}


Table 2. BACI ANOVA results for algal and invertebrate data sets showing transformations and options used in the analysis, overall test power to detect a statistical difference between periods at $\alpha=0.05$, and test statistics and probabilities of planned test comparisons between periods for each treatment. Results with a test power of less than 80 percent and significant $p$-values at $\alpha=0.05$ are underlined.

\begin{tabular}{|c|c|c|c|c|c|c|c|}
\hline $\begin{array}{l}\text { Taxon or Data } \\
\text { Analyzed } \\
\end{array}$ & $\begin{array}{l}\text { Transfor- } \\
\text { mation }\end{array}$ & $\begin{array}{l}\text { Auto- } \\
\text { regressiv } \\
\text { e Error } \\
\text { Structure }\end{array}$ & $\begin{array}{c}\text { Adjusted d.f. } \\
\text { in } \\
\text { F-Tests }\end{array}$ & $\begin{array}{l}\text { Period } \\
\text { Power }\end{array}$ & $\begin{array}{c}\text { Low Treatment } \\
\text { Period Contrast } \mathrm{F} \\
\text { p-value }\end{array}$ & $\begin{array}{l}\text { Mid Treatment } \\
\text { Period Contrast } \\
\text { p-value }\end{array}$ & $\begin{array}{c}\text { High Treatment } \\
\text { Period Contrast } \\
\text { p-value }\end{array}$ \\
\hline \multicolumn{8}{|l|}{$\underline{\text { Algae }}$} \\
\hline articulated corallines & $\operatorname{Arcsin}(\%)$ & No & $\mathrm{N}$ & $\underline{0.27}$ & 0.25 & 0.39 & $\underline{0.01}$ \\
\hline Endocladia muricata & $\log (x+1.0)$ & No & $\mathrm{N}$ & 0.92 & 0.35 & $\underline{0.01}$ & $\leq 0.01$ \\
\hline Fucus distichus & $\log (x+0.5)$ & No & $\mathrm{N}$ & 0.98 & 0.06 & $\underline{0.02}$ & $\leq 0.01$ \\
\hline $\begin{array}{l}\text { Gelidium } \\
\text { pusillum/coulteri }\end{array}$ & $\operatorname{Arcsin}(\%)$ & No & $\mathrm{N}$ & $\underline{0.08}$ & 0.76 & 0.64 & 0.68 \\
\hline $\begin{array}{l}\text { Hesperophycus } \\
\text { californicus }\end{array}$ & $\log (x+1.0)$ & $\operatorname{AR}(1)$ & $\mathrm{N}$ & $\underline{0.62}$ & $\leq 0.01$ & 0.33 & 0.70 \\
\hline Mastocarpus papillatus & $\log (x+0.5)$ & No & $\mathrm{N}$ & $>.99$ & $\leq 0.01$ & $\leq 0.01$ & $\leq 0.01$ \\
\hline Rockweeds (combined) & none & $\operatorname{AR}(1)$ & $\mathrm{N}$ & 0.87 & 0.38 & 0.49 & $\leq 0.01$ \\
\hline Silvetia compressa & $\operatorname{Arcsin}(\%)$ & $\mathrm{AR}(1)$ & $\mathrm{N}$ & 0.80 & 0.32 & 0.53 & $\leq 0.01$ \\
\hline Total Algal Cover & $\operatorname{Arcsin}(\%)$ & No & $\mathrm{N}$ & $\underline{0.79}$ & 0.06 & 0.14 & $\leq 0.01$ \\
\hline \multicolumn{8}{|l|}{ Invertebrates } \\
\hline Acanthinucella spp. & $\begin{array}{c}\log (x+0.01 \\
)\end{array}$ & No & $\mathrm{N}$ & $\underline{0.05}$ & 0.33 & 0.90 & 0.32 \\
\hline $\begin{array}{l}\text { Anthopleura } \\
\text { elegantissima }\end{array}$ & $\log (x+0.5)$ & No & $\mathrm{N}$ & $\underline{0.13}$ & 0.90 & 0.17 & 0.31 \\
\hline Chlorostoma funebralis & none & No & $\mathrm{Y}$ & $\underline{0.15}$ & 0.79 & 0.75 & $\underline{0.03}$ \\
\hline $\begin{array}{l}\text { Chthamalus fissus } \\
\text { cover }\end{array}$ & $\operatorname{Arcsin}(\%)$ & No & $\mathrm{N}$ & $\underline{0.07}$ & 0.22 & 0.64 & $\underline{0.01}$ \\
\hline Cyanoplax hartwegii & $\sqrt{ }(\mathrm{x}+1)$ & No & $\mathrm{N}$ & $\underline{0.47}$ & 0.91 & 0.25 & $\underline{0.01}$ \\
\hline Littorina spp. & $\log (x+0.5)$ & No & $\mathrm{N}$ & $\underline{0.58}$ & 0.09 & 0.09 & $\underline{0.04}$ \\
\hline Lottia asmi & $\log (x+1.0)$ & No & $\mathrm{N}$ & $\underline{0.05}$ & 0.17 & 0.59 & 0.20 \\
\hline Lottidae & $\log (x+0.1)$ & No & $\mathrm{N}$ & $\underline{0.35}$ & 0.49 & $\leq 0.01$ & 0.18 \\
\hline & $\log (x+0.01$ & & & & & & \\
\hline Mytilus spp. cover & ) & No & $\mathrm{N}$ & $\underline{0.08}$ & 0.58 & 0.60 & 0.21 \\
\hline Ocinebrina spp. & $\log (x+1.0)$ & No & $\mathrm{N}$ & $\underline{0.05}$ & 0.95 & 0.75 & 0.56 \\
\hline Pagurus spp. & $\log (x+0.1)$ & No & $\mathrm{N}$ & $\underline{0.06}$ & 0.18 & 0.45 & 0.13 \\
\hline $\begin{array}{l}\text { Invertebrate Species } \\
\text { Richness }\end{array}$ & $\log (x+1.0)$ & No & $\mathrm{Y}$ & $\underline{0.08}$ & 0.52 & 0.84 & 0.10 \\
\hline
\end{tabular}


Table 3. F-statistics and p-values of the differences in species abundance among Hazard Reef, Hazard-Mid and Hazard-Far sampling areas. Degrees of freedom for 'Site' is 2, for 'Segment (Site)' is 30, and 'Error' is 66. Significant $p$-values at $\alpha=0.05$ are underlined.

\begin{tabular}{|c|c|c|c|}
\hline & Mean Square & $\mathrm{F}$ & $\mathrm{P}$ \\
\hline \multicolumn{4}{|c|}{ Total Algal Cover } \\
\hline Site & 1846.00 & 6.61 & $\leq 0.01$ \\
\hline Segment (Site) & 279.40 & 0.95 & 0.55 \\
\hline Error & 294.80 & & \\
\hline \multicolumn{4}{|c|}{ Silvetia compressa } \\
\hline Site & 1.99 & 0.82 & 0.45 \\
\hline Segment (Site) & 2.43 & 1.94 & $\underline{0.01}$ \\
\hline Error & 1.25 & & \\
\hline \multicolumn{4}{|c|}{ Rockweeds (Silvetia and Hesperophycus combined) } \\
\hline Site & 2.30 & 1.10 & 0.35 \\
\hline Segment (Site) & 2.09 & 2.09 & $\leq 0.01$ \\
\hline Error & 1.00 & & \\
\hline \multicolumn{4}{|c|}{ Endocladia muricata } \\
\hline Site & 5.33 & 4.48 & $\underline{0.02}$ \\
\hline Segment (Site) & 1.19 & 1.10 & 0.37 \\
\hline Error & 1.08 & & \\
\hline \multicolumn{4}{|c|}{ Mastocarpus papillatus } \\
\hline Site & 0.36 & 0.74 & 4.84 \\
\hline Segment (Site) & 0.48 & 1.21 & 0.26 \\
\hline Error & 0.40 & & \\
\hline \multicolumn{4}{|c|}{ Lottidae (limpets) } \\
\hline Site & 84.68 & 13.16 & $\leq 0.01$ \\
\hline Segment (Site) & 6.43 & 0.69 & 0.87 \\
\hline Error & 9.38 & & \\
\hline \multicolumn{4}{|c|}{ Polyplacaphora (chitons) } \\
\hline Site & 1.35 & 2.15 & 0.13 \\
\hline Segment (Site) & 0.63 & 1.95 & $\underline{0.01}$ \\
\hline Error & 0.32 & & \\
\hline
\end{tabular}


Figure 1. Study locations: a) California State Park coastal shores in San Luis Obispo County, California; b) visitor count areas, field sampling transects, and field experiment location; c) Hazard Canyon field sampling transects.

Figure 2. Levels of visitor exposure observed at MDO State Park and levels tested experimentally. Exposure levels are standardized to $\mathrm{m}^{2}$ for comparison purposes. The exposure levels tested bracketed what we estimate occurs at MDO State Park in a year period.

Figure 3. Changes, relative to controls, in the percent cover of algae and seagrass in the treatment plots between the pre-treatment and treatment periods. Histogram bars that are on the left side of the zero center line represent decreases in cover, relative to controls, and histogram bars that are on the right side of the zero center line represent increases in cover, relative to controls. Changes that were statistically significant, relative to controls, are indicated with an asterisk.

Figure 4. Changes over time, relative to controls, in total non-crustose algal cover.

Figure 5. Non-metric multidimensional scaling of Czekanowski distances among average algal delta values (plot value - average of control plots) of the three exposure treatments, relative to controls. The survey number is printed above each symbol: circles $=$ low exposure treatment; down triangles $=$ medium exposure treatment; and squares $=$ heavy exposure treatment. The open symbols represent the surveys prior to application of the 
treatments and filled symbols after treatment application. Lines are used to show the time sequence among surveys.

Figure 6. Changes, relative to controls, in the density and cover of invertebrates in the treatment plots between pre-treatment and treatment periods. Histogram bars that are on the left side of the zero center line represent decreases in cover, relative to controls, and histogram bars that are on the right side of the zero center line represent increases in cover, relative to controls. Changes that were statistically significant, relative to controls, are indicated with an asterisk

Figure 7. Non-metric multidimensional scaling of Czekanowski distances among average invertebrate delta values (plot value - average of control plots) of the three exposure treatments, relative to controls. The survey is printed above each symbol: circles $=$ low exposure treatment; down triangles = medium exposure treatment; and squares $=$ heavy exposure treatment. The open symbols represent the surveys prior to application of the treatments and filled symbols after treatment application. Lines are used to show the time sequence among surveys.

Figure 8. The abundance of species sampled in the Montaña de Oro field observational study: a) algae; b) invertebrates. The letters above bars within a group indicate the results of a posteriori Tukey pairwise comparison tests $(\mathrm{p}<0.05)$. Within a group, abundances with different letters are significantly different from each other. Otherwise abundances within a group are not significantly different from each other. 
Figure 9. Comparison of foot traffic levels (footsteps) tested in various trampling experiments and the present experiment. Data are standardized to $1 \mathrm{~m}^{2}$ to compare studies. Data are also portrayed as the number of times the same footprint space was stepped on based on a footprint being $0.03 \mathrm{~m}^{2}$ in area and that the investigators distributed the footsteps evenly in the test plots during each treatment. 


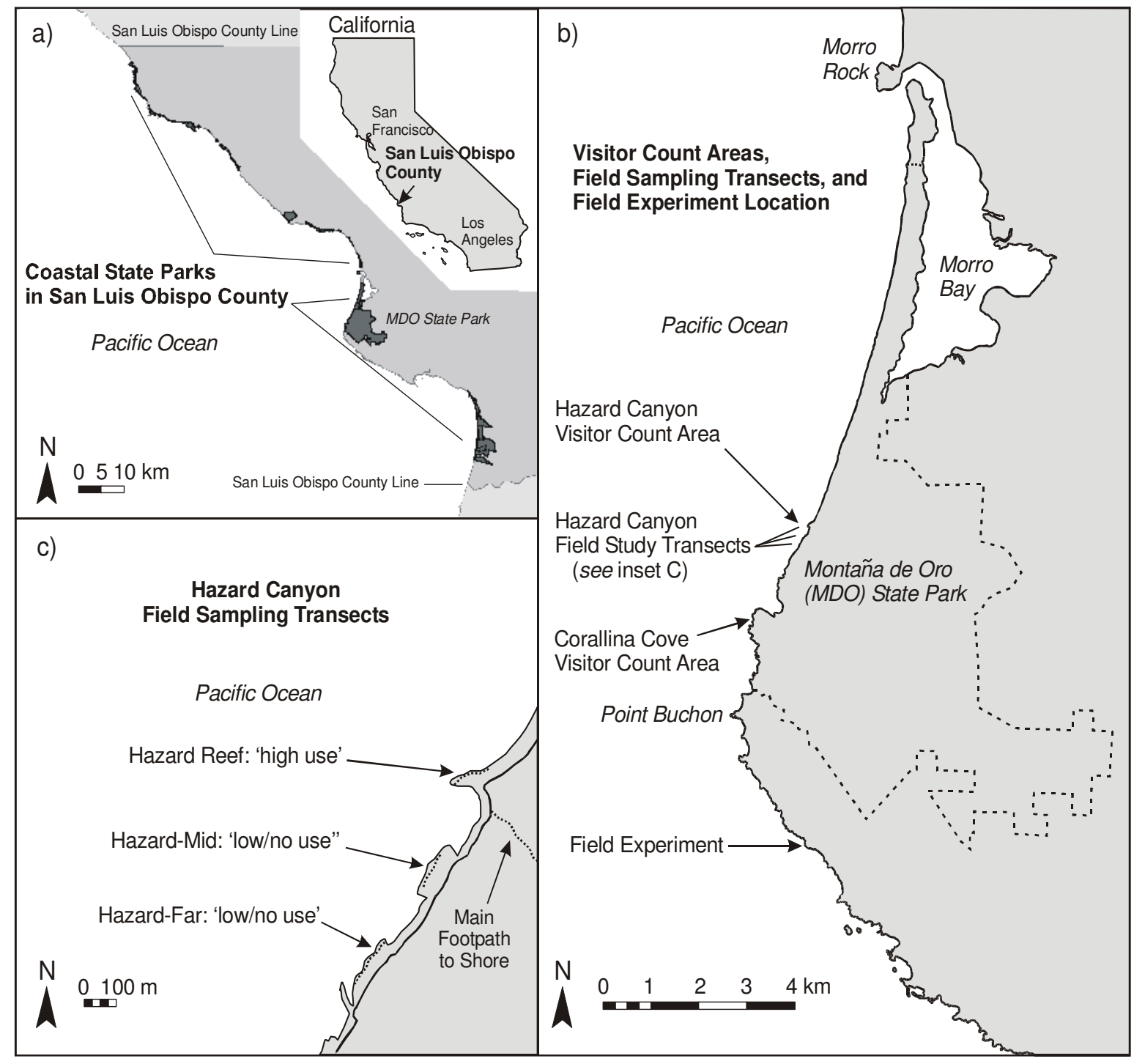

Figure 1. 


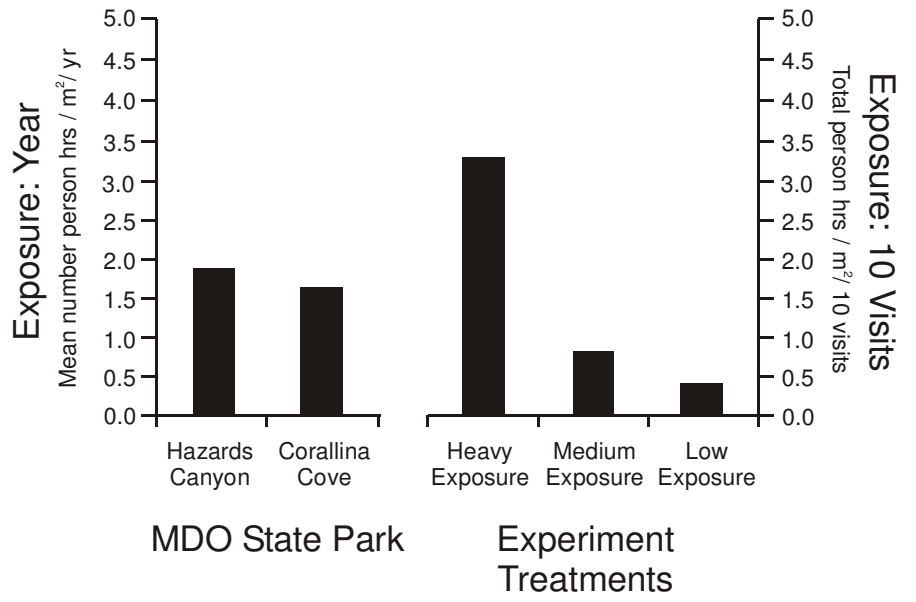

Figure 2. 


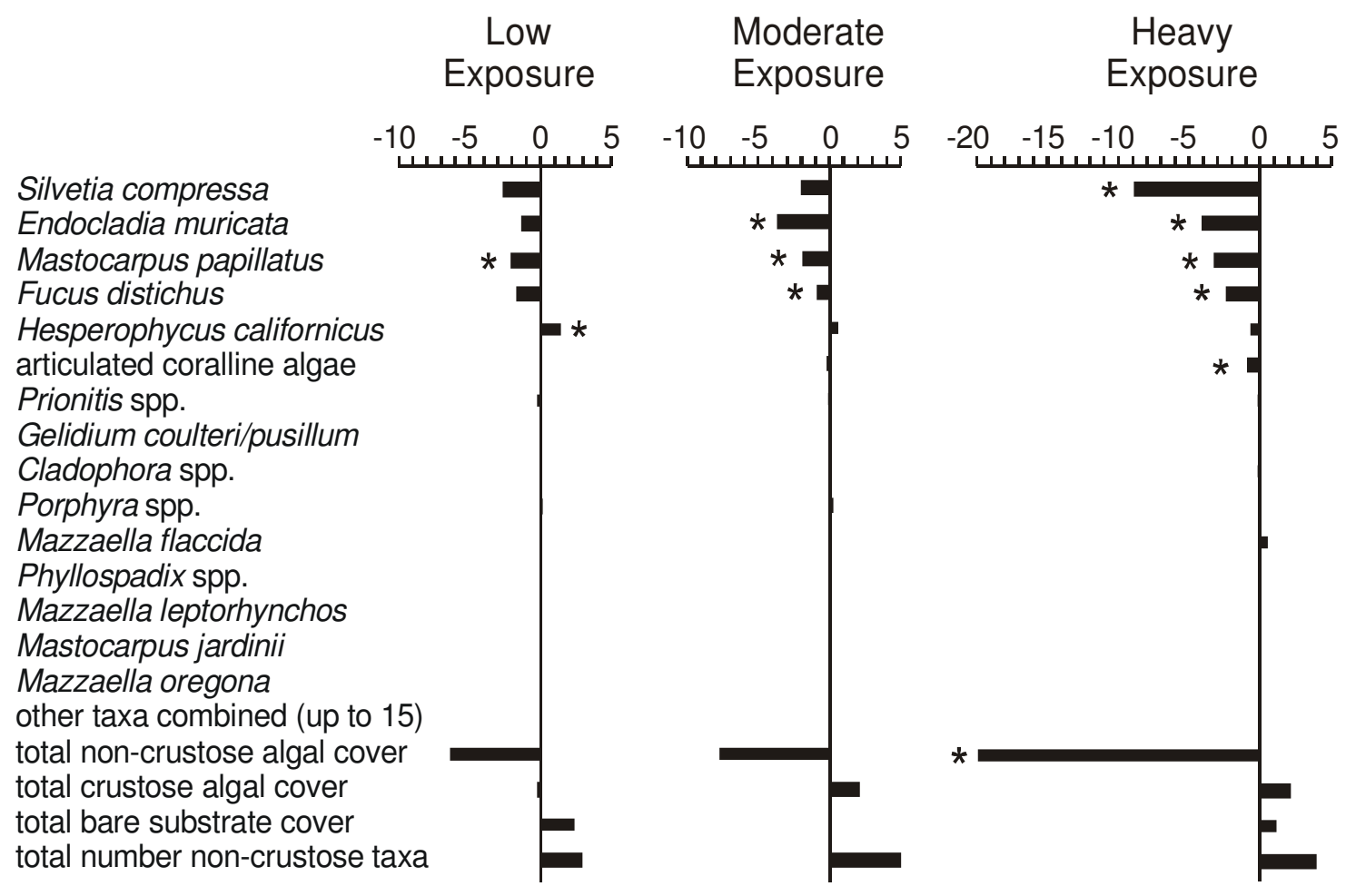

Figure 3. 


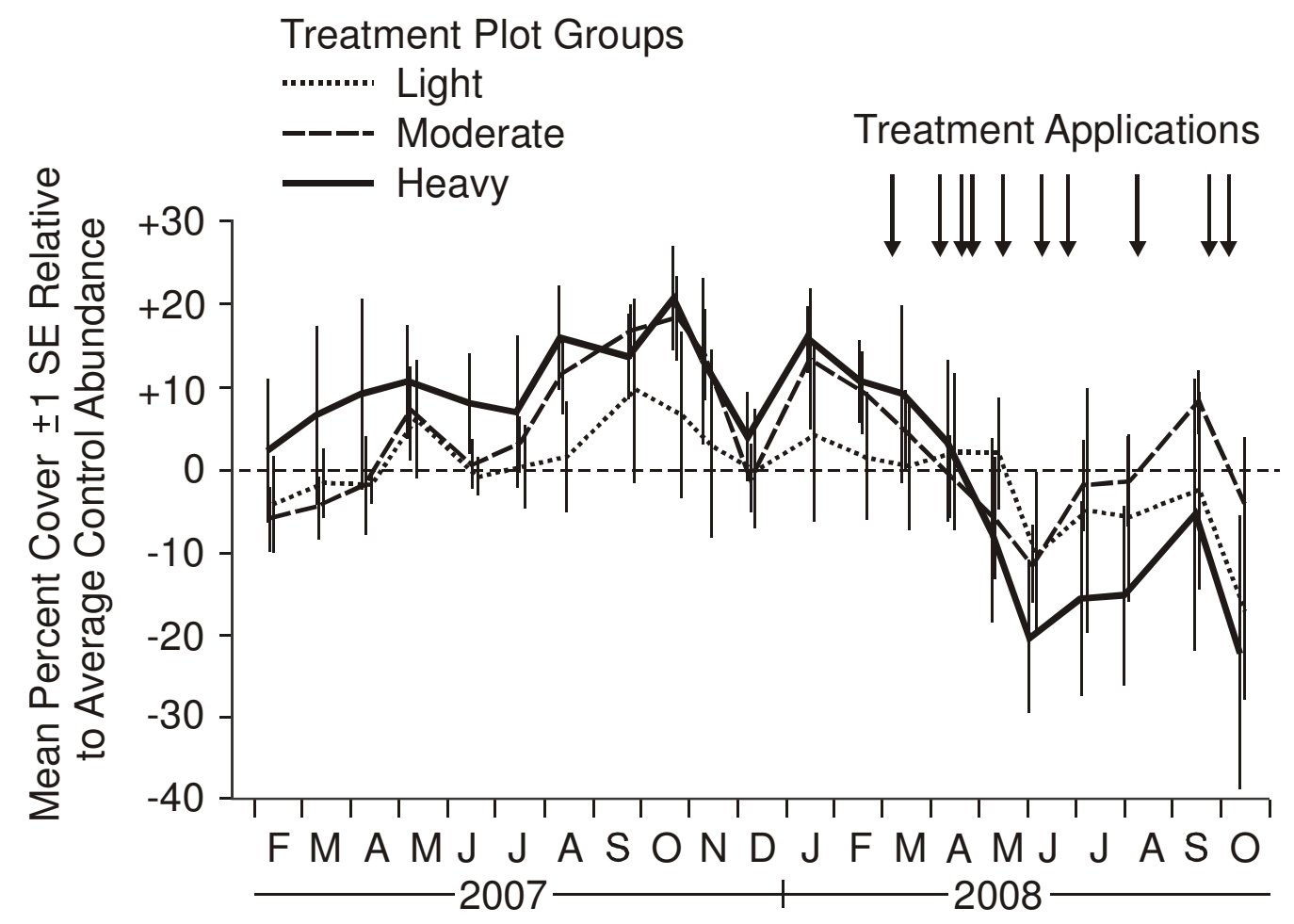

Figure 4. 


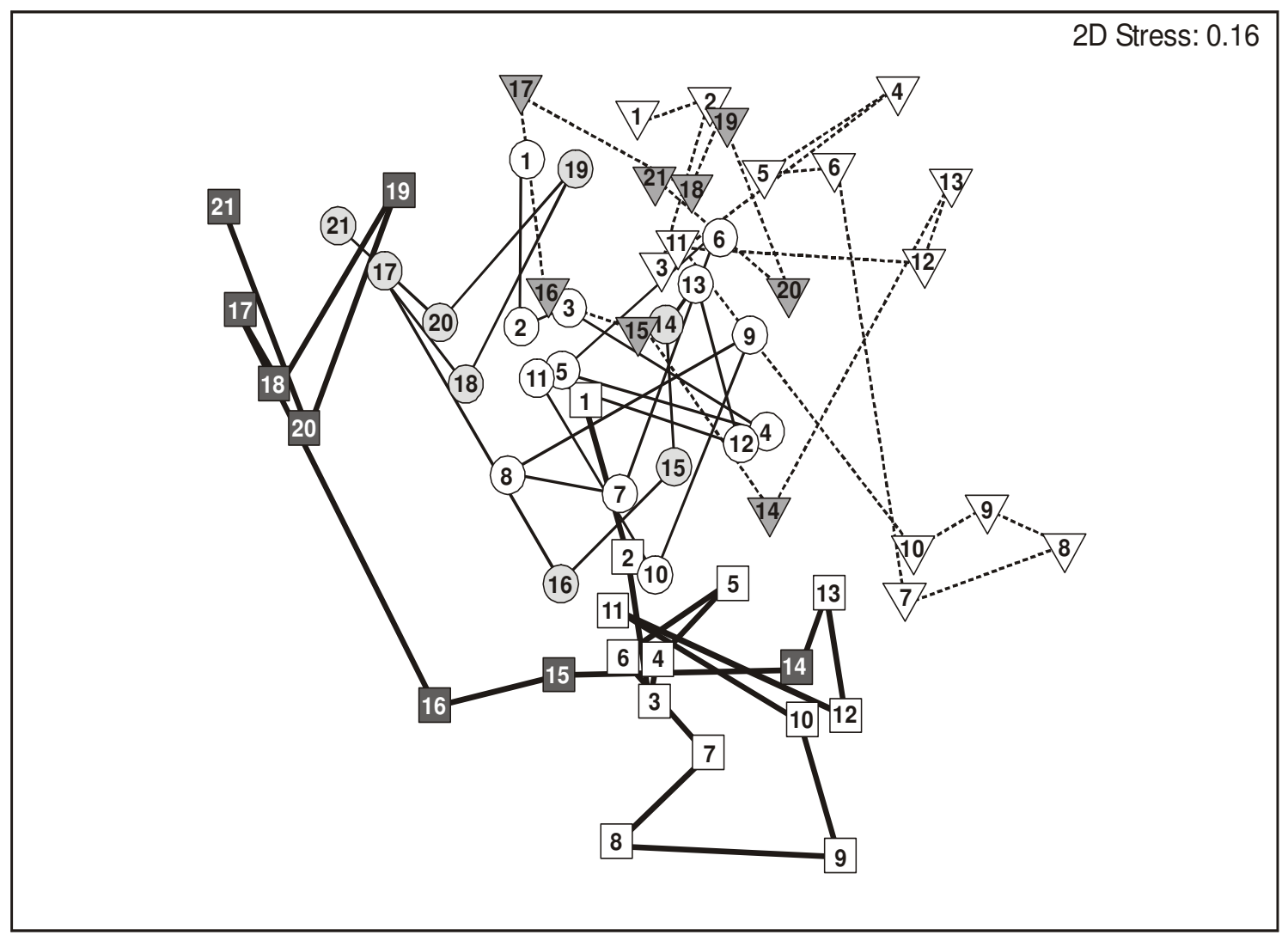

Figure 5. 


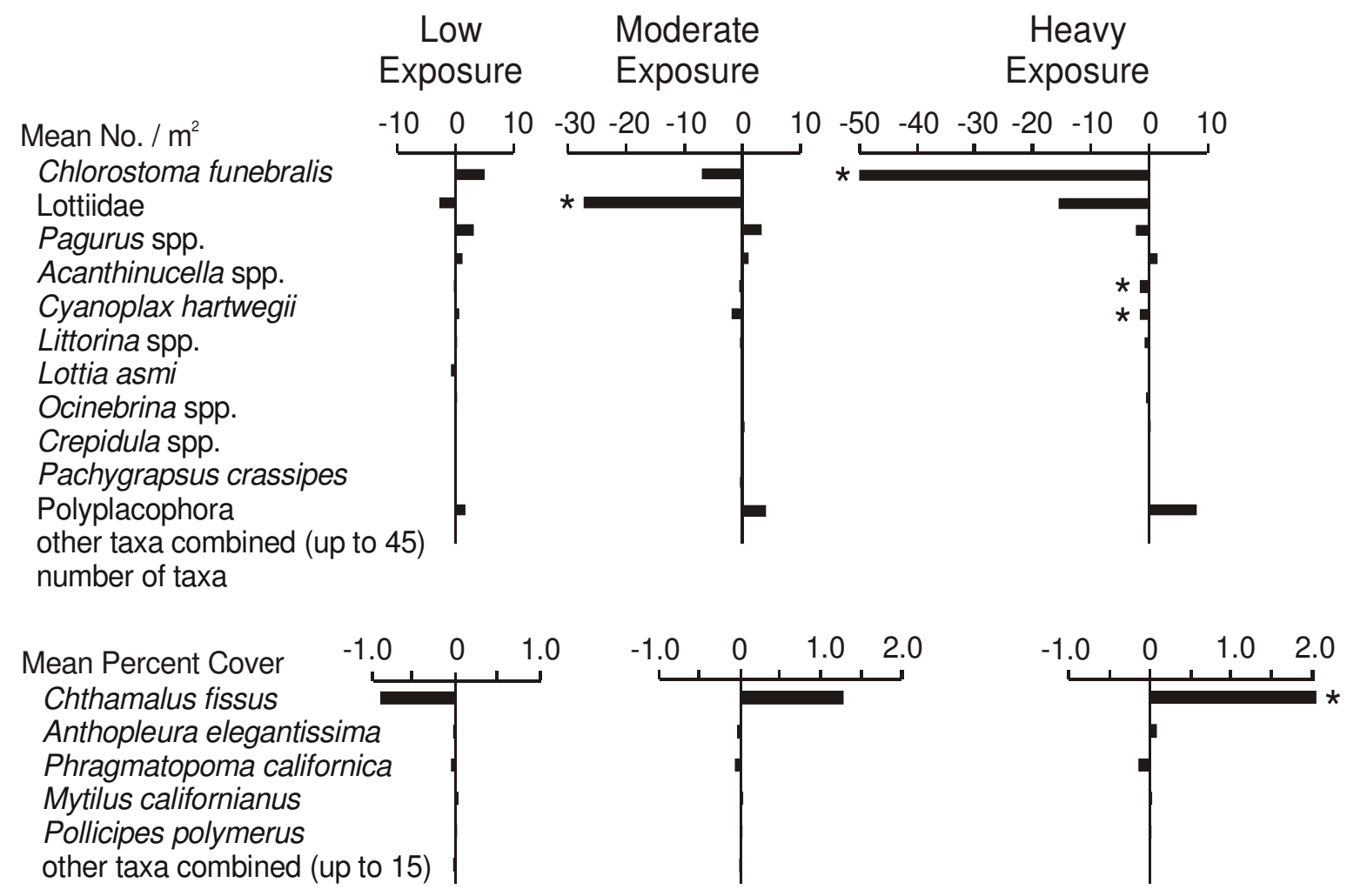

Figure 6. 


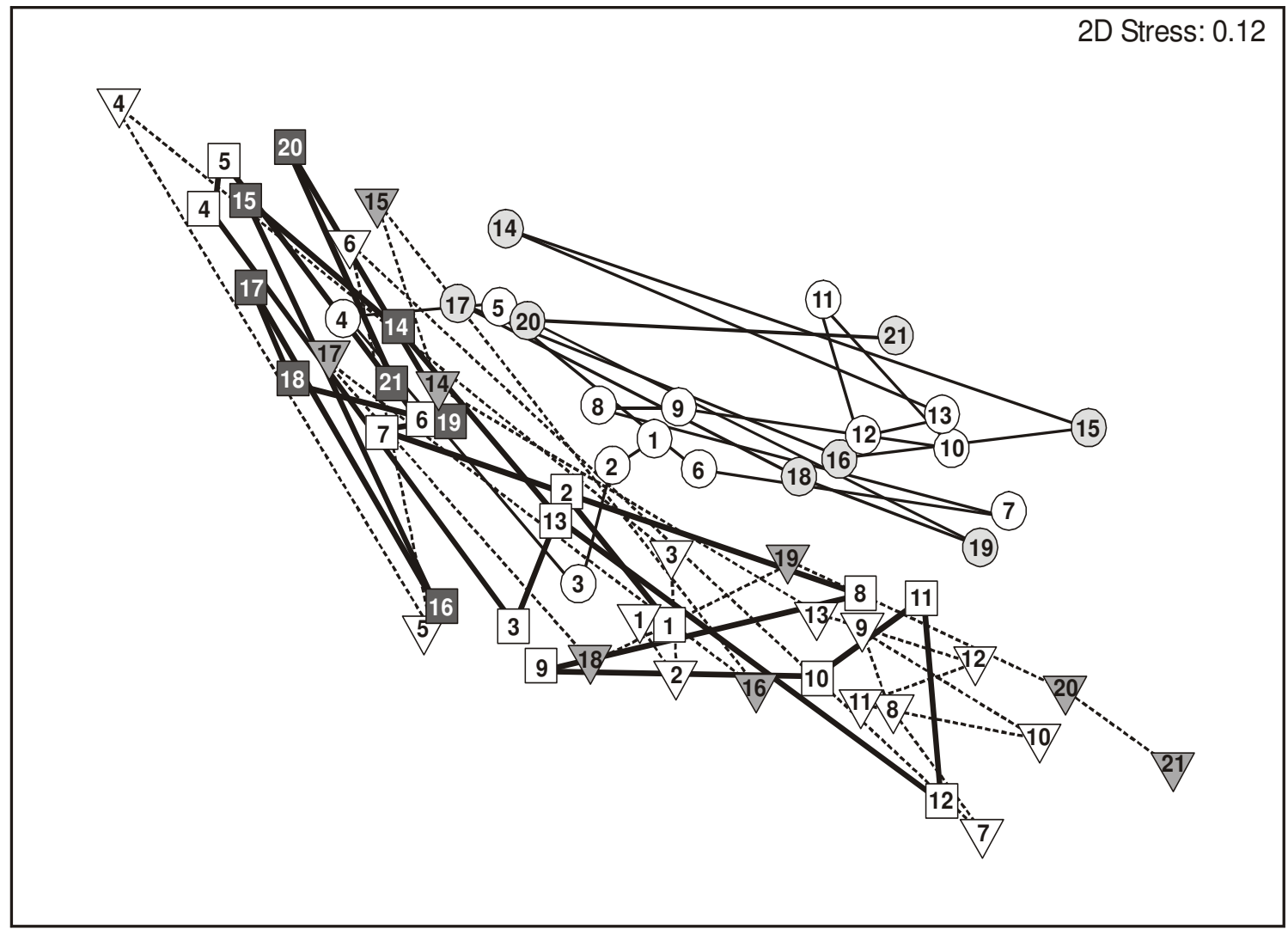

Figure 7. 


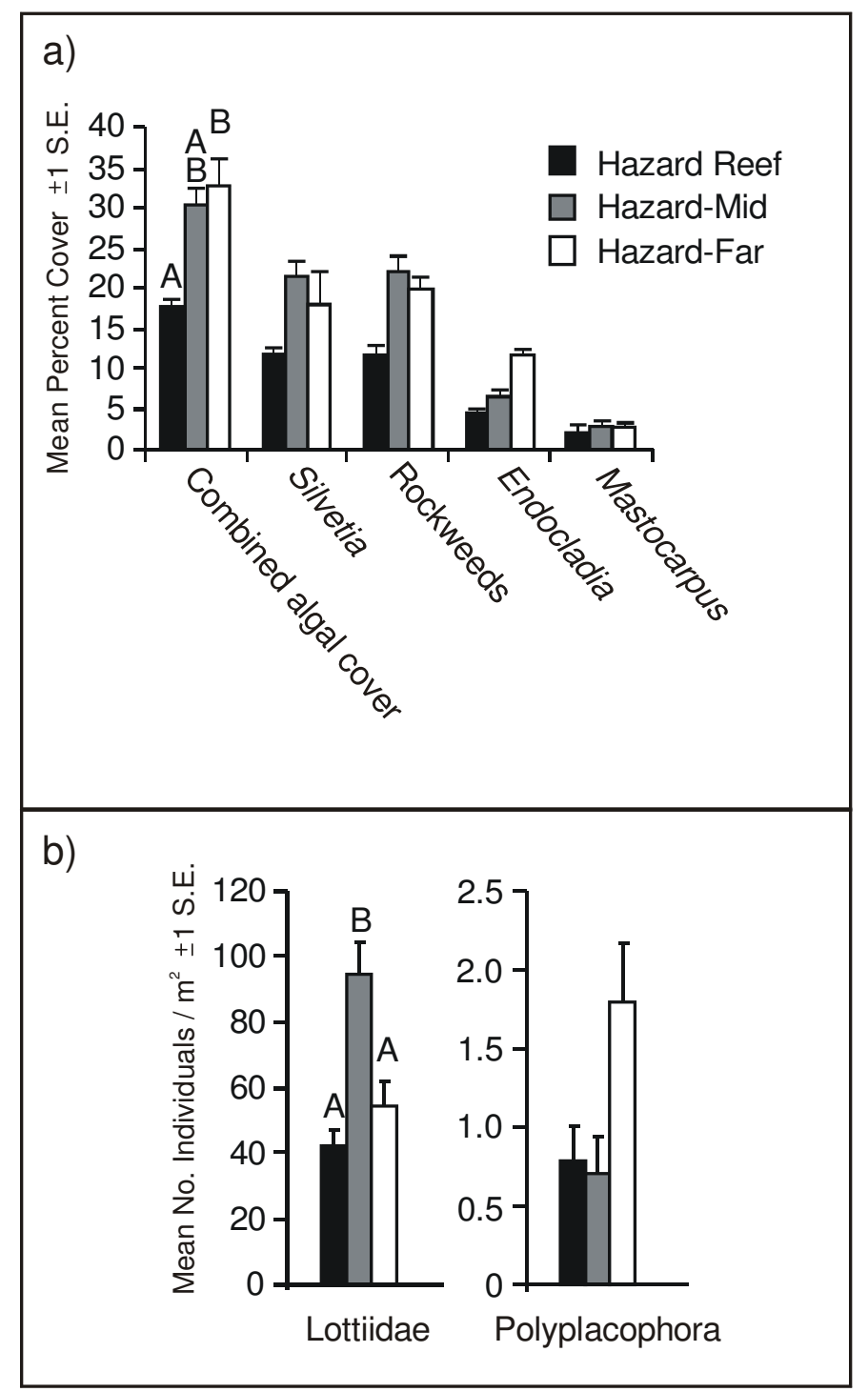

Figure 8. 


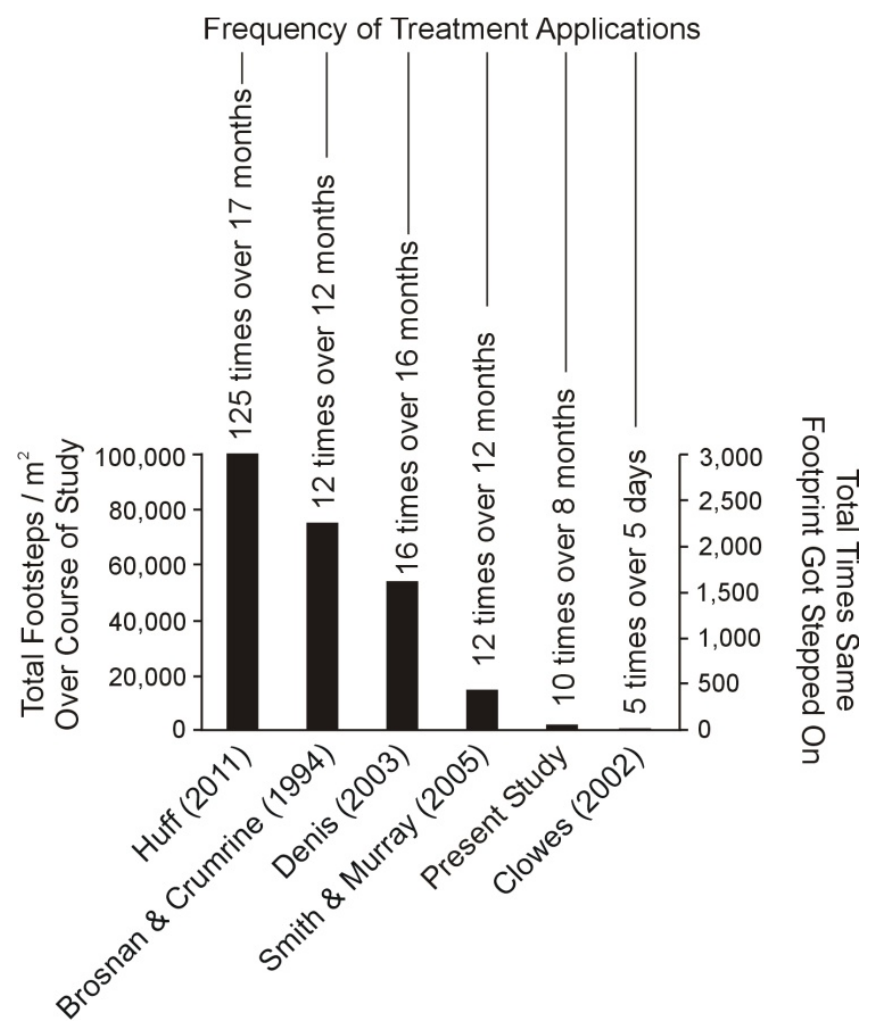

Figure 9. 


\section{Appendix 2}

The significant relationship between the number of parked cars and intertidal visitor density at Hazard Reef indicated that it may be possible to size parking areas such that they accommodate a maximum number of cars to allow a target visitor density leading to acceptable impact levels set by resource managers. Further controlled manipulation of parking lot size should be conducted in order to determine a causal relationship between the number of parking spaces and the intertidal visitor density. A ratio of parking spaces to visitor density could then be estimated and the following calculation could be conducted to determine the maximum number of spaces leading to the desired density of annual visitors. To appropriately size a parking lot, managers should determine the area of the rocky intertidal they are allowing access to, calculate the ratio of the area of their reef relative to Hazard Reef $\left(1,960 \mathrm{~m}^{2}\right.$ at $+0.61 \mathrm{~m}$ MLLW), and multiply by the target annual visitor density. Because the target annual visitor density would be related to the number of cars in the parking lot, it would be necessary to determine the target visitor density based on the number of cars parked in a parking area leading to a specific density of annual visitors. The number of cars parked in a lot will be used in an equation as a proxy for the annual density of visitors. Resource managers can reference the results of Appendix 1 to determine the target annual visitor density leading to acceptable impacts. As mentioned above, an experiment would be needed to determine the relationship between the number of cars parked in a parking lot and the annual intertidal visitor density, which would produce a figure similar Figure A 2.1. For this hypothetical example, I will assume an experiment had been conducted and a significant causal relationship was detected between the numbers of cars parked in a lot 
and the annual density of visitors (Fig. A 2.1). The calculation to determine an appropriately sized parking lot is described by the following equation:

$$
P_{s}=\left(A_{n} / A_{h}\right) P_{t}
$$

Where $P_{s}$ is the desired parking lot size for a new area, $A_{n}$ is the size of a new area, $A_{h}$ is the size of the CRKA at Hazard Reef, and $\mathrm{P}_{\mathrm{t}}$ is the parking lot size that corresponds to the target annaul visitor density (i.e., impact level).

For example, if there was a newly opened rocky intertidal habitat with an area of $2,500 \mathrm{~m}^{2}(+0.61 \mathrm{~m} \mathrm{MLLW})$ and managers wanted to allow fewer than 3.3 people $\mathrm{m}^{-2} \mathrm{yr}^{-1}$, which corresponds to 13.75 parking spaces in my hypothetical example $\left(\mathrm{P}_{\mathrm{t}}\right)($ Fig A 2.1), with a $95 \%$ confidence interval they would solve:

$$
\begin{aligned}
& P_{s}=\left(2,500 \mathrm{~m}^{2} / 1,960 \mathrm{~m}^{2}\right) 13.75 \\
& \mathrm{P}_{\mathrm{s}}=17.6 \mathrm{cars}
\end{aligned}
$$

Thus the parking lot should hold no more than 17 cars to keep visitor densities below 3.3 people $\mathrm{m}^{-2} \mathrm{yr}^{-1}$ with a $95 \%$ confidence interval at an intertidal site where intertidal exploration is the primary goal of visitors. 


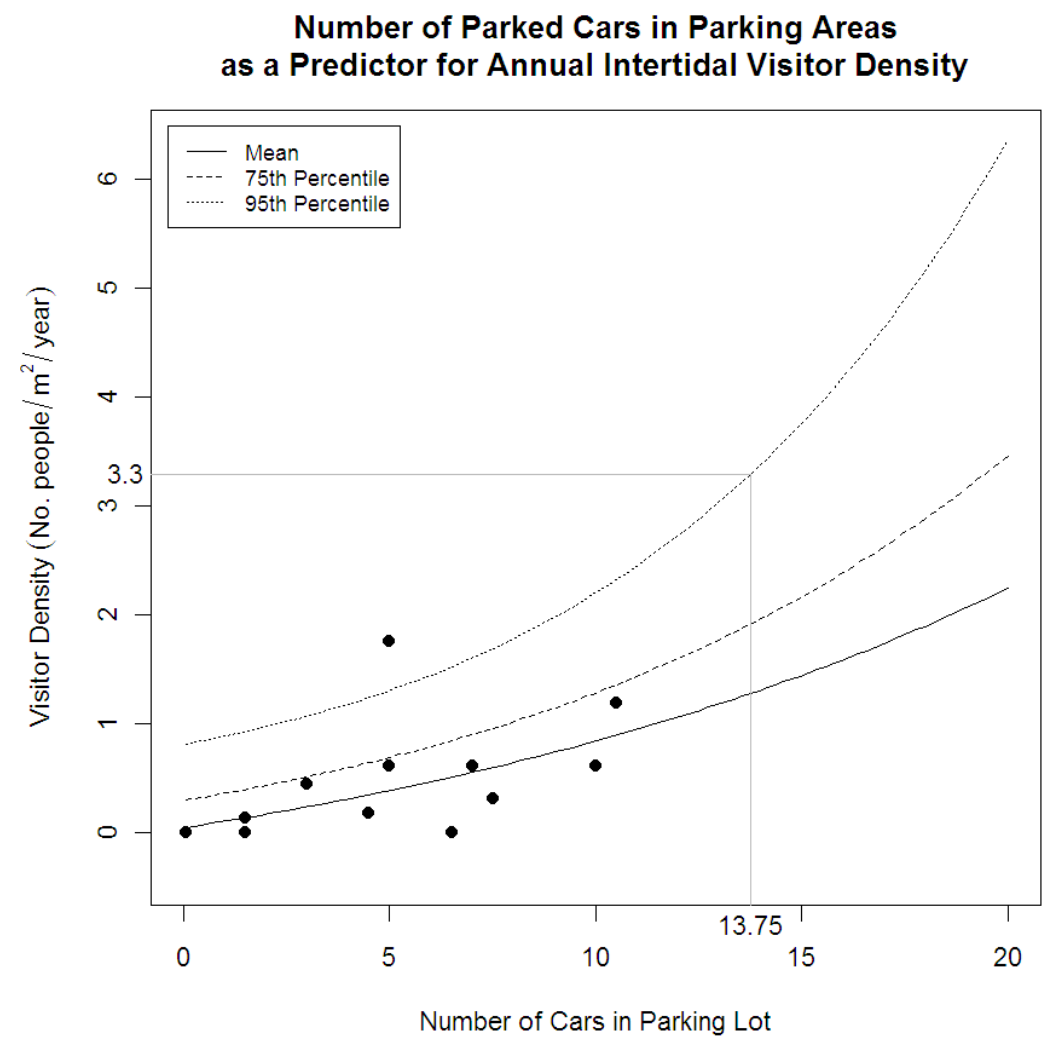

Figure A 2.1. An exponential model of parking lot size to predict annual intertidal visitor density at Hazard Reef. High experimental visitor density (3.3 people $\mathrm{m}^{-2} \mathrm{yr}^{-1}$ ) was expected to occur (95\% confidence) with a parking area of 13.75 cars. The mean line, $95 \%$ confidence interval, and $75 \%$ confidence interval were plotted to display the range of expected annual visitor densities with varying degrees of accuracy. NOTE: the annual visitor density was predicted by extrapolating beyond the parking lot car count values from our dataset. This was done to provide an example of how car counts could be used to predict annual visitor density. Before using parking areas to control the annual density of intertidal visitors using this method, researchers should obtain additional car count data. 